Linköping Studies in Science and Technology

Dissertation No. 1677

\title{
Radiation properties of coil-coated steel in building envelope surfaces and the influence on building thermal performance
}

Mohammad Ali Joudi

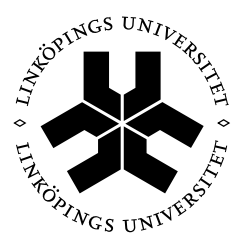

\section{Linköping University}

\author{
Division of Energy Systems \\ Department of Management and Engineering \\ Linköping University, Sweden
}


(C) Mohammad Ali Joudi 2015, unless otherwise noted. ISBN: 978-91-7519-047-1

ISSN: 0345-7524

Printed in Sweden by LiU-Tryck, Linköping 2015 


\section{Abstract}

Recent studies have shown that the optical properties of building exterior surfaces are important in terms of energy use and thermal comfort. While the majority of the studies are related to exterior surfaces, the radiation properties of interior surfaces are less thoroughly investigated. Development in the coil-coating industries has now made it possible to allocate different optical properties for both exterior and interior surfaces of steel-clad buildings. The aim of this thesis is to investigate the influence of surface radiation properties with the focus on the thermal emittance of the interior surfaces, the modeling approaches and their consequences in the context of the building energy performance and indoor thermal environment.

The study consists of both numerical and experimental investigations. The experimental investigations include parallel field measurements on three similar test cabins with different interior and exterior surface radiation properties in Borlänge, Sweden, and two ice rink arenas with normal and low emissive ceiling in Luleå, Sweden. The numerical methods include comparative simulations by the use of dynamic heat flux models, Building Energy Simulation (BES), Computational Fluid Dynamics (CFD) and a coupled model for BES and CFD. Several parametric studies and thermal performance analyses were carried out in combination with the different numerical methods.

The parallel field measurements on the test cabins include the air, surface and radiation temperatures and energy use during passive and active (heating and cooling) measurements. Both measurement and comparative simulation results indicate an improvement in the indoor thermal environment when the interior surfaces have low emittance. In the ice rink arenas, surface and radiation temperature measurements indicate a considerable reduction in the ceiling-to-ice radiation by the use of low emittance surfaces, in agreement with a ceiling-to-ice radiation model using schematic dynamic heat flux calculations.

The measurements in the test cabins indicate that the use of low emittance surfaces can increase the vertical indoor air temperature gradients depending on the time of day and outdoor conditions. This is 
in agreement with the transient CFD simulations having the boundary condition assigned on the exterior surfaces. The sensitivity analyses have been performed under different outdoor conditions and surface thermal radiation properties. The spatially resolved simulations indicate an increase in the air and surface temperature gradients by the use of low emittance coatings. This can allow for lower air temperature at the occupied zone during the summer.

The combined effect of interior and exterior reflective coatings in terms of energy use has been investigated by the use of building energy simulation for different climates and internal heat loads. The results indicate possible energy savings by the smart choice of optical properties on interior and exterior surfaces of the building.

Overall, it is concluded that the interior reflective coatings can contribute to building energy savings and improvement of the indoor thermal environment. This can be numerically investigated by the choice of appropriate models with respect to the level of detail and computational load. This thesis includes comparative simulations at different levels of detail. 


\section{Sammanfattning}

Tidigare studier har visat att de optiska egenskaperna hos yttre och inre ytor på byggnader har stor betydelse för byggnadernas energianvändning och termiska komfort. Majoriteten av studierna rör de yttre byggnadsytorna medan effekterna av de inre ytornas strålningsegenskaper inte undersökts lika ingående. Utveckling av nya material inom bandlackeringsindustrin har på senare tid möjliggjort större variation i optiska egenskaper både med avseende på termisk emittans hos interiöra ytor och total solreflektans hos yttre byggnadsytor. Avsikten med detta arbete är att undersöka betydelsen av byggnadsytors strålningsegenskaper, speciellt de intre ytornas termiska emittans, för byggnaders energiprestanda och inomhusklimat samt hur detta kan undersökas med olika simuleringsmetoder.

Detta arbete innehåller både numeriska simuleringar och experimentella mätningar. De experimentella studierna innefattar parallella fältmätningar på tre likvärdiga teststugor belägna i Borlänge med olika interiöra och exteriöra ytstrålningsegenskaper, samt två likvärdiga ishallar belägna i Luleå med olika termisk emittans i innertakytorna. De numeriska metoderna inkluderar jämförande simuleringar med hjälp av dynamiska värmeflödesmodeller, byggnadsenergisimulering (BES), fluiddynamisk simulering (CFD) samt en kopplad metod för kombinerad BES-CFD. Flera parameterstudier och analys av termiska prestanda har genomförts med dessa metoder.

De parallella mätningarna på teststugorna innefattar luft-, yt- och strålningstemperaturer samt energianvändning under förhållanden med aktiv kylning och värmning så väl som under passiva förhållanden. Både mätresultat och jämförande simuleringar visar på förbättrad termisk inomhusmiljö i teststugan med lägre termisk emittans på de inre vägg- och takytorna. I ishallarna visar de uppmätta yt- och strålningstemperaturerna på betydligt lägre värmestrålningsflöde mellan innertaket och isen i det fall innertaket har lägre termisk emitttans. Detta resultat reproduceras väl av en enkel strålningsmodell i en schematisk dynamisk värmeflödesberäkning. 
Lufttemperaturmätningarna $\mathrm{i}$ teststugorna visar att lågemitterande inre ytor kan förstärka de vertikala lufttemperaturgradienterna beroende på tiden på dygnet och utomhusförhållandena. Dessa resultat stämmer väl med tidsberoende CFD-simuleringar med dynamiska randvillkor $\mathrm{i}$ byggnadsmodellens exteriöra ytor. En känslighetsanalys görs här med avseende på utomhusförhållanden och optiska ytegenskaper. De rumsupplösta simuleringarna visar på förstärkta yt- och lufttemperaturgradienter då lågemitterande innerytor används. Detta tyder på att värmereflekternade beläggningar kan användas för att sänka temperaturen i nedre delen av en byggnad under sommaren.

Den kombinerade effekten av värmereflekterande innerytor och solreflekterande ytterytor på byggnaders energianvändning har undersökts med byggnadsenergisimulering för flera olika klimat och inre värmelaster. Resultatet visar på möjligheter att uppnå energibesparingar genom rätt val av optiska ytegenskaper på in- och utsidan av byggnaderna.

En övergripande slutsats är att inre värmereflekterande ytor med låg termisk emittans, kan bidra till lägre energiåtgång och förbättringar av det termiska inomhusklimatet. Detta kan simuleras i varierande grad beroende på detaljnivån i den valda simuleringsmodellen. 


\section{Acknowledgements}

This thesis work was mainly sponsored by SSAB Europe based on a joint-project with Plannja $\mathrm{AB}$ and Dalarna University with grants from the Knowledge Foundation (KK-stiftelsen).

I would like to express my gratitude to Professor Bahram Moshfegh who guided me throughout this study and made this thesis work possible. Dr. Harald Svedung for his brilliant ideas, unique comments and tremendous support that always helped and inspired me to reach further. Associate Professor Mats Rönnelid for his valuable advice during the study and his contribution to the initial project idea. Dr. Mathias Cehlin for all his incredible support and advice, especially in CFD simulations. Professor Ewa Wäckelgård and Dr. Per-Erik Augustsson who introduced me to the scientific community and gave me the opportunity to pursue this research pathway. Associate Professor Patrik Rohdin for his valuable comments on Paper VI. Mr. Thomas Forsberg, Mr. Ulf Kok and Mr. Niclas Ivarsson for experimental support. Ms. Elisabeth Larsson, Ms. Lena Sjöholm and Mr. Staffan Nygren for all the administrative help and technical support.

I would also like to thank all my current and former colleagues at SSAB in gamla försökshallen, OC-lab, Product Development and Labbis for the great working environment, enthusiasm and encouragement. My colleagues and fellow $\mathrm{PhD}$ students at Energy Technology, Dalarna University for providing such a friendly and warm research atmosphere and my fellow PhD students at University of Gävle. You all made this long journey joyful and endurable.

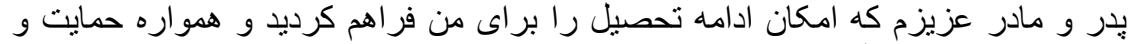

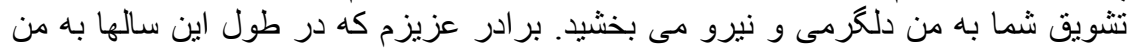
كمى و يارى داد.

Min blivande fru, Evelina! Du som målade mitt liv med kärlek och förståelse. Du stod ut med mig och gjorde det möjligt de allra längsta arbetsdagarna.

Finally, I would like to thank Family Khansari and Namazian for all the valuable advice and moral support that I received during these years. 


\section{List of appended papers}

Paper I Joudi, A., Svedung, H., Bales, C. and Rönnelid, M. 2011. Highly reflective coatings for interior and exterior steel cladding and the energy efficiency of buildings. Applied Energy, 88, 4655-4666.

Paper II Joudi, A., Svedung, H. and Rönnelid, M. 2011. Energy efficient surfaces on building sandwich panels - a dynamic simulation model. Energy and Buildings, 43, $2462-2467$.

Paper III Joudi, A., Rönnelid, M., Svedung, H. and Wäckelgård, E. 2011. Energy efficient buildings with functional steel cladding. World Renewable Energy Congress 2011, Linköping, Sweden.

Paper IV Joudi, A., Svedung, H., Cehlin, M. and Rönnelid, M. 2013. Reflective coatings for interior and exterior of buildings and improving thermal performance. Applied Energy, 103, 562-570.

Paper V Joudi, A., Cehlin, M., Svedung, H., Rönnelid, M. and Moshfegh, B. 2015. Numerical and experimental investigation of the influence of infrared reflective interior surfaces on building temperature distributions. Submitted in revised form to Indoor and Built Environment.

Paper VI Joudi, A., Cehlin, M., Svedung, H., Rohdin, P. and Moshfegh, B. 2015. Influence of reflective interior surfaces on indoor thermal environment and energy use using a coupling model for energy simulation and CFD. Submitted for journal publication. 


\section{Nomenclature}

\section{Latin Symbols}

\begin{tabular}{|c|c|}
\hline$A$ & surface area $\left(\mathrm{m}^{2}\right)$ \\
\hline$C_{\mu}$ & turbulent viscosity constant \\
\hline$C_{\varepsilon 1}$ & production constant in the turbulent energy dissipation equation \\
\hline$C_{\varepsilon 2}$ & dissipation constant in the turbulent energy dissipation equation \\
\hline$C_{\varepsilon 3}$ & buoyancy constant in the turbulent energy dissipation equation \\
\hline$C_{\text {cloud }}$ & dimensionless cloud cover factor \\
\hline$C_{d p 1 t o 5}$ & constants in the dew point temperature equation \\
\hline$C_{p}$ & specific heat $\left(\mathrm{J} \mathrm{kg}^{-1} \mathrm{~K}^{-1}\right)$ \\
\hline$C_{p s 1 t o 6}$ & constants in the saturated vapor pressure equation \\
\hline$d$ & diameter $(\mathrm{m})$ \\
\hline$D_{\text {wind }}$ & direction of the local wind velocity in degrees \\
\hline$f$ & view factor \\
\hline$g$ & gravity $\left(\mathrm{m} \mathrm{s}^{-2}\right)$ \\
\hline$G_{B}$ & turbulent production due to buoyancy in the turbulent model \\
\hline$h_{c}$ & convective heat transfer coefficient $\left(\mathrm{W} \mathrm{m}^{-2} \mathrm{~K}^{-1}\right)$ \\
\hline$h_{r}$ & radiative heat transfer coefficient $\left(\mathrm{W} \mathrm{m}^{-2} \mathrm{~K}^{-1}\right)$ \\
\hline$h r_{0}$ & time of day (hours after midnight) in the clear sky temperature equation \\
\hline$I_{\text {extratres }}$ & extraterrestrial solar irradiance $\left(\mathrm{W} \mathrm{m}^{-2}\right)$ \\
\hline$I_{d i r, n}$ & direct normal solar irradiance $\left(\mathrm{W} \mathrm{m}^{-2}\right)$ \\
\hline$I_{d i f f, h}$ & diffuse solar irradiance on a horizontal surface $\left(\mathrm{W} \mathrm{m}^{-2}\right)$ \\
\hline$I_{\text {global }}$ & global solar irradiance $\left(\mathrm{W} \mathrm{m}^{-2}\right)$ \\
\hline$I_{\text {gain }}$ & total gained irradiance on a surface dependent on the TSR value $\left(\mathrm{W} \mathrm{m}^{-2}\right)$ \\
\hline$I_{\text {incidnt }}$ & total incident irradiance on a surface $\left(\mathrm{W} \mathrm{m}^{-2}\right)$ \\
\hline$I R$ & Infrared \\
\hline$J$ & radiosity $\left(\mathrm{W} \mathrm{m}^{-2}\right)$ \\
\hline$k$ & turbulent kinetic energy $\left(\mathrm{m}^{2} \mathrm{~s}^{-2}\right)$ \\
\hline$k_{T}$ & hourly clearness index \\
\hline$M_{w}$ & molecular weight of the air $\left(\mathrm{kg} \mathrm{mol}^{-1}\right)$ \\
\hline$n_{d}$ & day number of the year \\
\hline$P$ & pressure $(\mathrm{Pa})$ \\
\hline$P_{v}$ & partial pressure of water vapor $(\mathrm{Pa})$ \\
\hline$P_{v, s}$ & saturated water vapor pressure $(\mathrm{Pa})$ \\
\hline $\operatorname{Pr}_{t}$ & turbulent Prandtl number \\
\hline$Q$ & heat transfer rate $(\mathrm{W})$ \\
\hline$q$ & heat flux; heat transfer rate per unit area $\left(\mathrm{W} \mathrm{m}^{-2}\right)$ \\
\hline$U$ & mean velocity $\left(\mathrm{m} \mathrm{s}^{-1}\right)$ \\
\hline$u^{\prime}$ & fluctuating velocity $\left(\mathrm{m} \mathrm{s}^{-1}\right)$ \\
\hline
\end{tabular}




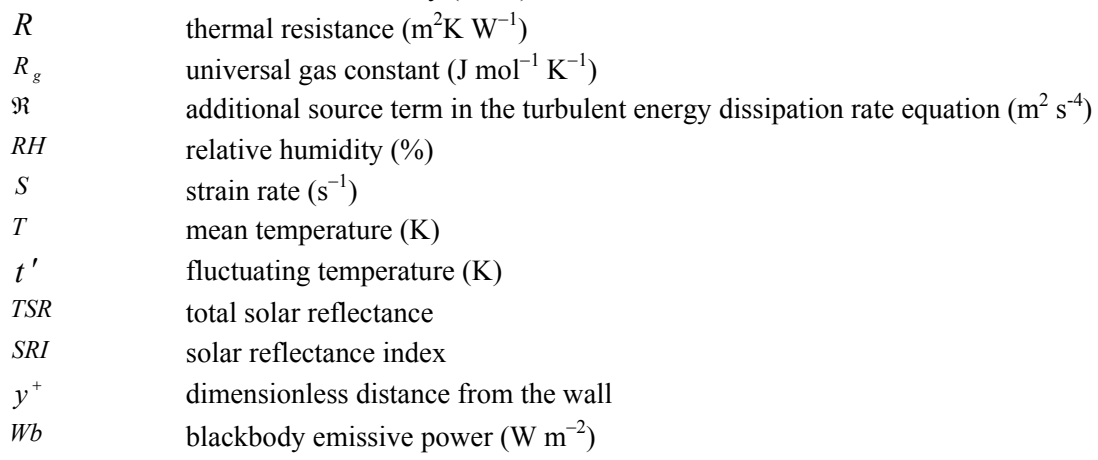

\section{Greek Symbols}

\begin{tabular}{|c|c|}
\hline$\varepsilon$ & turbulent energy dissipation rate $\left(\mathrm{m}^{2} \mathrm{~s}^{-3}\right)$ \\
\hline$\varepsilon_{\text {th }}$ & thermal emittance \\
\hline$\rho$ & density $\left(\mathrm{kg} \mathrm{m}^{-3}\right)$ \\
\hline$\rho_{\text {th }}$ & thermal reflectance \\
\hline$\tau$ & time $(s)$ \\
\hline$\theta$ & surface angle in degrees \\
\hline$\theta_{z}$ & zenith angel in degrees \\
\hline$v$ & kinematic viscosity $\left(\mathrm{m}^{2} \mathrm{~s}^{-1}\right)$ \\
\hline$v_{t}$ & turbulent kinematic viscosity $\left(\mathrm{m}^{2} \mathrm{~s}^{-1}\right)$ \\
\hline$\mu$ & dynamic viscosity $\left(\mathrm{kg} \mathrm{m}^{-1} \mathrm{~s}^{-1}\right)$ \\
\hline$\delta_{i j}$ & Kronecker delta function (equal to one for $i=j$, otherwise zero) \\
\hline$\delta_{s}$ & solar declination in degrees \\
\hline$\delta_{p k}$ & the visibility of $d A_{p}$ to $d A_{k}$ in the view factor equation \\
\hline$\lambda$ & thermal conductivity $\left(\mathrm{W} \mathrm{m}^{-1} \mathrm{~K}^{-1}\right)$ \\
\hline$\eta$ & ratio in the RNG $k-\varepsilon$ model \\
\hline$\eta_{0}$ & constant in the RNG $k-\varepsilon$ model \\
\hline$\sigma$ & Stefan-Boltzmann constant $\left(\mathrm{W} \mathrm{m}{ }^{-2} \mathrm{~K}^{-4}\right)$ \\
\hline$\sigma_{k}$ & turbulent Prandtl number for the turbulent kinetic energy \\
\hline$\sigma_{\varepsilon}$ & turbulent Prandtl number for the turbulent energy dissipation rate \\
\hline$\aleph$ & constant in the RNG $k-\varepsilon$ model \\
\hline$\alpha$ & thermal diffusivity $\left(\mathrm{m}^{2} \mathrm{~s}^{-1}\right)$ \\
\hline$\alpha_{t}$ & turbulent thermal diffusivity $\left(\mathrm{m}^{2} \mathrm{~s}^{-1}\right)$ \\
\hline$\alpha_{t h}$ & thermal absorbance \\
\hline$\beta$ & volumetric thermal expansion coefficient $\left(\mathrm{K}^{-1}\right)$ \\
\hline$\phi_{s}$ & latitude in degrees \\
\hline$\varphi$ & surface slope in degrees \\
\hline
\end{tabular}


$\omega_{s} \quad$ angular displacement of the sun in degrees

\section{Subscripts}

$\begin{array}{ll}a & \text { air } \\ \text { amb } & \text { ambient } \\ c e i & \text { ceiling } \\ \text { cond } & \text { conduction } \\ c o n v & \text { convection } \\ d p & \text { dew point } \\ e q & \text { equivalent } \\ \text { env } & \text { environment } \\ \text { ext } & \text { exterior } \\ \text { glb } & \text { globe } \\ \text { int } & \text { interior } \\ i, j, k & \text { index of Cartesian components } \\ \text { mrt } & \text { mean radiation temperature } \\ \text { nom } & \text { nominal } \\ \text { op } & \text { operative condition } \\ \text { opt } & \text { operative temperature } \\ r a d & \text { radiation } \\ r e f & \text { reference } \\ r i & \text { radiation from interior surface } \\ s & \text { surface } \\ \text { so } & \text { outside surface } \\ \text { si } & \text { inside surface } \\ & \end{array}$




\section{Table of Contents}

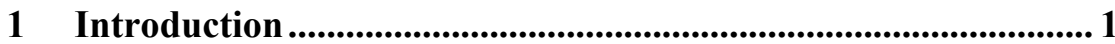

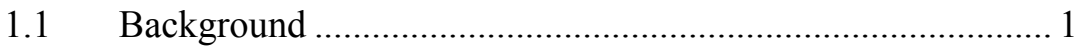

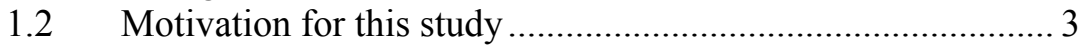

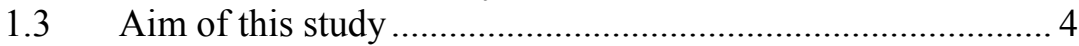

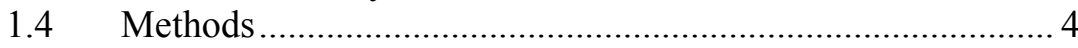

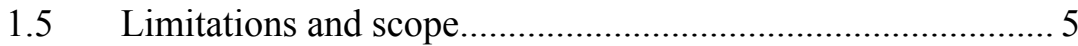

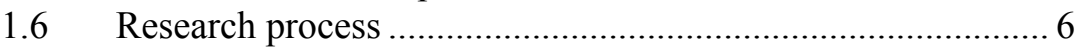

$1.7 \quad$ Appended papers in brief .................................................. 7

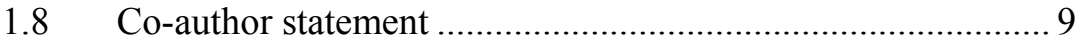

1.9 Optical properties of organic coated steel sheets ................... 10

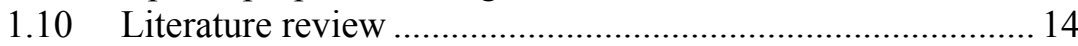

1.10 .1 Building energy simulation ............................................. 14

1.10.2 Computational fluid dynamics ........................................ 15

1.10.3 Coupling building energy simulation and CFD................ 18

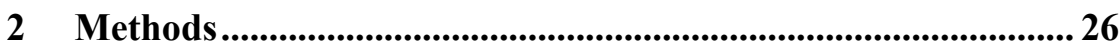

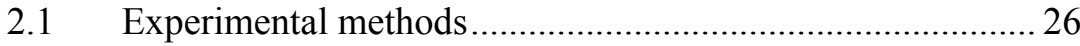

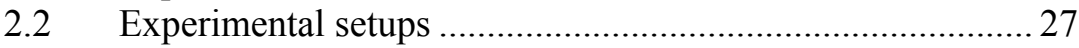

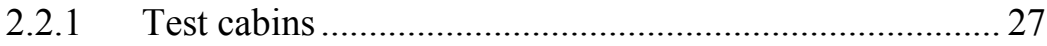

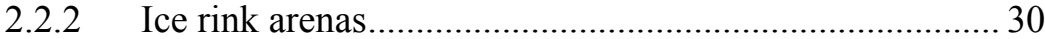

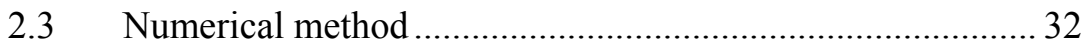

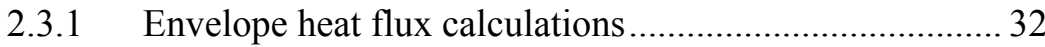

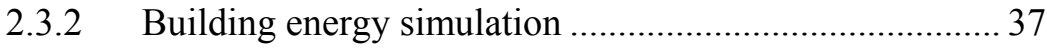

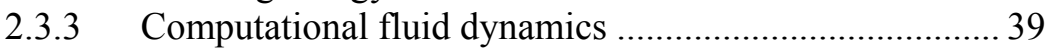

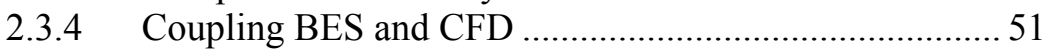

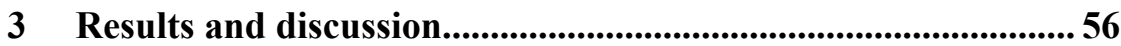

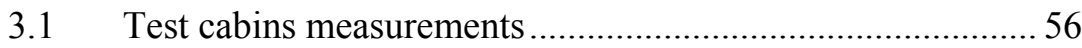

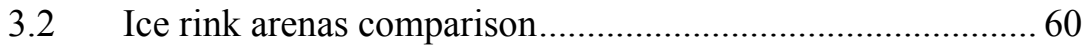

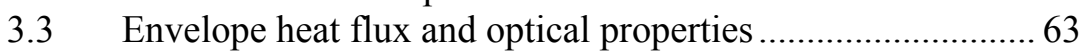

3.4 Internal load, climate factors and optical properties .............. 68

3.5 Air and surface temperature gradients ................................. 71

3.6 Coupling BES and CFD .................................................... 76

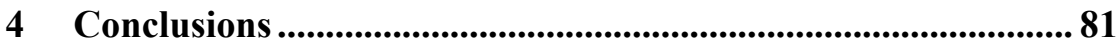

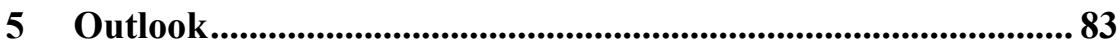

References ...................................................................................................... 84 


\section{Introduction}

\subsection{Background}

The built environment accounts for about $40 \%$ of the annual energy use and greenhouse gas emissions in Europe, where a considerable part of this energy is used for achieving desirable indoor climate. With regards to global warming concerns, the European Union has issued a 20-20-20 target with three key objectives to reduce energy use by $20 \%$, reduce $\mathrm{CO}_{2}$ emission by $20 \%$ of and utilize $20 \%$ more renewable energy by 2020 compared to the year 1990 . The 2030 and 2050 targets are among the progressive climate and energy policies after 2020. Moreover, several green building programs and certification systems such as LEED (Leadership in Energy and Environmental Design), BREAM (Building Research Establishment Environmental Assessment Method) and European EPBD (Energy Performance of Building Directive) are all aimed towards environmentally friendly building design including reduction of building energy use.

Energy is needed however to maintain a desirable indoor climate in buildings to support different activities and daily life. The requirement for efficient building energy management varies depending on building applications. It can vary from occupant comfort, food storage facilities, telecommunication centers, etc. For the occupied indoor climate, from an economic point of view, it is also important to maintain good indoor environment in order to reduce medical care and increase productivity.

This calls for a state-of-the-art design that both reduces energy use and improves indoor climate at the same time or maintains a desired indoor condition with less energy use. A holistic approach can be applied with both active and passive techniques. For instance, reducing solar heat gain can simultaneously improve occupant comfort and reduce the energy need for an auxiliary active cooling system.

To address the influence of the surface radiation properties, figure 1-1 (a) illustrates the heat transfer phenomena of a building envelope. As the solar irradiance reaches the exterior surface of the 
building envelope, some part of this irradiance is reflected due to TSR (total solar reflectance) properties of the surface and the remainder is absorbed by the exterior surface. Interior and exterior surfaces are coupled by conduction and can exchange energy with the respective environments via convection and radiation. The very first step of modeling the heat transfer in a building envelope is to consider a steady-state model having two-node surface temperature on interior and exterior sides of the envelope. This model of one-dimensional steadystate heat transfer is shown in figure 1-1 (b)

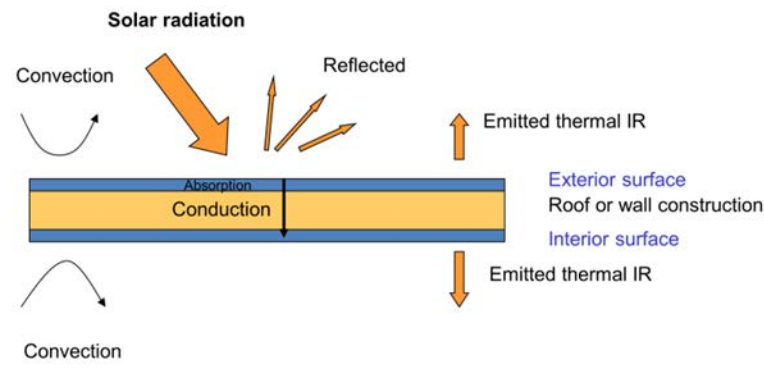

(a)

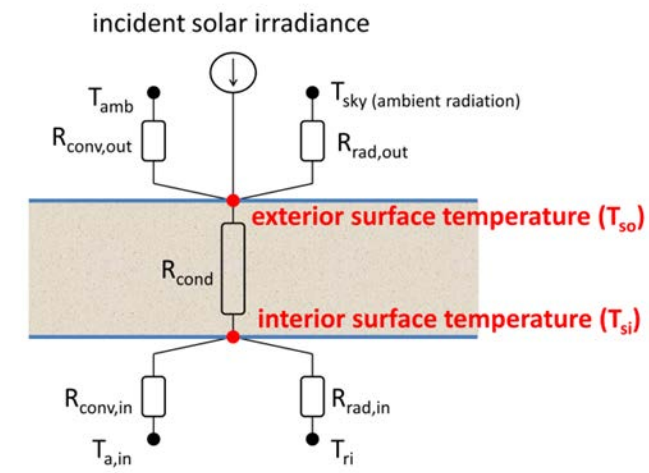

(b)

Figure 1-1 (a) Envelope heat transfer phenomenon and (b) schematic steady-state model 
Although the schematic steady-state model is simple, it is not necessarily the least important one. For instance, in several building codes and energy standards such as ASHRAE Standard 90.1 which concerns the radiation properties of the exterior surfaces, a similar steady-state approach is employed in the form of a factor called SRI (solar reflectance index) described in ASTM standard E1980. If a product has an SRI factor of more than e.g. 75 it can be labeled as "cool roof" and can then be categorized separately when it comes to required insulation thickness or have other privileges when applicable based on individual building regulations or standards.

\subsection{Motivation for this study}

Among the creative solutions to reduce building energy use and simultaneously improve the indoor climate is optimizing the radiation properties of the interior and exterior surfaces of the building envelope. For instance, reducing the solar gain of the building can reduce the energy needed for cooling or improve indoor thermal environment.

Development in the coil-coating industries has now made it possible to allocate correct solar and thermal radiation properties for steel-clad buildings. For aesthetic purposes, it is now even possible for some coil-coated products to have altered optical properties without changing the visible colors.

Different radiation properties on the interior and exterior building surfaces can affect the building thermal performance e.g., cool roofs for exterior surfaces presented in many studies such as (Jo et al. 2010; Konopacki and Akbari 2001; Wang et al. 2008; Wray and Akbari 2008), near-infrared (NIR) reflective pigments (Miller et al. 2004; Levinson, Akbari, and Reilly 2007;Song et al. 2014), mitigation of heat island effect by applying cool roof materials (Santamouris et al. 2012; Synnefa et al. 2011;Santamouris 2014; Rossi et al. 2015), indoor climate and temperature distribution (Daoud, Galanis, and Bellache 2008; Azemati et al. 2013) and reflective barrier for air space and attics (Baldinelli 2010;Saber 2012; Miranville et al. 2012;Belusko, Bruno, and Saman 2011). 
While the majority of studies are related to the exterior reflective surfaces or reflective barriers in the building construction air-gaps and attics, there are fewer studies evaluating the reflective coatings as building interior surfaces, the combined effect of interior and exterior reflective surfaces (on roofs and facades) and surveys of different modeling approaches and their consequences in the context of the building thermal performance of reflective coatings.

\subsection{Aim of this study}

The aim of the study is to investigate the effect of radiation properties of coil-coated steel sheet on building thermal performance. The research questions are:

- How does the reflectivity of interior and exterior surfaces affect the building thermal performance?

- What is the impact of interior reflective surface on the indoor conditions?

- How can numerical models help to understand and predict the thermal performance for different building applications and climate conditions?

The target groups for this thesis are those familiar with general physics and heat flux mechanisms, those who have general understating of building technology and material science and are familiar with general scientific modeling or numerical simulation. Architects, building project managers, building simulation developers and academics are among the target groups.

\subsection{Methods}

The methods include field measurements from three test cabins. The test cabins are similar and only differ in optical properties of the interior and exterior surfaces. Parallel measurement was employed to obtain comparative results from the field measurements. 
Field measurements on two ice rink arenas with normal and low emissive ceiling were used as another case study with significant indoor surface temperature asymmetry.

Numerical models at different levels of detail were chosen for the numerical investigation: envelope heat flux, building energy simulation (BES) and computational fluid dynamic (CFD) and coupling BES and CFD.

Numerical models were evaluated based on measurements. The parallel measurements in low-level controlled field experiments provided reliable comparative results to evaluate the capability of the numerical model in comparative validation.

The numerical models were also used in the sensitivity analysis to address the thermal performance of interior reflective cabins under different conditions.

\subsection{Limitations and scope}

The choice of the optical properties of the surfaces was based on available coil-coated steel products at the time of the test cabins' construction and it is assumed that the optical properties of flat surfaces remain constant. Long-term degradation of binder resin and pigments, dust gathering and dirt pickup, condensation and freezing are all factors that can affect the optical properties of the surfaces. The shape of the surface, e.g., corrugated profile can affect the radiation properties of the surfaces introducing ray traps. The optimization in the paint system and continued development in the paint formulation to improve the optical properties are aimed at minimizing any degradation of the functional surfaces. The exposed sample in the harsh coastal climate of Bohus-Malmön, north of Gothenburg, Sweden has shown only marginal effect on the surface optical properties after five years of exposure. These variations are not considered in this thesis work.

In the parametric study in Paper IV with focus on building thermal performance with different surface optical properties, windows are not considered. By doing this, the results are more straightforwardly 
comparable when it comes to e.g. building scale factor and internal loads variation.

In Paper V, the windows are not included for simplicity and results are validated against externally and internally blinded windows. The coupled BES and CFD model includes only interior walls, ceilings and floor surfaces. The door and windows are excluded from the model in order to minimize the number of surfaces in the iterative process to those with different radiation properties.

For the CFD-based studies, choice of wall function, number of cells and size, turbulence models and simulation time horizon were restricted by available computational sources and based on grid dependency analysis.

Analysis on the indoor climate is limited to those variables that are affected by interior reflective surfaces, e.g. mean radiation temperature and indoor air temperature gradient.

\subsection{Research process}

The project is divided into the following three parts:

- Field measurement study

- Numerical modeling and computational study

- Parametric and thermal performance study

The research starts with parallel field measurement on three test cabins, with different combination of interior and exterior surface radiation properties to realize the effects of having reflective surfaces on building interior and exterior surfaces. Ice rink arenas were another case study where the influence of the low emissive interior surface was considered. In the latter case the larger temperature asymmetry and the considerable direct interaction between roof and floor surfaces are evident.

Numerical models span from simple schematic steady-state model focused on envelope heat flux up to whole building simulation and CFD models. The numerical methods were evaluated and where necessary developed to analyze the building thermal performance. Comparative 
validations were employed with the focus on capturing the effects of surface optical properties on the indoor thermal climate.

\subsection{Appended papers in brief}

An experimental investigation is described in Paper I, where the test cabins with different combinations of solar radiation reflective coatings on exterior surfaces and thermal infrared radiation reflective coatings on interior surfaces are studied in parallel field measurement over the course of a year with a number of one or two-week-long experiments. The aim of this paper was to experimentally investigate the thermal performance of the test cabins and include the main experimental results for this thesis work regarding the test cabins. The study includes both passive and active experiments, the latter with floor heating and/or cooling air conditioner. The paper also includes a simple steady-state model to clarify the principle in the early stage modeling.

A numerical method for building envelope heat flux and the sensitivity study is presented in Paper II. This paper evaluates the sensitivity of the thermal energy flux through building envelope, by systematically varying the radiation properties of the surfaces, with regards to different climate conditions for southern, middle and northern Europe, different indoor radiation temperature, the insulation thickness, etc. This is the first hourly dynamic model in this thesis for calculating the effect of both interior and exterior optical properties in terms of net energy flux.

In the Paper III, two ice rink arenas have been used as case study objects to investigate the importance of interior surface radiation properties where there is a significant radiation temperature asymmetry between interior building surfaces. The ceiling radiation temperature is measured and compared in the two ice rink arenas with high and low emissive ceiling surfaces. The dynamic model presented in Paper II has been employed to address the ceiling radiation to the ice surfaces comparing different ceiling surface emittance. Based on Paper III, this thesis highlights the ceiling radiation temperature dependency on the surface longwave radiation properties and importance of the roof-to-ice heat flux for the ice rink arenas. 
The building energy simulation tool, IDA ICE is employed in Paper IV with the aim to address the influence of reflective coatings on the building thermal performance at building level under different scenarios with varying internal load, ventilation rate, climate data and different scales of the test cabin. The aim of this paper was to point out the dependence on other parameters determining the thermal performance of reflective coatings when it comes to the interior, exterior and combined effect of both interior and exterior reflective surfaces. This thesis highlights some of the results given in Paper IV, pointing out the overall thermal performance contributions from the reflective coatings at the building level.

The influence of the interior reflective coatings on the indoor air and surface temperature distribution is presented in Paper V, where computational fluid dynamics (CFD) is employed in a simulation method to account for both temporal and spatial discretization of the indoor air and surface temperatures. This thesis addresses the increased air and surface temperature gradients by the use of reflective coatings based on Paper V, where other modeling approaches fail to reproduce the spatial resolved temperature distribution of indoor air and surface temperature without consistent discretization of indoor air and interior surface.

The need for spatial resolution of building energy simulation to account for the indoor thermal environment (Paper IV) on the one hand and the inordinate computational load of the CFD simulation method (Paper V), on the other, advocates for the use of alternative solutions such as coupling methods as presented in Paper VI which can account for both high spatial resolution indoor thermal environment and energy use, simultaneously. This thesis uses the method presented in Paper VI as the reconciliation between spatial resolution and computational load. Table 1-1 arranges the papers based on whether interior or exterior surfaces are studied and on the choice of simulation method. 


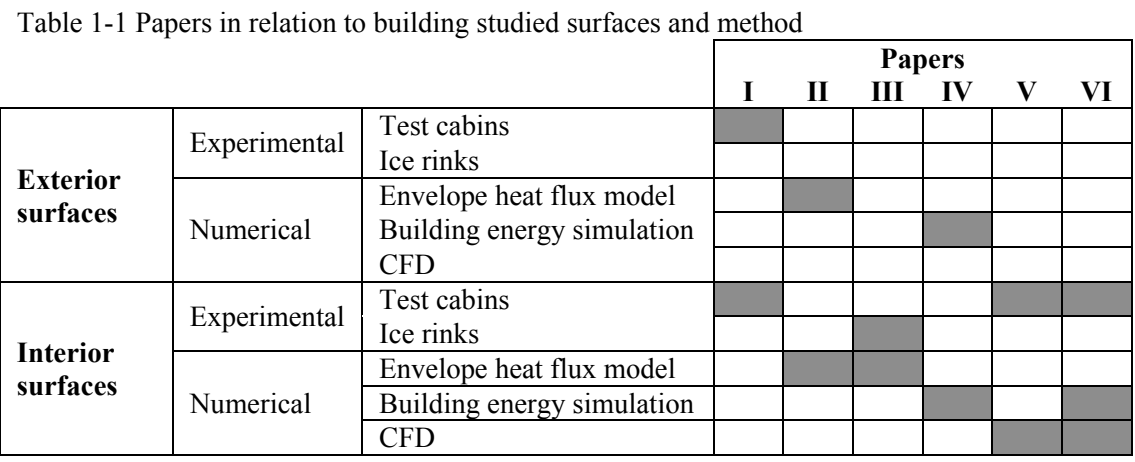

\subsection{Co-author statement}

The author of this thesis has conducted the main work including experimental and numerical investigations and is the main author of Papers I, II, IV, V and VI and the simulation part of Paper III. The main supervisor of this study was Professor Bahram Moshfegh.

In Papers I, II and IV Dr. Harald Svedung and Associate Professor Mats Rönnelid have contributed valuable comments and input throughout the whole process from planning, investigation, interpretation of results and final improvement of the manuscripts. In Paper I, Associate Professor Chris Bales has contributed helpful suggestions in the numerical model.

In Paper III, the author of this thesis has carried out the simulation and contributed the planning and evaluation of the ice rink measurements. The rest of the paper was contributed by the co-authors.

In Papers IV, V and VI the simulations have been carried out under supervision of Dr. Mathias Cehlin with valuable input, helpful advice and guidance throughout the simulation process.

Papers V and VI have been carried out under the supervision of Professor Bahram Moshfegh with valuable comments and useful suggestions in the planning, interpretation of results and final disposition and structure of the manuscripts. Dr. Harald Svedung and Dr. Mathias Cehlin contributed helpful advice during the preparation of 
the manuscripts. In Paper V, Associate Professor Mats Rönnelid has provided important inputs to the climate model. In Paper VI, Associate Professor Patrik Rohdin has contributed valuable and useful suggestions.

\subsection{Optical properties of organic coated steel sheets}

Most of the energy from the sun is found in the wavelength region between 0.25 to $2.5 \mu \mathrm{m}$; below the wavelength of $0.4 \mu \mathrm{m}$ is the UV (ultraviolet) region. The visible region starts from wavelength 0.4 to $0.8 \mu \mathrm{m}$. The human eye is sensitive in this region and perceives the surface reflectance in terms of darker and lighter colors. After the visible region until the wavelength of $2.5 \mu \mathrm{m}$ is the NIR (near infrared) region. More than half of the solar irradiance is actually coming in the NIR region (Duffie and Beckman 2006) and it is particularly interesting in the coil-coating application in the sense that it is possible to have dark colors but with higher TSR (total solar reflectance) values by using pigments that are reflective or translucent (not absorbing) in the near infrared region. The thermal radiation region (infrared radiation region) has longer wavelengths.

In hot climates, for example, exterior coatings can have also high NIR reflectance as well as high thermal emittance. High TSR coating reduces the solar gain and high thermal emittance helps the surface to cool down faster and lowers the equilibrium temperature at steady state by radiating to the environment like clear sky that can be up to $40^{\circ} \mathrm{C}$ lower than ambient air. With regard to different geographic regions, the coil-coated steel sheet can behave exclusively in different wavelengths.

The layout of coil-coated steel studied in the test cabins is presented in figure 1-2. The top coat paint layer thickness is about10 $\mu \mathrm{m}$ and aluminum flake thickness of typically less than $1 \mu \mathrm{m}$ with the diameter around $50 \mu \mathrm{m}$. For the exterior coatings, it is possible to add near infrared reflective pigment in the top coat to improve the total solar reflectance. High TSR pigments for exterior surfaces can either be reflective or transparent to NIR. 


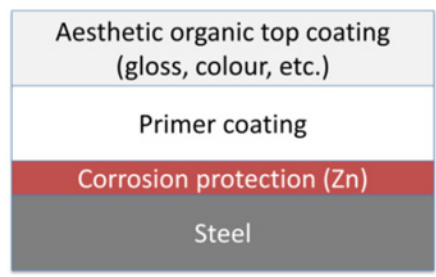

(a)

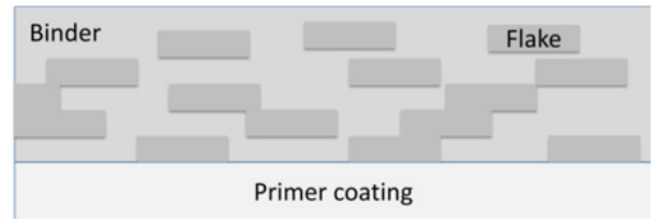

(b)

Figure 1-2 (a) paint system components of the coil-coated steel (b) the top coating for interior surfaces with high thermal reflective aluminum flakes in the binder

The high-TSR pigment used in the cabins is Paliogen black. That is an inorganic semi-conducting crystalline pigment with an extremely sharp and well-tuned transition from highly absorbing in the visible region to being highly transparent to NIR. In comparison, the use of carbon black pigment as in normal coil-coating pigmentations effectively reduces TSR by the strong absorption of NIR as well as visible light.

For interior coatings it is possible to increase the thermal reflectivity or, in other words, reduce the thermal emittance. The top coat for the reflective interior has aluminum flakes that give this coating low emittance. Both top coat and primer usually have a polyester binder. The top coating can have colored pigments or not, and the primer is usually white, generally given by titanium dioxide pigment.

Studying the interior reflective surfaces, the polyester binder has high absorption in the infrared giving rise to high thermal emittance. This is also the case with the primer. The aluminum flakes have low emittance. The coating thermal emittance is actually the combined effect of the flakes, binders and pigments in the top coat as well as in the primer. The 
flakes increases the reflectance (reduces the emittance) but they cannot totally take away the binder high emittance. Figure 1-2 shows the top coating. If the aluminum flakes do not align parallel to the surface and effectively screen the primer from the radiation on each other, the gaps between flakes penetrate down to the primer, which then results in a contribution to the emittance from the primer.

Regarding the distribution of the aluminum flakes in the paint layer, there are two main types: leafing flakes tend to migrate to the paint surface whereas non-leafing plates get more evenly distributed in the paint layer depending on the surface properties. The coating of the interior reflective cabin is based on the leafing aluminum flakes in an epoxy binder.

The optical properties of the coatings used in this work are measured with Perkin Elmer Lambda 900 with white integrating sphere between 0.3 to $2.5 \mu \mathrm{m}$ and Bruker Tensor 27 FTIR with gold integrating sphere in interval $2.5-21 \mu \mathrm{m}$ at Ångström Laboratory, Uppsala University. Figures 1-3 to 1-5 present the reflectance of coating at different wavelengths in blue line color where green and red curves represent the solar and thermal radiation spectra. In those figures, the blue line represents the reflectance of the surface. The green and the red lines represent the normalized intensity of radiation from the sun and blackbody radiation from a surface at temperature of $20^{\circ} \mathrm{C}$, respectively. 


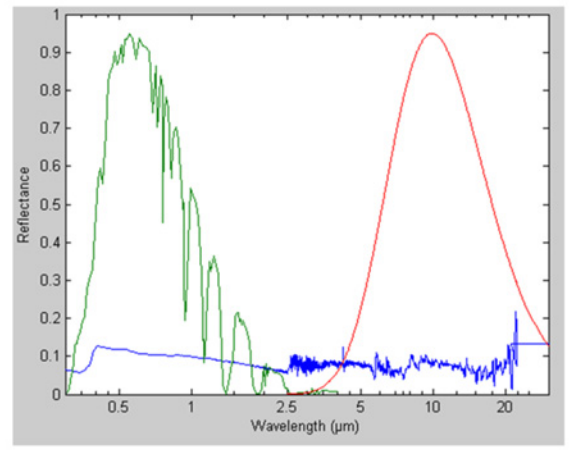

Figure 1-3 Normal dark grey for either interior or exterior surfaces

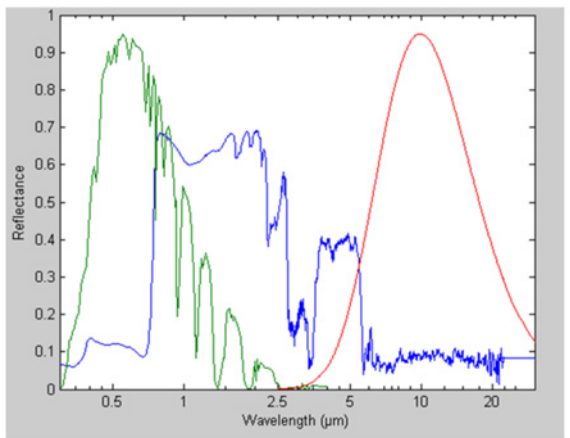

Figure 1-4 Reflective dark grey for exterior surfaces

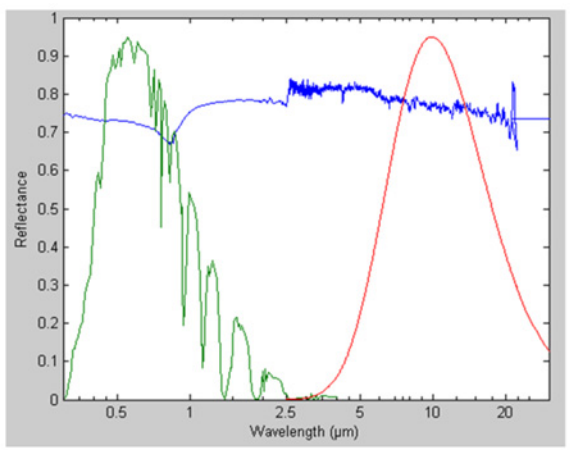

Figure 1-5 Reflective silver metallic for interior surfaces 


\subsection{Literature review}

\subsubsection{Building energy simulation}

Building energy simulation can play an important role in evaluating the energy use of buildings. It allows for modeling a building before it is built or before renovations are started. Various energy alternatives can be investigated and different options compared. Simulation can lead to an energy-optimized building.

Simulation is generally much less expensive and less time-consuming at this level than experimentation on real buildings. The small-scale experimental investigation can provide valuable information for the full-scale models with lower costs. However, small-scale measurement may not be scalable to full-scale models. On the other hand, the measurement is based on the real physical observation, rather than an output based on a set of theoretical equations arbitrarily defined in the building energy simulation tools available. Building energy simulation can produce "blind" results for those physical features that are not defined for them or lie outside the validity ranges.

A list of available building simulation performance tools are presented by the U.S. Department of Energy (DOE 2014). Crawley et al. (2008) compares the major twenty building energy simulation tools in terms of capabilities and features. Attia et al. (2012) shows the engineers top selection criterion for energy simulation to be the "accuracy and ability to simulate detailed and complex building components", e.g. detailed simulation of a passive solar building design with high resolution and quality.

The building energy simulation of IDA ICE (EQUA 2009a;Sahlin et al. 2004) has been used for this study. IDA ICE is a dynamic multi-zone simulation with simple user interface and full flexibility for advanced users. It is a whole building simulation performance tool with a variety of heating and cooling systems and different controllers and validates with respect to ANSI/ASHRAE Standard 140-2004 (EQUA 2010a), CEN Standard EN 15265-2007 (EQUA 2010b) and CIBSE validation (Moosberger 2007). 
Building energy simulation has been used in many studies to address the influence of cool roof. A recent study by Revel et al. (2014) using ESP-r software indicates cooling reduction in different places in Europe. They also point out the potential savings by using high solar reflective surfaces on the façade especially for high-rise buildings.

Zheng et al. (2015) used EnergyPlus software to study the influence of thermochromic coatings on energy use. The solar reflectance of the thermochromic coatings increase when they are heated. Their simulation results indicate that there is a potential energy savings in the climate regions with warm summer and cold winter.

Dabaieh et al. (2015) used Design Builder simulation software to evaluate the building thermal performance of the cool roofs for residential buildings in Cairo, Egypt. Their study shows remarkable improvement in thermal comfort (reducing the discomfort hours by $53 \%$ ) and cooling energy savings at summer seasons by the use of cool roof.

Earlier studies indicate the advantages of using different building simulation software to study various aspects of high reflective exterior surfaces and cool roofs for different types of buildings and climates. More information regarding the use of BES to predict the thermal performance of exterior reflective surfaces can be found in the review study by (Hernández-Pérez et al. 2014).

\subsubsection{Computational fluid dynamics}

In recent decades, CFD has been used to predict indoor thermal environment, air quality and contaminant concentrations. The use of CFD in predicting the indoor air flow pattern goes back to the 1970s (Axley and Nielsen 2008). In principle, CFD discretizes the simulation domain into a number of cells. Then the governing equation is applied for each cell. There are generally three levels of CFD simulations: Reynolds-Averaged Navier-Stokes (RANS), Large-Eddy Simulation (LES) and Direct Numerical simulation (DNS).

The DNS model solves for all small eddies without any approximation but it requires a fine mesh to capture all small eddies at Kolmogorov 
micro scale. The ratio of smallest to largest length scale for one-dimensional turbulent flow is in the magnitude of $\mathrm{Re}^{3 / 4}$. For three-dimensional indoor airflow it becomes in the order of $\mathrm{Re}^{9 / 4}$. Assuming a Reynolds number of about $10^{5}$ for a typical indoor airflow, the required cell number is about $10^{11}$ which is not an easy task even for the current supercomputers. Furthermore, a transient simulation requires very fine temporal discretization where the ratio of the smallest to largest time scale is about $\mathrm{Re}^{1 / 2}$. Therefore, DNS is by far too computationally heavy for current computers (Nakahashi 2008;Srebric 2011; Versteeg and Malalasekera 2007).

The LES model solves for all large eddies but uses approximation for the small eddies. LES relies on the definition of large-eddy and small-eddy scales. The large eddies are directly solved in LES (filtered governing equations), but for the small eddies, the turbulent transport approximation is used. The accuracy of the LES model depends on the correct selection of sub-grid scale model (Chen and Srebric 2002). Although the LES model is less computationally demanding than DNS in terms of both spatial and temporal discretization, the LES model is still computationally burdensome for common design practice of indoor airflow. (Sagaut 2006;Srebric 2011;Ferziger and Perić 1996).

RANS (Reynolds-Averaged Navier-Stokes) is the most commonly used model in CFD simulation. It has the least computational load and is most economical compared to other models. Its accuracy is reasonably good in most common engineering problems. In RANS the instabilities are time-averaged and the effect of the turbulence is modeled on the mean flow using different methods.

Measurements in the test cabins have shown that the low emissive interior coatings can affect the indoor air temperature gradient. The use of low emissive interior surface increases the air temperature gradient in the absence of forced ventilation across the interior surfaces. This air temperature gradient also varies with the time of the day and is largest in the middle of the day where there is the highest radiation asymmetry (Joudi, Svedung, et al. 2011).

In the building energy simulation, the spatial resolution of air temperature is limited to a number of zones and is assumed as a uniform 
air temperature in each zone without further information on local air flow pattern (Van Treeck 2011). Regarding the indoor air temperature gradient, the detailed temperature distribution can be provided by CFD (Van Treeck 2011).

The influence of the low emissive surfaces on the indoor air temperature gradient cannot be predicted by the use of common building energy simulation programs which are based on the well-mixed assumption or the "zone" uniform properties. Although such simulation tools are useful for estimating annual energy use (Joudi et al. 2013), the lack of spatial resolution in such models makes it inappropriate to address spatially resolved phenomena such as temperature gradients.

One way to improve the spatial resolution is the use of multi-zone or zonal model (Daoud, Galanis, and Bellache 2008) which divides the total indoor air volume into a few smaller zones. Each zone maintains the bulk property of a single zone and the relation between the zones is established by empirical or semi-empirical equations. However, dividing a single zone into several zones in which the uniform properties are valid can be hard to estimate beforehand. It requires a good understating of the flow field. Secondly, the convection correlation between air nodes and between air node and interior surface temperature are underestimated (Peeters, Beausoleil-Morrison, and Novoselac 2011). Computational fluid dynamics (CFD) is useful when the research question concerns spatially resolved properties and restrictions of the multi-zone model are detrimental to the accuracy of the simulation.

The surface radiation properties can affect the indoor air temperature distributions via surface temperature in the natural and mixed convention. To account for the interplay between surface and adjacent air it is essential to maintain a consistent spatial resolution for both surface and adjacent air. The full interaction between air and surface temperature gradients are only fully captured if both domains are spatially discretized. The sharp geometric separation between the two domains can harm the accuracy of the overall model (Woloszyn et al. 2009). For example, having one surface temperature coupled with discretized air volume, is an artefact to capture the full temperature gradient of the adjacent indoor air. 
Revel et al. (2014) used CFD to address the temperature distribution on the small cabin with $7.2 \mathrm{~m} 2$ and a horizontal roof to evaluate the influence of high reflective exterior surface. Their study shows reduction in peak surface temperature on both interior and exterior surfaces, in agreement with the experimental results. Azemati et al. (2013) used steady-state two-dimensional CFD to evaluate the influence of exterior reflective surfaces on the indoor air temperature distribution on a small enclosure. (Xamán et al. 2010) used CFD simulation to study the effect of reflective exterior surfaces in the cavity indicating the reduction of indoor air temperatures with white roof (exterior surfaces). Wang et al. (2014) used CFD to study the influence of convection and radiation heat transfer in an industrial building with a high temperature internal heat source with different surface emittance in order to predict the effect on heat transfer, temperature and flow distribution. (BorgeDiez et al. 2013;Sekar et al. 2012) have also used CFD to address the influence of reflective exterior surfaces. More information can be found at the review study by (Hernández-Pérez et al. 2014).

\subsubsection{Coupling building energy simulation and CFD}

The correct determination of convection heat transfer coefficients is important for building thermal performance prediction (BeausoleilMorrison and Strachan 1999;Peeters, Beausoleil-Morrison, and Novoselac 2011;Goldstein and Novoselac 2010; Fohanno and Polidori 2006). There are two ways to obtain the convection heat transfer coefficients, either derived experimentally or predicted numerically by the use of CFD.

An extensive review of natural, forced and mixed convection correlations is given by (Peeters, Beausoleil-Morrison, and Novoselac 2011) for both free surface and confined surfaces (enclosed space). The simple coefficient can be based on a temperature difference between air and surface, the slope of the surface and characteristic length, such as those presented by (Brown 1963;Brown and Isfält 1974;Min et al. 1956). Those coefficients, although easy to use, neglect the characteristics of the flow field which can reduce the accuracy of the convection heat transfer coefficient. 
In general, enclosed space convection correlations have better accuracy compared to free surface correlations. This is due to the fact that in the free surface correlations, the effect of the neighboring surfaces on the main flow field is not taken into account. The overall flow pattern can affect the flow on a specific surface which is considered in the enclosed space correlations. Such correlations are obtained from extensive experimental studies on confined space surfaces. (Peeters, BeausoleilMorrison, and Novoselac 2011)

Although enclosed space correlations give the most realistic values for the convection heat transfer coefficients, there are cases for which no experimental correlation exists, e.g. tilted ceiling surface in a room with floor heating system. Furthermore, according to (Peeters, BeausoleilMorrison, and Novoselac 2011), non-uniformity of indoor air temperature, characteristic dimension, different indoor obstacle and airflow disturbance can influence the accuracy of convection correlations. Those correlations are obtained under well-controlled experimental environments with specific boundary condition.

There are basically two sources of concern when it comes to predicting the effect of interior reflective coatings on building thermal performance. The first is the lack of spatial resolution and non-uniformity of indoor air. The second is the correct consideration of convection heat transfer. Regarding the first one, there are recommendations, such as evaluating the dimensionless temperature gradient by (Wang and Chen 2008) to evaluate if the uniform air temperature assumption is acceptable or not. But when it comes to the second concern, not only the correct determination of convection heat transfer coefficients is challenging; many convection correlations are the function of the difference between surface and reference air temperature. The non-uniformity of indoor air can make it even more complex when it comes to correct determination of the reference temperature. The uncertainties caused by stratification in proper selection of the reference air temperature is addressed by (Beausoleil-Morrison and Strachan 1999).

The convection heat transfer coefficient can also be obtained numerically by the use of CFD which is a robust tool for predicting air temperature distribution. However, the accuracy of the CFD model depends greatly on the correct choice of numerical model and efficient 
discretization of the flow field. There can be considerable difference in heat transfer coefficients between convection correlation and those obtained from CFD as indicated by (Zhai et al. 2002;Zhang, Lam, et al. 2013). Finding the correct convection heat transfer coefficient by the use of CFD also requires consideration of computational time and cost efficiency. Although a zonal model by the use of airflow network can to some extent account for non-uniform distribution of the air, the use of CFD is still a better alternative (Mora, Gadgil, and Wurtz 2003).

The accuracy of the CFD results is also sensitive to the provided boundary conditions. These boundary conditions can be obtained from available experiments or other simulated results, such as building energy simulation. BES can provide an overall estimation of annual building energy use and temperature variations which can be used to provide boundary conditions for CFD.

However, the application of CFD can be prohibitively limited in terms of space size and time period (Van Treeck 2011), which is hardly the case for BES. Besides, there are wide varieties of HVAC systems available and coded in BES, which is still uncommon in CFD tools.

Then there is the idea of combining building energy simulation and CFD. A combined BES - CFD program can both improve the accuracy of the indoor airflow prediction of the BES program and provide the correct boundary condition for the CFD simulation (Clarke 2001;Hensen 1999;Srebric 2011). Such a combined model is beneficial wherever the interconnection between discretized indoor climate, outdoor variations and interaction of HVAC system are equally important and influential to the overall building performance prediction.

There are, of course, other approaches to overcome the shortcomings of common BES without coupling BES with CFD. They are generally called the "remedy methods". There are different variations of such remedy methods; quasi-3D sub-zonal airflow model (Bonvini, Leva, and Zavaglio 2012), Fast Fluid Dynamics, FFD (Zuo and Chen 2009), contribution ratio of indoor climate or CRI (Zhang, Hiyama, et al. 2013), the advection-diffusion response factors by (Hiyama and Kato 2011) or improved zonal model for forced convection by (Abadie et al. 2012). All these methods are much faster than CFD-coupled energy 
simulation and are more comparable with common BES computations in terms of computational time. However, their accuracy and detail levels though better than BES, are generally less than the standard CFD (and, arguably, comparable to coarse CFD). Nevertheless, these remedy methods are rather newborns and their limitations and uncertainties are under constant investigation.

Combining building energy simulation and CFD, has been addressed in many studies in the literature, e.g. (Negrão 1998;Zhai and Chen 2003, 2004;Zhai et al. 2002), passive cooling through night ventilation (Leenknegt et al. 2012), naturally ventilated rooms (Wang and Wong 2008, 2009), evaluating the performance for PCM heat exchangers (Gowreesunker, Tassou, and Kolokotroni 2013) or adaptive coupling with conflation algorithm (Beausoleil-Morrison 2000;Bartak et al. 2002) . Due to the continuous increase of the computational load, combining CFD and BES is becoming more and more popular. Coupling BES and CFD can be an indication of future simulation trends as computers are getting faster, calculation time shorter and CFD is becoming a more user-friendly tool (Chen 2009).

Generally speaking, any form of coupling BES and CFD is to answer four fundamental questions:

- Coupling Variables: What are the exchange variables between the simulation domains?

- Coupling Method: How do the two simulation domains exchange variables?

- Coupling Scheme: When should the coupling occur?

- Coupling Platform: Where is the coupling performed? Internal or external coupling? The tools and practical issues?

There are originally two coupling methods for BES and CFD co-simulation; Dynamic coupling and Quasi-dynamic coupling methods as shown in figure 1-6. 


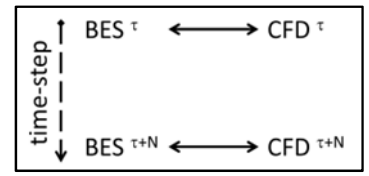

(a)

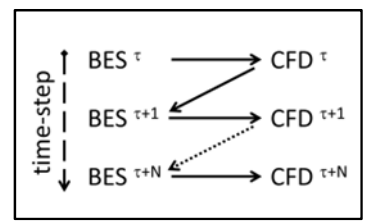

(b)

Figure 1-6 (a) dynamic coupling (b) Quasi-dynamic methods

The dynamic coupling comes from an iterative approach, where two models need to be solved using each other's results as input and setting up a data loop with constant feedback. Within each time-step, this loop will iterate until it reaches fair stability (convergence) with regards to its relaxation factor. After convergence, the model jumps to the next time-step, iterating again until desired convergence.

In quasi-dynamic method, the models run after each other, using results from the previous time. The quasi-dynamic and dynamic are the same for infinitely small simulation time-step. In general, the quasi-dynamic method is faster since it does not have the iterative process of the dynamic method. However, simulation time-step must be small enough and chopped carefully to correctly capture the dynamic behavior of the overall model and avoid inaccurate results. For instance, if the boundary condition is rapidly changing, the time-step size in the quasi-dynamic method should be short enough to capture the transient effects.

With selection of the quasi-dynamic method care must be taken to choose a short enough time-step that responds to the changes in the boundary conditions, for the need to consider how the boundary condition are changing. Although the use of the quasi-dynamic method can result in faster simulation performance, accuracy and stability can be less robust (Sahlin 2003). In the quasi-dynamic method, sudden 
changes can cause instabilities. This requires a control measure to shorten and tailor the time-steps during the simulation period. This is not the case in the dynamic coupling but it takes more simulation time.

The coupling (either dynamic or quasi-dynamic) can have different coupling schemes varying from hourly, several times in an hour or even several times in a year. (Zhai 2003) provides reviews of different coupling scheme and methods and introduces the virtual (bin) coupling which is a very interesting method for longer simulation time period such as addressing annual results. In the virtual coupling method, the results after each coupling performance are stored in a database to further use in recurring simulation time-step and increase the simulation speed. A guideline for appropriate use of the coupling method is presented in (Zhai and Chen 2006).

An integrated coupling method is presented by (Novoselac 2005) where the coupling does not necessarily occur after a fully converged CFD solution. In this method, CFD gives results to BES after a finite number of iterations (not fully converged results) where both BES and CFD progress simultaneously towards a common integrated solution. There, an increase in computational speed was shown.

Different ways to exchange variables between BES and CFD have been evaluated by (Zhai and Chen 2005) in terms of convergence, stability and speed with the top three methods presented in table 1-2. In all those methods, the best exchange variable from BES to CFD is the surface temperature $\left(T_{s}\right)$ which is used as the boundary condition in the CFD simulation. The returning one to more convection-related term from CFD to BES, however, is consistent among different methods. There are other forms of coupling as well such as pressure coupling for the airflow though large opening or atrium as presented by (Wang and Chen 2007).

Table 1-2 The top three variable exchange method from (Zhai and Chen 2005)

\begin{tabular}{|l|c|c|}
\cline { 2 - 3 } \multicolumn{1}{c|}{} & BES $\rightarrow$ CFD & CFD $\rightarrow$ BES \\
\hline Method (I) & $T_{s}$ & $T_{\text {air }}$ and $h_{c}$ \\
\hline Method (II) & $T_{s}$ & $h_{c, n o m}$ \\
\hline Method (III) & $T_{s}$ & $q_{c o n v}$ \\
\hline
\end{tabular}


According to (Zhai and Chen 2005), method (I) is the best method in terms of all convergence, stability and speed where $T_{a}$ and $h_{c}$ are the local air temperature and convection heat transfer coefficient, respectively. The second best method (II) uses the nominal convection heat transfer coefficient $\left(h_{c, n o m}\right)$. It has the same speed but when it comes to convergence and stability it ranks lower than the first method. In both methods (I) and (II), the exchange of convection heat transfer coefficient (either as local or nominal) provides an implicit iteration of surface temperature in BES. However, in method (III) using convection heat flux forms an explicit iteration of surface temperature in BES. Method (III) has the lowest ranking in terms of speed among other methods.

Method (I) requires both convection heat transfer coefficients and the local air temperatures. The local air temperature can be obtained from CFD as e.g. the mass weighted temperature of the air between 10 to 20 $\mathrm{cm}$ out of the wall (Novoselac 2005) and convection heat transfer coefficient can be obtained from empirical or semi-empirical correlation (Beausoleil-Morrison 2000; Novoselac 2005). Convection heat transfer coefficient can also be derived from CFD.

The convection heat transfer coefficient from method (II) needs to have one temperature as the reference air temperature. This air temperature can be an average of vertical or horizontal indoor air temperature (Wallenten 1999) or even mass weighted average of the indoor air. However, the convection heat transfer from the interior surfaces remains constant as the convection heat transfer coefficient is a weighted value based on a reference temperature. More precisely, the convection heat transfer coefficient is the fraction of the convection heat flux by an air-to-surface temperature difference where the reference air temperature can be chosen e.g. as the average indoor temperature or the mixed air temperature from the BES.

Regarding the practical issues and the coupling platform, the coupling can be internal or external, depending on where the coupling engine sits. In the internal coupling, the coupling engine is integrated or added as a module in either the CFD or BES simulation platforms. (Negrao 1995;Beausoleil-Morrison 2000) are examples of the internal coupling where the coupling engine is in the BES. In the external coupling 
(Djunaedy 2005;Djunaedy, Hensen, and Loomans 2003), the coupling engine is located elsewhere in a third simulation environment or an external source acts as the run-time communicator between the BES and CFD.

External coupling is arguably more attractive than the internal coupling due to the flexibility of having an external source and keeping the stand-alone BES or CFD tools untouched. With the external coupling, it is simply possible to use parallel computing techniques in CFD, benefiting the constant development and evolution of each individual program without needing to heavily update the source codes. There are also, unfortunately, a limited number of RANS models, wall functions and solver settings for existing internal coupling models. Simple or shoe-box geometries, maximum grid size and simulation time limitation can be other restrictions of internal coupling (Wang and Wong 2009). The decision to choose the best coupling platform is moreover a matter of personal preference and field of expertise. (Djunaedy, Hensen, and Loomans 2004) present a comparison between internal and external coupling concluding that the main advantages of using an external coupling is the freedom of the user to choose the best available simulation tools which in turn can contribute to the most accurate results with the shortest simulation time.

The internal coupling engines are mainly performed automatically. However, the external coupling can either be automatic such as (Fan, Hayashi, and Ito 2012;Zhang, Lam, et al. 2013) or manual such as (Barbason and Reiter 2014). Although automatic coupling is preferable, flexibility and the freedom of the user to manipulate the coupling procedure may be restricted. Starting with the manual coupling can provide valuable intuition for later tailoring of the automated coupling for further simulation. 


\section{Methods}

\subsection{Experimental methods}

Measurements include passive and active (heating and cooling) test during different times of the year. During the passive test, all HVAC systems are turned off and the dampers are closed. The purpose of the passive test was to monitor the passive behavior of the cabins with regards to variation of climate and different optical properties while the active test was aimed at the energy performance of the cabins. Parallel measurements on the test cabins enable the search for comparative key values to address the relative differences between the cabins and to evaluate the simulation performance accordingly.

Each test cabin was equipped with one PC logger with the cold junction accuracy of $\pm 0.5^{\circ} \mathrm{C}$ at $25 \pm 10^{\circ} \mathrm{C}$. Separate electricity meters for heating, cooling and auxiliary consumption were installed in each cabin. The electricity meters were programmed to generate 1000 pulses per $1 \mathrm{kWh}$. These pulses were then counted by the data loggers. The nominal accuracy of the electricity meters is $2 \%$.

Infrared thermocouples, IRt/c were used to detect the amount of thermal energy from a surface as IR radiation. Sensors detect only specific IR wavelengths. So other sources of radiation with different wavelengths such as shortwave solar radiation would not interfere. This equipment can be used to measure both surface temperature (with correction for surface emittance) and radiation temperature from a targeted surface.

The black sphere globe thermometers were used to measure operative temperature. They measure a mixture of the spherically integrated radiation temperature and, depending on the air speed, air temperature.

Air temperatures have been measured using K-type thermocouple. These sensors have short response time and secondly their small sensitive head eliminates the radiation effect of the surroundings. The surface-mounted K-type and magnetic thermocouples were used for the surface temperature measurements. Calibration has been done by the manufacturer. Other equipment with no exact calibration or accuracy, have been tested at SSAB Tunnplåt calibration section. 
Mean radiation temperature, MRT is calculated based on equation (2-1) (ASHRAE 2005) from the black sphere globe measurements. The mean radiation temperature is the uniform temperature of an imaginary black enclosure which would result in the same heat loss by radiation from a person at actual enclosure. The globe thermal emittance is 0.95 .

$$
T_{m r t}=\left(T_{\mathrm{glb}}^{4}+\frac{1.1 \times 10^{8} U_{a}^{0.6}}{\varepsilon_{t h, \mathrm{glb}} d_{\mathrm{glb}}^{0.4}}\left(T_{\mathrm{glb}}-T_{a}\right)\right)^{0.25}
$$

\subsection{Experimental setups}

\subsubsection{Test cabins}

The experiments have been carried out on available study objects, including three similar test cabins (figure 2-1) with coated steel sheet surfaces on both interior and exterior sides with the coating combination given in table 2-1. The cabin specification is given in table 2-2 and the air temperature measurement points are shown in figure 2-2. These cabins were built at SSAB for demonstrating the performance of different interior and exterior surfaces and were later used for the validation of the model as full-scale test object.

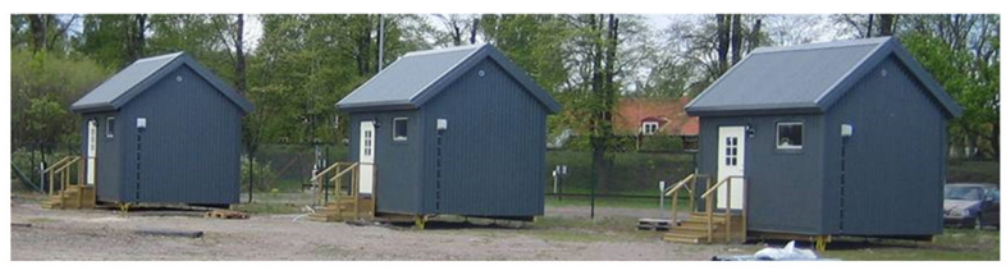

Figure 2-1 Test cabins with the optical properties given in table 2-1, from left to right: normal cabin, both-side reflective cabin and interior reflective cabin 
Table 2-1 Test cabins coating combinations

\begin{tabular}{|l|l|l|}
\hline \multirow{2}{*}{ normal cabin } & Exterior & $\begin{array}{l}T S R=0.10 \\
\varepsilon_{t h}=0.92\end{array}$ \\
\cline { 2 - 3 } & Interior & $\varepsilon_{t h}=0.91$ \\
\hline \multirow{3}{*}{ interior reflective cabin } & Exterior & $\begin{array}{l}T S R=0.10 \\
\varepsilon_{t h}=0.92\end{array}$ \\
\cline { 2 - 3 } & Interior & $\varepsilon_{t h}=0.25$ \\
\hline \multirow{3}{*}{ both-side reflective cabin } & Exterior & $\begin{array}{l}T S R=0.39 \\
\varepsilon_{t h}=0.92\end{array}$ \\
\cline { 2 - 3 } & Interior & $\varepsilon_{t h}=0.25$ \\
\hline
\end{tabular}

Parallel measurements have been carried out on the test cabins. The passive experiments - without any heating, cooling or ventilation - were made to study the differences, between cabins, in response to the measured surface, air, and radiation temperatures with the daily variations in the external conditions. Active tests, with the use of the HVAC systems with certain set point temperatures, were made in order to compare, between cabins, the amount of energy needed for heating and cooling. The ratio between the surface size of the heated floor and that of the total remaining interior surfaces is 0.26 .

Table 2-2 Test cabin specification

\begin{tabular}{|l|l|}
\hline Location & Borlänge, Sweden \\
\hline Latitude & $60^{\circ} \mathrm{North}$ \\
\hline Wall U-value & $0.247 \mathrm{~W} / \mathrm{m}^{2 \circ} \mathrm{C}$ \\
\hline Roof U-value & $0.207 \mathrm{~W} / \mathrm{m}^{2 \circ} \mathrm{C}$ \\
\hline Floor U-value & $0.158 \mathrm{~W} / \mathrm{m}^{2 \circ} \mathrm{C}$ \\
\hline Inside floor & $13 \mathrm{~m}^{2}$ \\
\hline Glazing & air conditioner EER:4.08 \\
\hline Cooling & Electrical floor heating \\
\hline Heating & $1.04 \mathrm{l} /\left(\mathrm{sm}^{2}\right)$ at $50 \mathrm{~Pa}$ \\
\hline Infiltration & Negligible \\
\hline $\begin{array}{l}\text { Internal } \\
\text { equipment load }\end{array}$
\end{tabular}




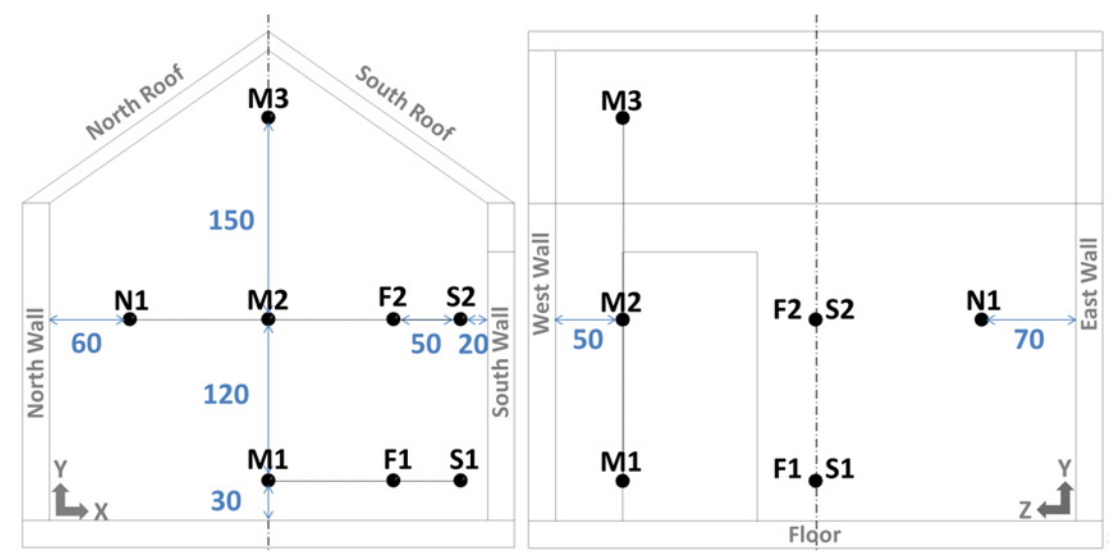

Figure 2-2 Air temperature measurement points at three levels (M1, M2 and M3) 


\subsubsection{Ice rink arenas}

Two ice arenas have been considered as case study objects with the aim to investigate the influence of low emittance interior surfaces in ice hockey rinks regarding cooling energy. Measurements have been done in two ice arenas in northen Sweden, one with lower and one with higher ceiling emittance. The low emissive arena has galvanized steel ceiling. Measurements include air temperature measurement at different height levels, surface temperature measurement and radiation temperatures in both ice rink arenas.

For the field measurements two indoor ice rinks were chosen with similarly constructed roofs. The Coop Arena C-Hall is located in the center of Luleå. It has a long side exterior wall facing south-east. The Coop Arena C-Hall has a shallow dark steel gable roof with an unpainted hot-dip galvanized partially perforated steel sheet profile as interior roof surface facing the ice. The thermal emittance of a flat hot-dip galvanized steel sheet surface was measured using an integrating sphere spectrophotometer to between 0.06 and 0.26 depending on aging of the surface in humid conditions. The Coop Arena $\mathrm{C}$-Hall is thus chosen here as the low thermal emittance interior roof surface ice rink.

As the high thermal emittance interior roof surface ice rink, a small single-rink ice facility located in Sunderbyn less than $10 \mathrm{~km}$ northeast from Luleå was chosen. The Sunderbyn ice rink has a long side exterior wall facing southeast and a white steel gable roof with a pre-painted white polyester coated partially perforated steel sheet profile as interior roof surface. The ceiling surface efficient thermal emittance is in this case above 0.9. Both facilities have a design roof U-value of 0.18 $\mathrm{W} /\left(\mathrm{m}^{2} \mathrm{~K}\right)$. The two ice rink arenas are shown in figure 2-3 and dimensions given in figure 2-4. The ratio between the surface size of the ice and that of the total remaining interior surfaces in Coop Arena is about 0.36 . The ratio between the ceiling and the enclosing surfaces including the ice is about 0.62 . 

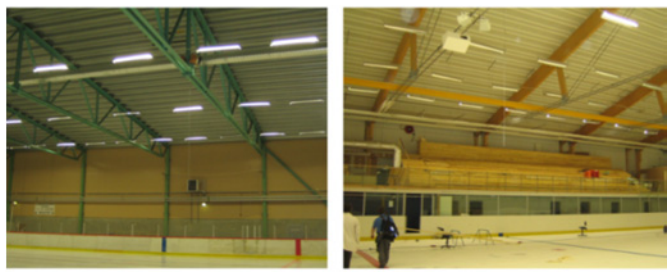

Figure 2-3 Coop Arena C-Hall with low emissive ceiling (left) and Sunderbyn arena with high emissive ceiling (right)
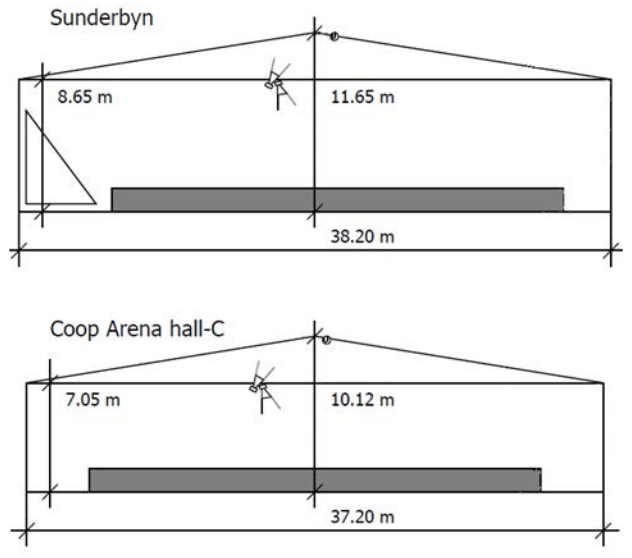

Figure 2-4 Ice rink arenas dimensions for Sunderbyn arena with normal and Coop Arena C-Hall with low emissive ceiling 


\subsection{Numerical method}

\subsubsection{Envelope heat flux calculations}

The schematic dynamic model presented in figure 2-5 takes into account the effect of both surface optical properties and thermal mass on the total heat flux. The thermal mass of the building envelope is spatially discretized into a number of thermal cells where the relative discretized thermal mass of each layer is disseminated on each node (cell) These thermal nodes act like capacitors in a thermal circuit model (Bring, Sahlin, and Vuolle 1999c). The dynamic model embodies the same concept used in the steady-state model for the interior and exterior surface nodes. The thermal analogy circuit is presented in figure 2-5. The schematic dynamic model is capable of solving for transient boundary condition and when connected to a climate file, it can provide annual analysis.

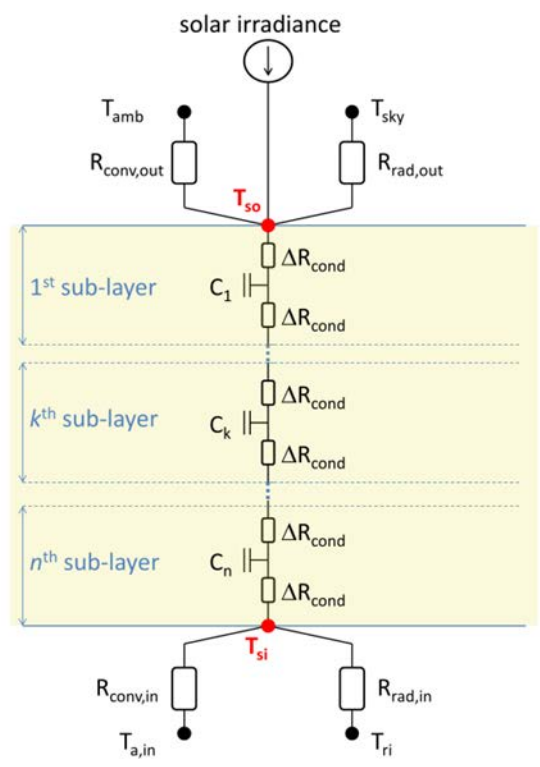

Figure 2-5 Schematic dynamic model of heat flux calculation 
The corresponding system of non-linear equations is given in equation (2-2) and includes $(n+2)$ thermal balance equation around envelope bulk layer cell nodes placed between the exterior and interior surface nodes.

$$
\left\{\begin{array}{l}
I_{\text {incidnt }}(1-T S R)-\frac{T_{s o}-T_{a m b}}{R_{\text {conv }, \text { out }}}-\sigma \varepsilon_{\text {th,ext }}\left(T_{\text {so }}^{4}-T_{s k y}^{4}\right)=\frac{T_{s o}-T_{1}}{\Delta R_{\text {cond }}} \\
\frac{T_{s o}-T_{1}}{\Delta R_{\text {cond }}}-\frac{T_{1}-T_{2}}{2 \Delta R_{\text {cond }}}=\rho C_{p} \Delta l \frac{\partial T_{1}}{\partial \tau} \\
\frac{T_{k-1}+T_{k+1}-2 T_{k}}{2 \Delta R_{\text {cond }}}=\rho C_{p} \Delta l \frac{\partial T_{k}}{\partial \tau}, \quad k=2, \ldots,(n-1) \\
\frac{T_{n-1}-T_{n}}{2 \Delta R_{\text {cond }}}-\frac{T_{n}-T_{s i}}{\Delta R_{\text {cond }}}=\rho C_{p} \Delta l \frac{\partial T_{n}}{\partial \tau} \\
\frac{T_{n}-T_{s i}}{\Delta R_{\text {cond }}}=\frac{T_{s i}-T_{a, \text { in }}}{R_{\text {conv }, \text { in }}}-\sigma \varepsilon_{\text {th,int }}\left(T_{s i}^{4}-T_{r i}^{4}\right)
\end{array}\right.
$$

$T_{r i}$ is the interior radiation temperature which is the radiation temperature as seen by the interior surface. $\Delta l$ relates to the $n$-th share of the thickness where $\mathrm{n}$ is the number of the cells and $\Delta R_{\text {cond }}=\frac{1}{2 n} R_{\text {cond }}$.

IDA simulation is used to build up an hourly dynamic model, as shown in figure 2-6. The model consists of default IDA components and one user-defined SiNODE component. The CLIMATE module receives data from a climate source file or a synthetic climate generator, calculates sun position and provides data for the FACE module. In the FACE module, data are processed based on construction parameters such as slope and azimuth of the exterior surface. TQFACE module takes into account parameters such as optical properties of the exterior surface. FDWALL module is a finite difference model that calculates for the $n$ cell temperatures. Finally SiNODE module represents the interior surface node temperature that couples the model with the indoor air and radiation temperatures. Interior convective heat transfer coefficients are 
assumed to be $5.0 \mathrm{Wm}^{-2} \mathrm{~K}^{-1}$ for upward heat flow and $0.7 \mathrm{Wm}^{-2} \mathrm{~K}^{-1}$ for downward heat flow according to SS-EN-ISO 6946 (2007).

To investigate the sensitivity of the heat flux to the optical properties on both exterior and interior surfaces, the hourly dynamic model is employed for the building envelope based on table 2-3 assuming a sandwich panel with exterior and interior steel sheets glued on insulation in between as shown in figure 2-7. Interior radiation temperature and indoor air temperature are important parameters affecting the panel heat flux.

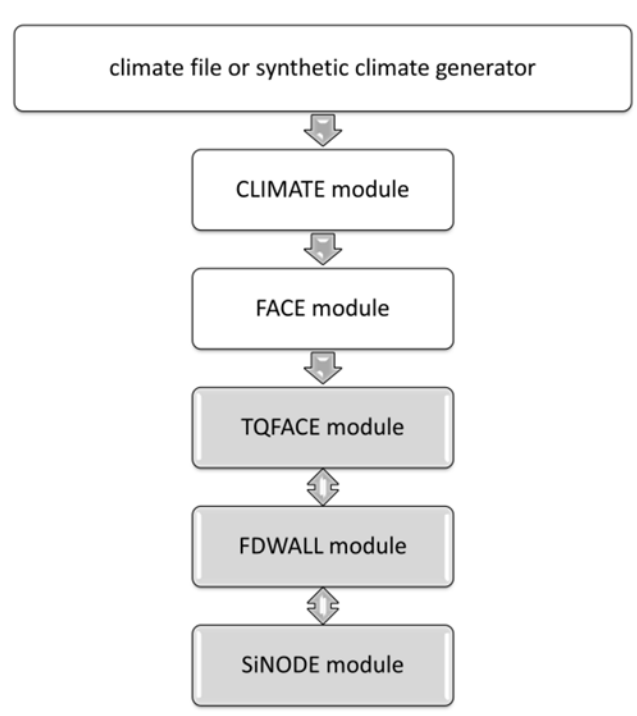

Figure 2-6 IDA components used in hourly dynamic model 


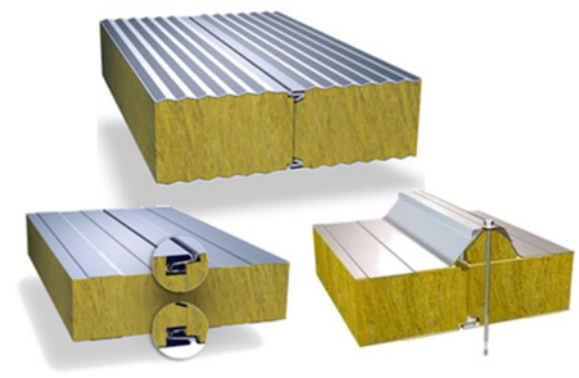

Figure 2-7 Sandwich panels - examples from (Ruukki 2015)

Table 2-3 Roof properties for the hourly dynamic model

\begin{tabular}{|c|c|c|c|}
\hline Sandwich panel properties & $\begin{array}{l}\text { Thermal conductivity } \\
\text { Specific heat } \\
\text { Thickness } \\
\text { Density }\end{array}$ & $\begin{array}{l}0.036 \\
750 \\
0.15 \\
20\end{array}$ & $\begin{array}{l}\left(\mathrm{Wm}^{-1} \mathrm{~K}^{-1}\right) \\
\left(\mathrm{J} \mathrm{kg}^{-1} \mathrm{~K}^{-1}\right) \\
(\mathrm{m}) \\
\left(\mathrm{kgm}^{-3}\right)\end{array}$ \\
\hline Number of the cells & $n$ & 32 & $(-)$ \\
\hline Inside air temperature & $T_{a, i n}$ & 20 & $\left({ }^{\circ} \mathrm{C}\right)$ \\
\hline Interior radiation temperature & $T_{r i}$ & 20 & $\left({ }^{\circ} \mathrm{C}\right)$ \\
\hline \multirow{2}{*}{ Interior convective coefficient } & Downward heat flux & 0.7 & $\left(\mathrm{Wm}^{-2} \mathrm{~K}\right)$ \\
\hline & Upward heat flux & 5.0 & $\left(\mathrm{Wm}^{-2} \mathrm{~K}\right)$ \\
\hline
\end{tabular}

Interior radiation temperature is set in the SiNODE, by setting the interior radiative temperature, $T_{r i}$ some degrees higher than the indoor air temperature, $T_{a, i n}$ the current model makes a simple representative of e.g. an active floor heating. $T_{r i}<T_{a, i n}$ may be found e.g. in an indoor ice hockey arena.

In the ice rink arena cases, to investigate the flux of thermal radiation from the ceiling to the ice with both low and high emissive ceiling surfaces, the model presented in (Joudi, Svedung, and Rönnelid 2011) is employed. Both the interior and exterior surface temperatures, as well as discrete cell temperatures through the roof panel are simultaneously solved and coupled in an hourly dynamic simulation with varying outdoor conditions. Input parameters to the aforementioned dynamic model are shown in table 2-4, and the parallel surface models as shown in figure 2-8 (Joudi, Rönnelid, et al. 2011). 


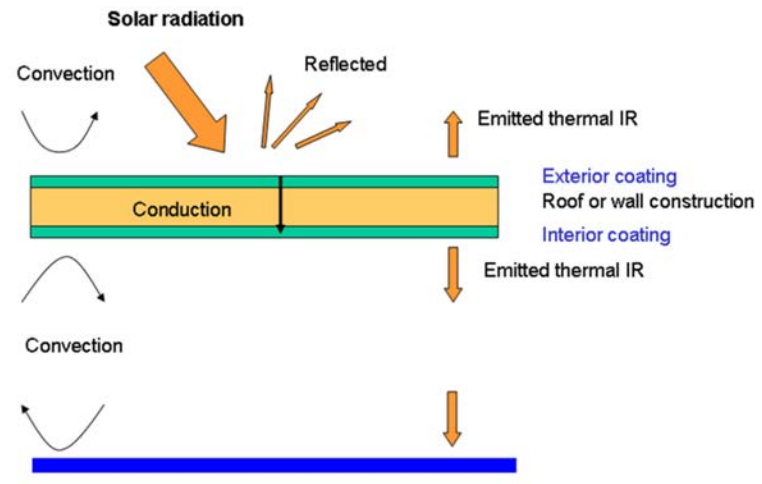

Figure 2-8 Schematic ice rink arena model for the ceiling to ice radiation calculation

Table 2-4 Ice rink arena model input parameters

\begin{tabular}{llll}
\hline \multirow{2}{*}{ Location } & \multicolumn{3}{l}{ Stockholm } \\
\hline \multirow{3}{*}{\begin{tabular}{l} 
Insulation \\
\cline { 2 - 4 }
\end{tabular}} & thickness & 0.3 & $(\mathrm{~m})$ \\
\cline { 2 - 4 } & Thermal conductivity & 0.036 & $\left(\mathrm{Wm}^{-1} \mathrm{~K}^{-1}\right)$ \\
\cline { 2 - 4 } & Density & 20 & $\left(\mathrm{Kgm}^{-3}\right)$ \\
\cline { 2 - 4 } & Specific heat & 750 & $\left(\mathrm{Jkg}^{-1} \mathrm{~K}^{-1}\right)$ \\
\hline \multirow{2}{*}{$\begin{array}{l}\text { Exterior roof } \\
\text { optical properties }\end{array}$} & Total Solar Reflectance & 0.3 & - \\
\cline { 2 - 4 } & Thermal Emittance & 0.9 & - \\
\hline Air temperature under the ceiling & 12 & $\left({ }^{\circ} \mathrm{C}\right)$ \\
\hline Ice surface temperature & -4 & $\left({ }^{\circ} \mathrm{C}\right)$ \\
\hline
\end{tabular}

The effective thermal emittance from the interior of the roof is given by equation (2-3) (ASHRAE 2006).

$\varepsilon_{\text {effective }}=\left[\frac{1}{f_{\text {cei-ice }}}+\left(\frac{1}{\varepsilon_{t h, c e i}}-1\right)+\frac{A_{c e i}}{A_{\text {ice }}}\left(\frac{1}{\varepsilon_{t h, i c e}}-1\right)\right]^{-1}$ 


\subsubsection{Building energy simulation}

In a building energy simulation, there is a dynamic interaction between building, occupants, indoor equipment appliances, HVAC system and primary energy sources (Hensen and Lamberts 2011). The schematic dynamic model described above can only predict the thermal behavior of a building envelope or panel under given boundary condition, but it is unable to predict how different conditions can form in a larger building structure. In the building energy simulation, the dynamic model of the envelope can be considered as a component used in the building energy simulation platform in conjunction with other participating components such as HVAC systems, etc. Including mechanisms for maintaining heat balance, e.g., mimicking HVAC in the realistic model enables the building energy simulation to respond in a feasible way to varying boundary conditions with the result depending on chosen parameters.

For the optical properties of interior and exterior surfaces, IDA ICE is able to adjust the longwave and shortwave radiation properties. Sahlin (2000) reviews fundamental modeling, solution methods and compares some methods of solving complex models. He mentions superiority of equation-based methods (used in IDA) "in almost all key technical aspects" (Sahlin 2000) compared to traditional methods, while pointing out the existing argument of higher execution speed in the traditional methods.

For radiation heat transfer from interior surfaces of a zone with non-horizontal ceiling, IDA ICE uses the concept of mean radiation temperature inside "Energy Model" that simplifies the geometry-related complexity in the view factor calculation. The mean radiation temperature in equation (2-4) is based on interior surface temperatures, thermal emittance and internal radiation heat transfer sources from lighting, equipment and people. These radiation heat transfer sources are assumed to be distributed among internal surfaces based on area ratio (Bring, Sahlin, and Vuolle 1999c).

$Q_{r a d, s}+\sum_{k=1}^{N} h_{r, i} A_{i}\left(T_{s i, k}-T_{m r t}\right)=0$, 
Where $T_{s i, k}$ is the interior surface temperature a for all surfaces related to the zone from $k=1$ to $N$, where $N$ is the number of surfaces. $h_{r, i}$ is the linearized longwave heat transfer coefficient which is derived from surface emittance and third power of the absolute surface temperature (Bring, Sahlin, and Vuolle 1999c).

In IDA ICE, the operative temperature is assumed to be an average of air and mean radiation temperature according to equation (2-5). In this simplification, radiative and convective heat transfer coefficients are assumed to be equal and detailed indoor climate is not available to account for the corresponding convective and radiative heat transfer coefficients based on e.g. indoor air velocity and detailed view factors, where $T_{a, \text { mixed }}$ is the well-mixed air temperature.

$T_{\text {opt }}=0.5\left(T_{a, \text { mixed }}+T_{\text {mrt }}\right)$

IDA ICE 4 is used to simulate the cabin under different climate and indoor conditions. Building energy simulation makes it possible to address the interaction of different coating combinations of optical surface properties with other varying conditions at the building level. The comparative validation for the annual energy simulation performance of IDA ICE is presented in Paper IV.

The test cabins have been studied under different scenarios as presented by (Joudi et al. 2013). In this sensitivity analysis, windows and doors are omitted and operative temperature is set to $20 \pm 1^{\circ} \mathrm{C}$ where the ideal heater and cooler were employed. The concept of ideal heater and cooler is useful where detailed information about the heating or cooling systems is neither available nor motivated. The heating and cooling system in this concept have constant performance parameter and no specified physical location inside the zone which simplifies for e.g. view factor dependency or conduction to certain wall or roof surface. For the ideal cooler, coefficient of performance is 3.0 and the ideal heater has radiation fraction of $0.4(40 \%$ of the internal load is assumed via radiation) in this simulation study (EQUA 2009b).

The interaction of the building surface optical properties, internal load and climate factors are addressed in this study. The cases include the 
interaction of reflective interior cabin with difference in internal load and the compound effect of reflective interior and exterior surfaces. Simulations are performed on a building example with the scale 3 times the original size of the cabins with the same interior surface ratio and U-values and internal load of $40 \mathrm{Wm}^{-2}$ and 1.5 air change per hour ventilation based on the work presented in (Joudi et al. 2013).

\subsubsection{Computational fluid dynamics}

\subsubsection{Turbulence modeling}

In the RANS model, the flow field variables are first presented in the form of mean flow and fluctuation parts. Then all fluctuations and instabilities are averaged and approximated by use of turbulence modeling. The CFD simulations are normally much faster due to less required grid number compared to LES and DNS. However, the accuracy can be potentially less than the other two models. RANS is widely applied for indoor climate prediction with reasonably good accuracy and affordable computational costs. Equation (2-6) is used to present velocity, as one of the flow filed variables. Equation (2-7) is the product of instantaneous velocities that are used in governing equations (Chen 1995;Srebric 2011;Wilcox 1998)

$$
\begin{aligned}
& \widetilde{u}_{i}=U_{i}+u_{i}^{\prime} \\
& \overline{\widetilde{u}_{i} \widetilde{u}_{j}}=\overline{U_{i} U_{j}}+\overline{U_{i} u_{j}^{\prime}}+\overline{u_{i}^{\prime} U_{j}}+\overline{u_{i}^{\prime} u_{j}^{\prime}}=U_{i} U_{j}+\overline{u_{i}^{\prime} u_{j}^{\prime}}
\end{aligned}
$$

The resulting three main governing equations, called ReynoldsAveraged Navier-Stockes (RANS) equations, for a Newtonian fluid and incompressible flow (typical indoor airflow) are continuity, momentum and energy as presented in equations (2-8) to (2-10), respectively. (Chen 1995; Lin et al. 2011;Posner, Buchanan, and Dunn-Rankin 2003;Srebric 2011;Wilcox 1998) 


$$
\begin{aligned}
& \frac{\partial U_{i}}{\partial x_{i}}=0 \\
& \frac{\partial U_{i}}{\partial \tau}+U_{j} \frac{\partial U_{i}}{\partial x_{j}}=-\frac{1}{\rho} \frac{\partial P}{\partial x_{i}}+\frac{\left(\rho-\rho_{r e f}\right)}{\rho} g_{i}+\frac{\partial}{\partial x_{j}}\left(v\left(\frac{\partial U_{i}}{\partial x_{j}}+\frac{\partial U_{j}}{\partial x_{i}}\right)-\overline{u_{i}^{\prime} u_{j}^{\prime}}\right) \\
& \frac{\partial T}{\partial \tau}+U_{j} \frac{\partial T}{\partial x_{j}}=\frac{\partial}{\partial x_{j}}\left(\alpha \frac{\partial T}{\partial x_{j}}-\overline{u_{i}^{\prime} t^{\prime}}\right)
\end{aligned}
$$

For an incompressible ideal gas, density is calculated according to equation (2-11). The universal gas constant is $8.314 \mathrm{~J} /(\mathrm{mol} \mathrm{K})$.

$$
\rho=\frac{P_{o p}}{\frac{R_{g}}{M_{w}} T}
$$

Among different RANS models RNG $k-\varepsilon$ (Yakhot and Orszag 1986; Yakhot et al. 1992) yields satisfactory performance when it comes to natural convection studies (Awbi 2013; Shati 2013;Zhang et al. 2007;Bulińska, Popiołek, and Buliński 2014) which is therefor used in this study.

The Reynolds stresses $\left(\overline{u_{i}^{\prime} u_{j}^{\prime}}\right)$ in equation (2-9) are approximated based on the eddy-viscosity hypothesis in equation (2-12) and turbulent kinematic viscosity $\left(v_{t}\right)$ is given in equation (2-13). Reynolds heat fluxes $\left(\overline{u_{i}^{\prime} t^{\prime}}\right)$ are approximated by eddy-diffusivity hypothesis in equation (2-14) where the turbulent kinematic diffusivity $\left(\alpha_{t}\right)$ is based on equation (2-15) in terms of the turbulent kinematic viscosity and the turbulent Prandtl number. 
$\overline{u_{i}^{\prime} u_{j}^{\prime}}=-v_{t}\left(\frac{\partial U_{i}}{\partial x_{j}}+\frac{\partial U_{j}}{\partial x_{i}}\right)+\frac{2}{3} \delta_{i j} k$

$v_{t}=C_{\mu} \frac{k^{2}}{\varepsilon}$

$\overline{u_{i}^{\prime} t^{\prime}}=-\alpha_{t} \frac{\partial T}{\partial x_{i}}$

$\alpha_{t}=\frac{v_{t}}{\operatorname{Pr}_{t}}$

The two closing equations for the standard two-equation eddy-viscosity $k-\varepsilon$ model, i.e, turbulent kinetic energy and turbulent energy dissipation rate are given in equations (2-16) and (2-17), respectively. The shear contribution to turbulent energy production and the turbulent energy production due to buoyancy are defined in equations (2-18) and (2-19), respectively (Lin, Chow, and Tsang 2006;Gebremedhin and $\mathrm{Wu}$ 2003; Rouaud and Havet 2002).

$$
\begin{aligned}
& \frac{\partial k}{\partial \tau}+U_{j} \frac{\partial k}{\partial x_{j}}=\frac{1}{\rho} \frac{\partial}{\partial x_{j}}\left(\left(\mu+\frac{\mu_{t}}{\sigma_{k}}\right) \frac{\partial k}{\partial x_{j}}\right)+G_{B}+P_{k}-\varepsilon \\
& \frac{\partial \varepsilon}{\partial \tau}+U_{j} \frac{\partial \varepsilon}{\partial x_{j}}=\frac{1}{\rho} \frac{\partial}{\partial x_{j}}\left(\left(\mu+\frac{\mu_{t}}{\sigma_{\varepsilon}}\right) \frac{\partial \varepsilon}{\partial x_{j}}\right)+\left(C_{\varepsilon 1} P_{k}-C_{\varepsilon 2} \varepsilon+C_{\varepsilon 1} C_{\varepsilon 3} G_{B}\right) \varepsilon / k-\Re \\
& P_{k}=v_{t}\left(\frac{\partial U_{i}}{\partial x_{j}}+\frac{\partial U_{j}}{\partial x_{i}}\right) \frac{\partial U_{i}}{\partial x_{j}} \\
& G_{B}=g_{i} \beta \frac{v_{t}}{\operatorname{Pr}_{t}} \frac{\partial T}{\partial x_{i}}
\end{aligned}
$$

The Renormalization group $k-\varepsilon$ model (RNG) compared to the standard $k-\varepsilon$ model yields an additional source term for the turbulent energy dissipation rate and takes into account the effect of small-scale turbulence which are presented in equations (2-20) and (2-21). The constants in the RNG $k-\varepsilon$ used in this numerical study are summarized in table 2-5. 


$$
\begin{aligned}
& \Re=\frac{C_{\mu} \eta^{3}\left(1-\frac{\eta}{\eta_{0}}\right)}{1+\aleph \eta^{3}}\left(\frac{\varepsilon^{2}}{k}\right) \\
& \eta=S \frac{k}{\varepsilon} ; S=\sqrt{2 S_{i j} S_{i j}} ; S_{i j}=\frac{1}{2}\left(\frac{\partial U_{i}}{\partial x_{i}}+\frac{\partial U_{j}}{\partial x_{i}}\right)
\end{aligned}
$$

Table 2-5 Constants used in the RNG k- $\varepsilon$ equations

\begin{tabular}{|c|c|c|c|c|c|c|c|c|}
\hline$C_{\mu}$ & $C_{\varepsilon 1}$ & $C_{\varepsilon 2}$ & $C_{\varepsilon 3}$ & $\sigma_{k}$ & $\sigma_{\varepsilon}$ & $\eta_{0}$ & $\aleph$ & $P r_{t}$ \\
\hline 0.0845 & 1.42 & 1.68 & $\tanh \left|\frac{v}{u}\right|$ & 1.393 & 1.393 & 4.38 & 0.012 & 0.85 \\
\hline
\end{tabular}

\subsubsection{Radiation model}

Different radiation models including P-1, Rosseland, Discrete Transfer Radiation Model (DTRM), Discrete ordinates (DO) and surface-to-surface (S2S) radiation models are presented in (ANSYS/Fluent 2009) and their advantages, disadvantages and computational requirements are compared there. S2S does not account for participating media while other models can account for opacity or optical thickness of the medium including the scattering and absorption coefficients. For the enclosure radiation heat transfer in the absence of participating medium and particles, S2S radiation model is suitable and efficient. Once the view factor is calculated in the S2S model, simulation time per iteration is faster than DO and DTRM models (ANSYS/Fluent 2009).

S2S radiation model assumes the surfaces are grey and diffuse. The infrared radiation properties are independent of wavelength according to equation (2-22). The surface reflectivity is diffuse, i.e, it distributes the radiation uniformly in all directions (ANSYS/Fluent 2009;Duffie and Beckman 2006).

$$
\varepsilon_{t h}=\alpha_{t h}=1-\rho_{t h}
$$

The total radiation leaving a surface is the sum of emitted energy due to the surface temperature and reflected radiation from surroundings as presented in equation (2-23) where $q_{r a d, p}$ is the radiation energy flux 
leaving the surface $p$ and $f_{p k}$ is the view factor between surface $p$ and $k$ for $k=1$ to $N$ surfaces according to equation (2-24) and the reciprocity relation in equation (2-25).

$$
\begin{aligned}
& q_{r a d, p}=\varepsilon_{t h, p} \sigma T_{p}^{4}+\rho_{p} \sum_{k=1}^{N} f_{p k} q_{r, k} \\
& f_{p k}=\frac{1}{A_{p}} \iint_{A_{p} A_{k}} \frac{\cos \theta_{p} \cos \theta_{k}}{\pi r^{2}} \delta_{p k} d A_{p} d A_{k} \\
& A_{p} f_{p k}=A_{k} f_{k p}
\end{aligned}
$$

\subsubsection{Mesh strategy}

The CFD model of the test cabins includes building envelope, roof and floor in connection with ambient thermal boundary condition (figure 2-9). Exterior boundary conditions are equally assigned to the cabins and where the only difference between the cabins is the emittance of their interior surfaces.

ANSYS Icepak (Icepak 2009) was used for building the model and grid according to (Joudi et al. 2015). The transient boundary conditions were assigned in ANSYS FLUENT for numerical solution. For more information, see (Joudi et al. 2013).

\subsubsection{Boundary conditions}

The procedure, data flow and interface between weather input, IDA ICE and CFD are briefly illustrated in figure 2-10. The boundary condition related to varying outdoor climate is assigned to exterior surfaces. In order to interface different simulation environments, data are processed in two main stages located before and after IDA ICE. In the first stage, real climate data is fed into IDA ICE and in the second stage, IDA ICE results are turned into CFD boundary condition, respectively. 

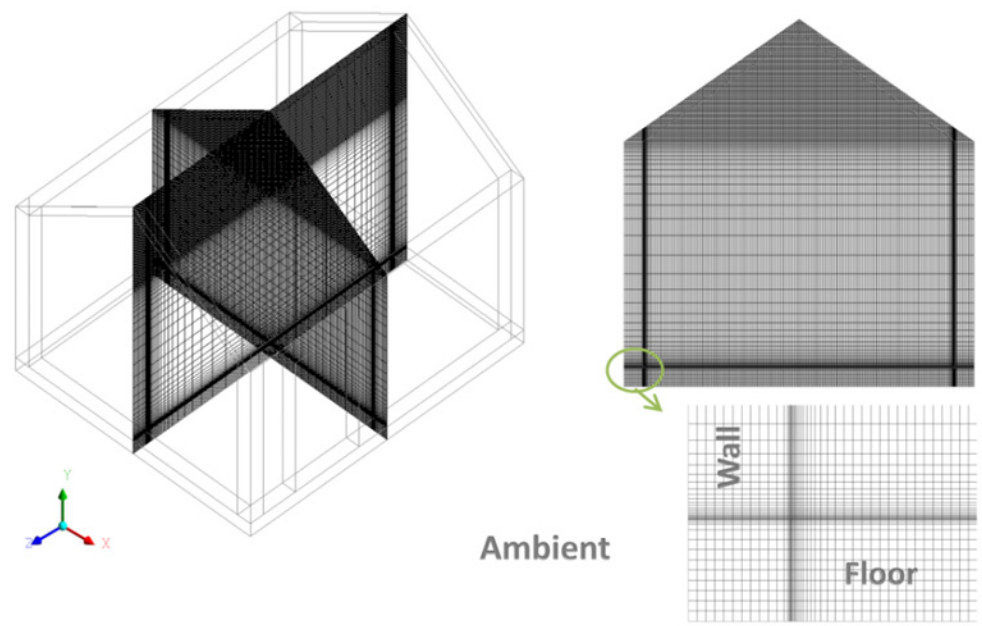

Figure 2-9 The cabins model in the CFD simulation

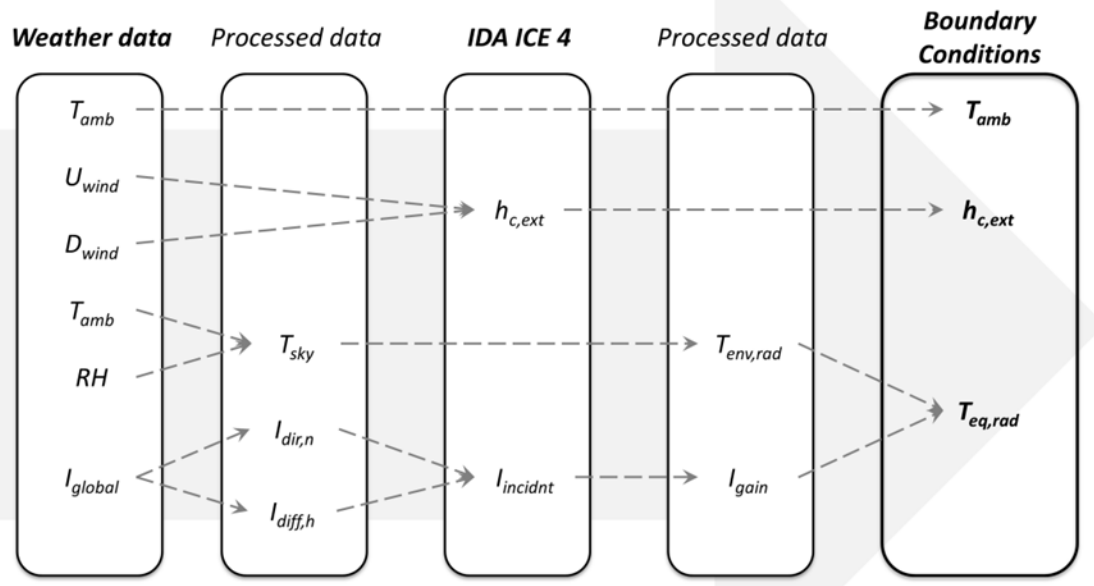

Figure 2-10 The boundary conditions data flow for the CFD model 
The model is transient allowing for interplay between indoor and outdoor environment, with the outdoor climate as the main driving force to influence indoor conditions on the two cabins with and without low emissive interior coatings. For simplicity, solar radiation through the windows is not considered in the CFD model. In the field measurement windows were blinded for a better comparison with the CFD results with the aim to focus more on the longwave radiation properties of the interior surfaces.

Meteorological wind speed and direction from SMHI weather station located at Borlänge airport (about 10 kilometers southwest of the cabins) are fed in the climate source file of IDA ICE. The local wind speed including windward or leeward direction of each surface is then calculated based on (Bring, Sahlin, and Vuolle 1999a).The convective heat transfer coefficient for each surface of the building is calculated individually from the FACE module available in IDA ICE. For more information refer to (Bring, Sahlin, and Vuolle 1999a).

Each exterior surface exchanges radiation with sky at absolute sky temperature and ground at absolute ground temperature depending on surface view facts. (Ground is assumed to have the same temperature as the ambient air in IDA ICE). Equation (2-26) represent an equivalent radiation temperature for CFD boundary condition, called environment radiation temperature, $T_{\text {rad,env }}$ which includes both sky and ground temperatures with their respective view factors, where the slope of the surface is similar to TQFACE module function in IDA ICE $\left(90^{\circ}\right.$ for vertical surfaces and $180^{\circ}$ for horizontal surfacing facing upward). By this method, for each surface only one environment radiation temperature is defined that can be used as the radiative reference temperature in boundary condition of CFD.

$T_{\text {rad }, \text { env }}^{4} \equiv\left(\frac{1+\cos \varphi}{2}\right) T_{s k y}^{4}+\left(\frac{1-\cos \varphi}{2}\right) T_{\text {ground }}^{4}$

Solar irradiance data from SMHI weather station include direct and global irradiance. IDA ICE requires direct normal irradiance and diffuse irradiance on a horizontal surface as climate input. At the time of measurement, global irradiance was the only available solar radiation component which was measured at the Borlänge airport. Hence, 
equation (2-27) to (2-31) from (Duffie and Beckman 2006) are used to model the other solar radiation components needed to prepare the boundary condition at the first data processing level so that IDA ICE can calculate the incident total radiation on individual wall and roof on all sides. Equation (2-27) is used to model the diffuse solar radiation on a horizontal surface based on hourly clearness index. Equation (2-30) is employed to calculate normal direct irradiance.

$$
\begin{aligned}
& \frac{I_{\text {diff }, h}}{I_{\text {global }}}= \begin{cases}1.0-0.09 k_{T} \quad, k_{T} \leq 0.22 \\
0.955-0.1604 k_{T}+4.388 k_{T}^{2}-16.638 k_{T}^{3}+12.336 k_{T}^{4}, 0.22<k_{T} \leq 0.8 \\
0.165 & , k_{T}>0.8\end{cases} \\
& k_{T}=\frac{I_{\text {global }}}{I_{\text {exteratres }}} \\
& I_{\text {extratres }}=1367 \times\left(1+0.033 \cos \frac{360 n_{d}}{365}\right) \cos \theta_{z} \\
& I_{\text {dir }, n}=\frac{I_{\text {global }}-I_{\text {diff }, h}}{\cos \left(\theta_{z}\right)} \\
& \cos \left(\theta_{z}\right)=\sin \left(\delta_{s}\right) \sin \left(\phi_{s}\right)+\cos \left(\delta_{s}\right) \cos \left(\phi_{s}\right) \cos \left(\omega_{s}\right)
\end{aligned}
$$

Total incident irradiance on a surface is calculated in the FACE module in IDA ICE as the sum of direct normal irradiance, diffuse radiation from sky and diffuse radiation reflected from ground. In order to account for both total solar gain and convective heat dissipation from exterior surfaces, an equivalent radiation temperature is introduced which incorporates both longwave radiation and solar gain into one radiation temperature, called equivalent radiation temperature $\left(T_{\text {eq, rad }}\right)$. This concept is used herewith to interface the IDA ICE and CFD simulation environment and connect the input climate data processed in IDA ICE to the boundary conditions for the simulation in ANSYS Fluent. Equation (2-32) represents the concept of equivalent radiation temperature, where it takes into account both the longwave radiative heat dissipation from the exterior surfaces and the total solar gain, dependent on the surface TSR. Equation (2-32) is then simplified into equation (2-33). Thereafter, equivalent radiation temperature will be 
used in CFD boundary condition in which both longwave radiation and solar gain are combined.

$$
\begin{aligned}
& \varepsilon_{t h, e x t} \sigma A\left(T_{s o}^{4}-T_{\text {rad }, e n v}^{4}\right)-A(1-T S R) I_{\text {incidnt }} \equiv \varepsilon_{\text {th }, e x t} \sigma A\left(T_{s o}^{4}-T_{\text {eq,rad }}^{4}\right) \\
& T_{\text {eq,rad }} \equiv\left(T_{\text {rad,env }}^{4}+\frac{(1-T S R)}{\varepsilon_{t h} \sigma} I_{\text {incidnt }}\right)^{0.25}
\end{aligned}
$$

In IDA ICE, the sky temperature is assumed to be constantly $5 \mathrm{~K}$ lower than the ambient air. In Paper V, for better estimation of exterior longwave radiation exchange, equations (2-34) to (2-39) are used accordingly and more accurate estimation of sky temperature is provided for the boundary condition of CFD. The procedure is illustrated in figure 2-11.

Clear sky temperature is calculated based on equation (2-34) as a function of ambient air temperature, dew point temperature and hour from midnight based on (Duffie and Beckman 2006). The required dew point temperature, is derived from equations (2-35) to (2-37) from (ASHRAE 2005). Dew point temperature is gained from equation (2-35) with the constants given in table 2-6, where partial pressure of water vapor is obtained from equation (2-36) (based on relative humidity and saturated water pressure) and saturated water vapor pressure is calculated from equation (2-37) (for over liquid water based on the absolute temperature) and the constants given in table 2-7.

Sky temperature lies somewhere between clear sky temperature from equation (2-34) and ambient air temperatures (assuming that overcast sky has the same temperature as the ambient air). (Morrison 2001) used cloud cover factor between 1 and 8 to estimate longwave radiation under partially cloudy sky. Using the same concept, sky temperature can be estimated from equation (2-38) considering dimensionless cloud cover factor. Equation (2-39) introduces cloud cover factor based on sky clearness index according to equations (2-28) and (2-29) by (Duffie and Beckman 2006). The cloud cover factor during the night is hereby assumed to change linearly between the days before and after. The resultant sky temperature is shown in figure 2-12. 


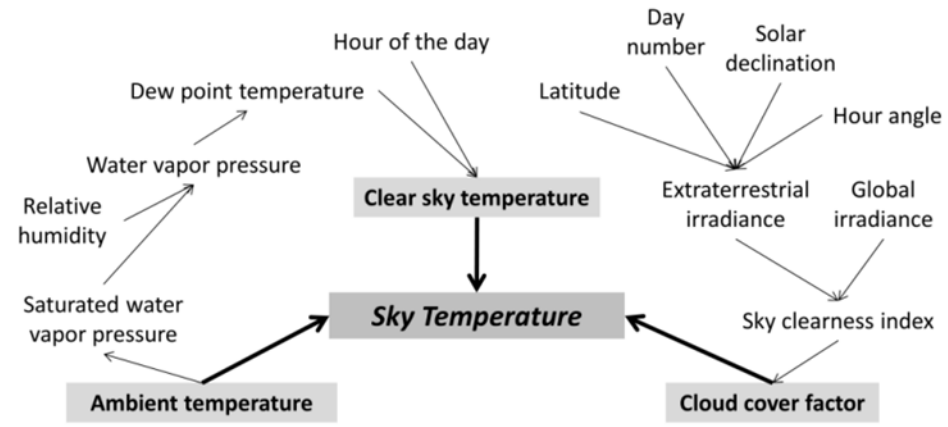

Figure 2-11 Schematic of sky temperature calculation from climate data

$$
\begin{aligned}
& T_{\text {clear } S k y}=T_{a m b}\left(0.711+0.0056 T_{d p}+0.000073 T_{d p}^{2}+0.013 \cos \left(15 h r_{0}\right)\right)^{0.25} \\
& T_{d p}=C_{d p 1}+C_{d p 2} \ln \left(p_{v}\right)+C_{d p 3}\left(\ln \left(p_{v}\right)\right)^{2}+C_{d p 4}\left(\ln \left(p_{v}\right)\right)^{3}+C_{d p 5}\left(p_{v}\right)^{0.1984}, 0<T_{d p}<93 \\
& p_{v}=R H \times p_{v, s} \\
& p_{v, s}=\exp \left(C_{p s 1} T^{-1}+C_{p s 2}+C_{p s 3} T+C_{p s 4} T^{2}+C_{p s 5} T^{3}+C_{p s 6} \ln (T)\right), 0<T<200
\end{aligned}
$$

Table 2-6 Constants for dew point temperature in equation (2-35)

\begin{tabular}{|c|c|c|c|c|}
\hline$C_{d p 1}$ & $C_{d p 2}$ & $C_{d p 3}$ & $C_{d p 4}$ & $C_{d p 5}$ \\
\hline 6.54 & 14.526 & 0.7389 & 0.09486 & 0.4569 \\
\hline
\end{tabular}

Table 2-7 Constants for saturated vapor pressure in equation (2-37)

\begin{tabular}{|c|c|c|c|c|c|}
\hline$C_{p s 1}$ & $C_{p s 2}$ & $C_{p s 3}$ & $C_{p s 4}$ & $C_{p s 5}$ & $C_{p s 6}$ \\
\hline-5800.2206 & 1.3914993 & -0.048640239 & $4.1764768 \times 10^{-5}$ & $-1.4452093 \times 10^{-8}$ & 6.5459673 \\
\hline
\end{tabular}

$$
\begin{aligned}
& T_{\text {sky }}=C_{\text {cloud }} T_{\text {amb }}+\left(1-C_{\text {cloud }}\right) T_{\text {clearSky }} \\
& C_{\text {cloud }}= \begin{cases}0 & , k_{T}>0.8 \\
\frac{0.8-k_{T}}{0.7} & , 0.1 \leq k_{T} \leq 0.8 \\
1 & , k_{T}<0.1\end{cases}
\end{aligned}
$$




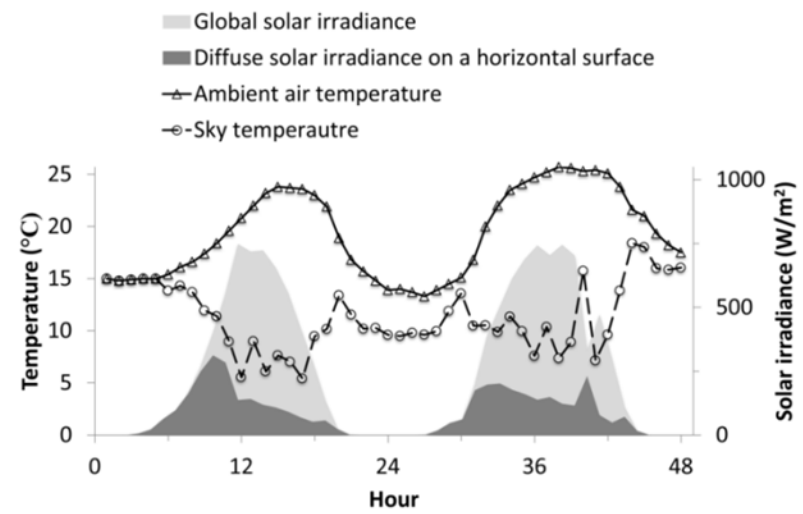

Figure 2-12 Solar irradiance components, ambient air and sky temperatures during the simulation period

\subsubsection{Wall treatment}

In the wall-bounded region, the no-slip condition and sharp gradients near the wall affect the flow field in the sense that the assumption of the isotropic eddy-viscosity in the RANS models is no longer valid in the wall-bounded region. In the near-wall region, curvature, vortices, change in the direction of the flow and buoyancy are anisotropic sources. The near-wall region can indeed encounter large gradient, intense momentum exchange and thermal energy transfer. Therefore, special treatment is required to solve for the wall-bounded flow field; a solution that also depends on the choice of RANS model that solves for the main flow field. Reliable results can be achieved via proper selection of both RANS and near-wall models (Kim et al. 2005). Temperature profile in this region must be determined correctly for correct heat transfer calculation.

Standard wall function by Launder and Spalding (1974) is the most common model that uses the semi-empirical log law of the wall to bridge over the blending and viscous sub-layer regions and connect the fully turbulent region to the wall surfaces. In that sense, the first node sits in fully turbulent region $\left(\mathrm{y}^{+}>30\right)$ preferably close to 30 to model the turbulent region as much as possible. The standard wall function is simple and less computationally demanding. However, it is not the most 
accurate model when it comes to indoor convection prediction, especially natural convection cases (Zhang, Zhou, and Wang 2013;Awbi 1998).

However, the Enhanced Wall Function (ANSYS/Fluent 2009) does not rely on the empirical law-of-the-wall and improves the accuracy by also considering for low-Re flows and predicts better for e.g. natural convection cases (Shati 2013). This approach is more computationally demanding since the grid should be fine enough to provide $\mathrm{y}^{+}<5$. The Enhanced Wall Function for the $\mathrm{y}^{+}<1$ is identical to two-layer wall model which has the best predicting performance for natural convection (Chen 1995). Enhanced wall function is the most computationally expensive because the grid should be so fine that the first node sits very close to the wall in the viscous sub-layer region.

\subsubsection{Numerical aspects}

The finite volume code ANSYS/Fluent 14.5 is used to numerically solve the governing equations with a segregated scheme. Semi-implicit method for pressure-linked equations (SIMPLE) algorithm (ANSYS/Fluent 2009) is used to solve the pressure-velocity coupling. The spatial discretization consisted of a second-order upwind scheme (ANSYS/Fluent 2009) for the nonlinear terms and the second-order for the viscous terms. Generally, higher order schemes can improve the prediction accuracy and are more highly recommended compared to the first-order schemes. For the transient CFD simulation, the time integration was performed by a second-order implicit scheme with temporal discretization of 30 seconds time steps. In the coupling method, the CFD simulation is steady-state at each BES-CFD iterative time steps.

For all the CFD simulations, the convergence criteria are based on normalized residuals of $10^{-3}$ and $10^{-8}$ for continuity and energy, respectively. The convergence residuals of velocities, turbulent kinetic energy and turbulent dissipation rate were less than $10^{-3}$. In the CFD simulation of the coupling method, the error of overall heat flux balanced was less than $0.2 \%$. 


\subsubsection{Coupling BES and CFD}

On the BES - CFD level, computational fluid dynamic is employed the purpose being to overcome the restrictions of the air model in BES simulation tools to predict for the indoor environment. In building energy simulation tools when it comes to the air model, it is necessary to define the zone borders and establish the interconnection between them (in zonal model), e.g. how can a room be divided into several zones? Where are the zone borders? Is the well mixed assumption valid in each divided zone? Although there have been several studies to address this issue, by replacing the airflow model with a CFD simulation, defining the zones will no longer be an issue of concern. CFD naturally contributes to better prediction of the convection. The use of CFD in the simulation platform will however generally increase the simulation time considerably depending on the individual case.

There are also two levels of CFD when it comes to coupling BES and CFD: the coarse and standard CFD. The finer the CFD grid, the more accurate the results are and the longer is the simulation time will be. In the BES - CFD approach, the multi-zone air flow model inside the building energy simulation tool can be either totally or partially replaced by the CFD model. The expected accuracy and detail of results determine the level in which the CFD model is needed. On the other hand, the computational load and time span of expected simulated results are practical factors that limit the utilization of the CFD model. It should be mentioned that in the BES - CFD approach, the thermal model inside the BES is usually kept unchanged.

On the one hand, the use of CFD facilitates the calculation of the indoor air temperate distribution and surface convection. On the other hand, CFD confines the simulation time horizon due to computational load and does not convey the related HVAC system modules. It is of course possible to model the HVAC system in CFD simulation environment by implementing the user defined functions, however, as most of the HVAC modules are already available in BES, to re-write the code in the CFD is rather inconvenient since the HVAC system codes are essentially the same regardless of simulation environment. Moreover, it does not contribute to the computational restriction of the CFD 
simulation (as long as any explicit fluid dynamic contributions from the HVAC modules are not considered).

The BES can benefit from the CFD indoor discretized air domain, while addressing the energy use by the desirable HVAC system. The downside is that due to the different spatial discretization of BES and $\mathrm{CFD}$, an unavoidable sharp transition occurs at the interface of the two domains, e.g. the single interior surface temperature provided by the BES is the uniformly distributed surface temperature boundary condition in CFD, where a highly discretized indoor air volume will interface one temperature alongside the surface. The surface convection is also not an exception in this case since the convection heat transfer coefficients are also averaged surface values.

\subsubsection{Coupling variables}

The exchange variables across the two simulation domains are presented in figure 2-13 where $T_{s}, T_{\text {ref }}$ are surface and reference air temperatures, respectively. Convection heat transfer coefficient is based on the reference air temperature, according to equation (2-40) from combining Newton's cooling law with surface heat flux, which in this case is only convective heat flux.

$$
h_{c}=\frac{-\lambda\left(\frac{\partial T}{\partial y}\right)_{y=0}}{T_{s}-T_{\text {ref }}}
$$

In favor of fewer variables updated at each iterative exchange, the mixed air temperature calculated by the BES is used as the reference temperature for convection heat transfer coefficient from CFD. The surface convection heat flux is indeed the CFD contribution to the BES since the air temperature and relative convection heat transfer coefficient are just a translation of the surface convection calculated by the CFD. 


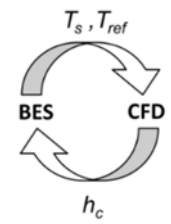

Figure 2-13 Coupling variables between building energy simulation and CFD

The surface heat transfer is presented in figure 2-14 where conduction and radiation are calculated in BES and convection in CFD. The coupling task is in fact to find a surface temperature that satisfies the heat balance equations for conduction, convection and radiation.

The surface heat balance equation is presented in equation (2-41) where subscript $p$ is the thermal node on each surface.

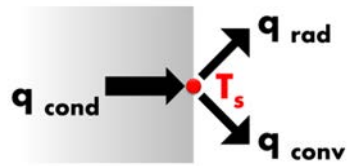

Figure 2-14 Heat flux at the surface where BES and CFD share a common surface temperatures

$Q_{\text {cond }, p}=h_{c, p} A_{p}\left(T_{s, p}-T_{r e f}\right)+\frac{W b_{p}-J_{p}}{R_{p}}$

$W b$ is the blackbody emissive power according to Stefan-Boltzmann law in equation (2-42) for absolute surface temperature. The radiation heat exchange for $\mathrm{n}$ opaque enclosing surfaces are given in equation (2-43) where $R_{p}$ in equation (2-44) is due to surface emittance and $R_{k p}$ in equation (2-45) is based on the view factors between surfaces. For more information refer to (ASHRAE 2005).

$$
\begin{aligned}
& W b=\sigma T_{s}^{4} \\
& \frac{W b_{p}-J_{p}}{R_{p}}+\sum_{k=1}^{n} \frac{J_{k}-J_{p}}{R_{p k}}=0
\end{aligned}
$$




$$
\begin{aligned}
& R_{p}=\frac{1-\varepsilon_{t h, p}}{\varepsilon_{t h, p} A_{p}} \\
& R_{p k}=\frac{1}{A_{p} f_{p k}}=\frac{1}{A_{k} f_{k p}}
\end{aligned}
$$

\subsubsection{Coupling tools and links}

Simulation tools and their links are shown in figure 2-15. They are categorized based on their function: build-up and solver tools. Icepak is used to build-up geometry and mesh for the FLUENT solver machine which can be run in parallel processors. FLUENT reads the boundary conditions and gives the results for coupling iteration. IDA ICE is used for energy simulation including HVAC system. NMF Translator is used to modify the built model of IDA ICE into a new BES model called IDACoupling. In IDACoupling the connections to CFD and interfaces are established and radiation model of the non-horizontal ceiling is improved from the calculated view factor of Icepak. A macro enabled Excel file (.xlsm file) is used to boundary condition exchange between the BES and CFD tools. This file acts as the coupling machine; evaluates solution convergence and saves exchanging history. This external coupling is performed manually at this stage.

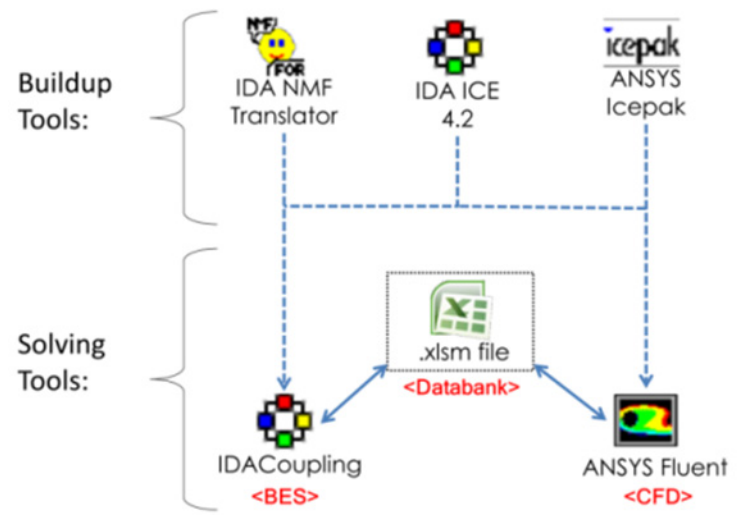

Figure 2-15 Simulation tools and datelines used in the coupling method 


\subsubsection{Coupling strategy}

In this coupling method, CFD is not transient and steady-state model is assumed for each time-step, i.e., steady state is assumed to be reached by the air volume in each time-step while propagating the dynamics of the BES. Less computational load and stability in convergence are the main motivation in these assumptions. Within each BES time-step (usually hourly) there is no transient parameter needed for the results (Djunaedy 2005). The heat flux through typical wall is of the order of $10^{3}$ seconds or hours but for a room with typical temperature to reach steady-state natural convection flow is of the order of $10^{1}$ or $10^{2}$ seconds (Zhai 2003). As an example, in a fan-ventilated room, after turning off the fan, it takes only a few seconds for the air to change to buoyancy driven air flow pattern (Novoselac 2005).

To initialize CFD, the mean air temperature from the BES is used. First CFD run is performed. The convergence criteria to update the CFD boundary condition for each BES -CFD iteration is considered as 0.001 $\mathrm{W} \mathrm{m}{ }^{-2} \mathrm{~K}^{-1}$ for convection heat transfer coefficient, comparing the last three consecutive iterations. This partially converged solution and updating the boundary condition in BES - CFD loop is in line with integrated coupling suggested by (Novoselac 2005). The convergence criteria for all CFD simulation runs are based on the convection heat transfer coefficient as mentioned above. After finding a converged solution for the coupling iterations, the last CFD runs until full convergence. This final solution is used to report the air temperature distribution at that time step. For more information regarding the CFD simulation is given in Paper VI.

For the consecutive time-steps, the results from the previously available CFD results are used via interpolation. The initializing with interpolated values saves considerable CFD simulation time.

To investigate the energy use by the use of floor heating system, BES and CFD coupling is performed addressing both indoor thermal environment with high spatial resolution and floor heating energy use for a winter design day in Stockholm (ASHRAE 2001). In this numerical setup the floor temperature is set to $26^{\circ} \mathrm{C}$. 


\section{Results and discussion}

\subsection{Test cabins measurements}

The passive test (without active heating or cooling) has been carried out on the test cabins during four days in the summer with solar radiation and ambient air temperature given in figure 3-1.

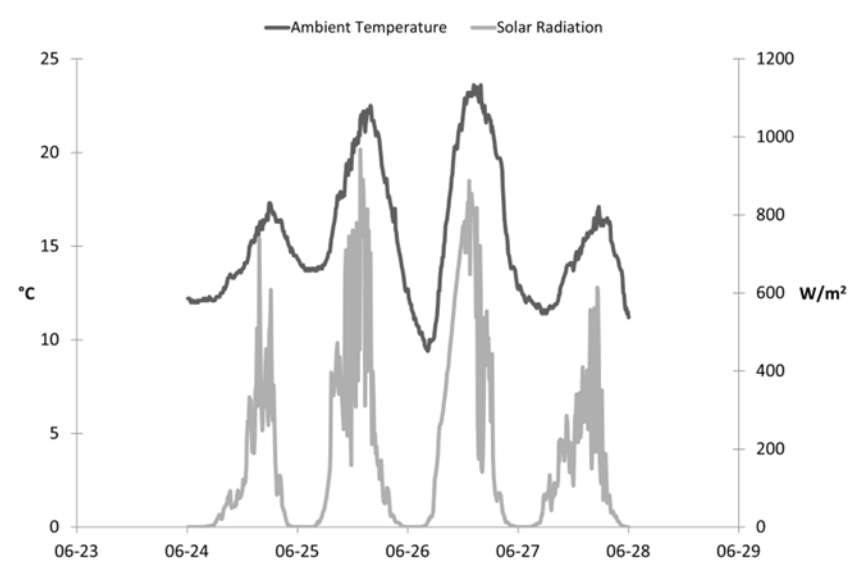

Figure 3-1 Solar radiation and ambient air temperature measured during the passive test

The mean radiation temperature measured inside the cabins is shown in figure 3-2. The highest mean radiation temperature belongs to the normal cabin. In the interior reflective cabin having low emissive interior reduces the maximum mean radiation temperature (at day peak). Low emissive interior coatings act as a radiation barrier to the floor surface and to the black sphere globe thermometer from which the mean radiation temperature is calculated. At the time of minimum radiation temperature during the night, the radiation temperature in the interior reflective cabin is slightly higher than that in the normal cabin. 


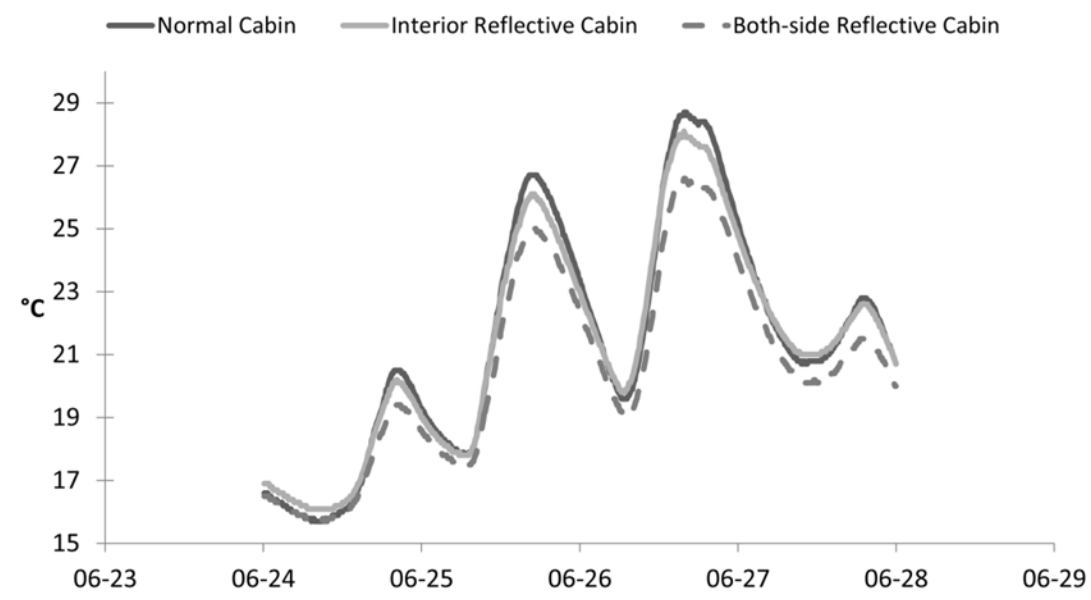

Figure 3-2 Mean radiation temperatures at $+3.0 \mathrm{~m}$ above the floor

The lowest mean radiation temperature belongs to the both-side reflective cabin. It is a compound effect of both having high total solar reflectance coating on the exterior reducing the solar gain and low thermal emissive interior surfaces. The both-side reflective cabin also has lower minimum radiation temperature at night since the total gain during the day was reduced due to reflective exterior surfaces.

Active heating and cooling test with the electrical floor heating and split type air conditioner with different set-point temperatures varying from $17^{\circ} \mathrm{C}$ to $23^{\circ} \mathrm{C}$ has been carried out on the test cabins during one- or two-week-long test periods limited by the capacity of the data loggers. The heating and cooling electrical consumption has been separately measured during the active tests.

Figure 3-3 is the comparison of the electrical energy consumption of the interior reflective and both-side reflective cabin to that in the normal cabin. As shown in figure 3-3, reflective interior coating reduces electrical heating consumption as less radiation from the heated floor is absorbed and dissipated by interior surfaces. Cooling electrical consumption is reduced as the low emittance interiors contribute to the increased surface resistivity toward the heat flux into the building. 


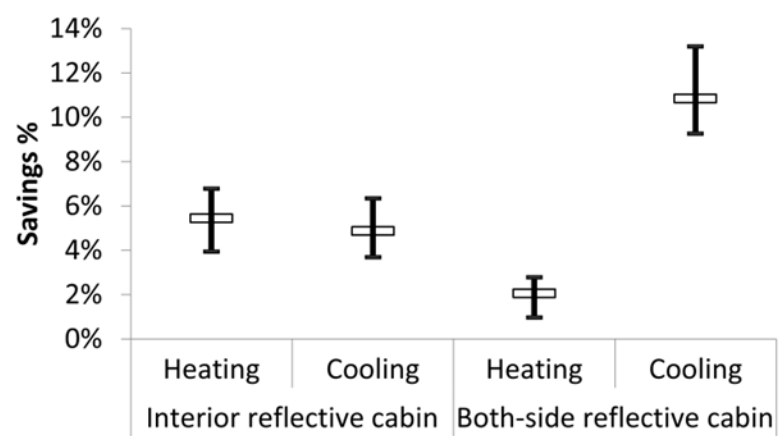

Figure 3-3 Measurement results from the test, where lower limit relates to 25th percentile (Q1), mid values are median values and upper limit is the 75th percentile (Q3)

In the both-side reflective cabin, high TSR exterior considerably reduces cooling electrical consumption. However, high TSR coating in the exterior surfaces inflicts heating penalty during cold periods. The heating saving of the both-side interior reflective cabin therefore is less than the interior reflective cabin due to the decreased absorption of solar radiation.

During a winter heating test, the radiation temperature is measured with the infrared thermometers pointing upward to the upper half of the test cabins as shown in figure 3-4. The interior surface temperature is presented in figure 3-5. The interior surface temperature in the ceiling of the cabin with reflective interior is considerably lower than that in the normal cabin while the radiation temperature reflected back during the floor heating test (figure 3-4) is almost the same in the two cabins or even slightly higher in the interior reflective cabin. This lower interior surface temperature results in lower temperature gradient across the building envelope. Consequently, this can reduce the building heat loss and contribute to the heating energy saving, which is consistent with the differences in the measured floor heating electrical consumption in the two cabins. 


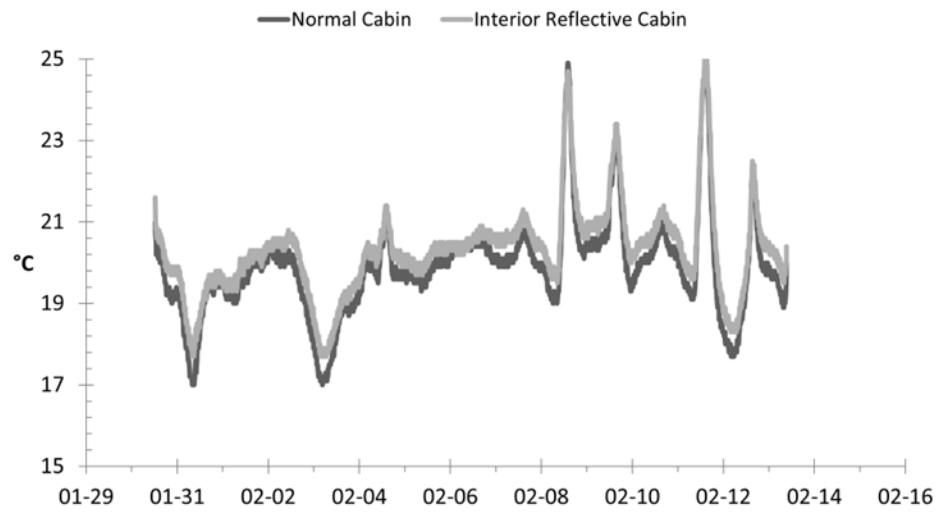

Figure 3-4 Direct radiation temperature from upper part of the test cabins interior during the floor heating test

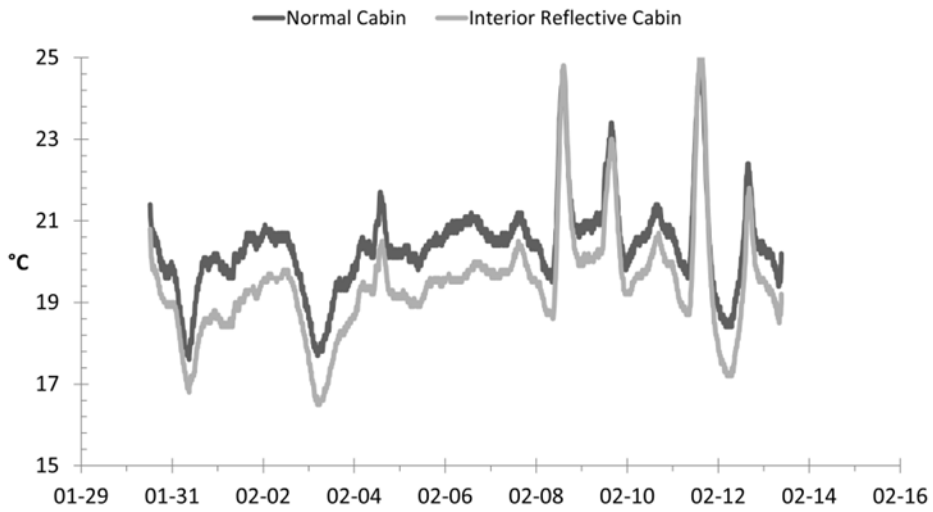

Figure 3-5 Interior south-facing roof surface temperature during the floor heating test. 


\subsection{Ice rink arenas comparison}

Interior ceiling surface temperature and radiation temperatures from the ceiling are measured in the two ice rinks during some days in late August. In figure 3-6 the radiation temperature seen by the upwards looking pyrometer in the highly emissive ceiling surface is very close to the ceiling surface temperature measured by a thermocouple mounted in contact with the surface. On the contrary, in the ice rink with the low emissive ceiling surface the measured radiation temperature is much lower and closer to the ice temperature. The radiation temperatures from the ceiling in both arenas are between the ice and surface temperatures. This indicates a reduced radiation from the ceiling to the ice in the low emissive ceiling arena.

Thermal radiation to the ice surface calculated based on schematic dynamic model is shown in figure 3-7 for three different sets of effective emittance values of the interior roof. It shows that using low emissive coating on the roof interior decreases the radiative heat dissipation to the ice surface, resulting in less cooling load to maintain the ice surface at the desired temperature. On the other hand, the monthly variation in the low emissive interior roofs is almost negligible, arguably as the interior air temperature is maintained constant.

Figure 3-8 demonstrates the sensitivity of adjacent air temperature to the net radiation heat flux from the ceiling to the ice surface with different interior roof emittance. The overall trend, regardless of the emittance values, indicates that lowering the air temperature adjacent to the ceiling, decreases the amount of thermal radiation to the ice surface. The reason is that the interior surface "node" receives less convective heat gain from the adjacent air node. In other words, it is better to keep the warm air away from the ceiling. The low emissive ceiling reduces the radiative heat flux to the ice and allows for a higher near-ceiling air temperature. 


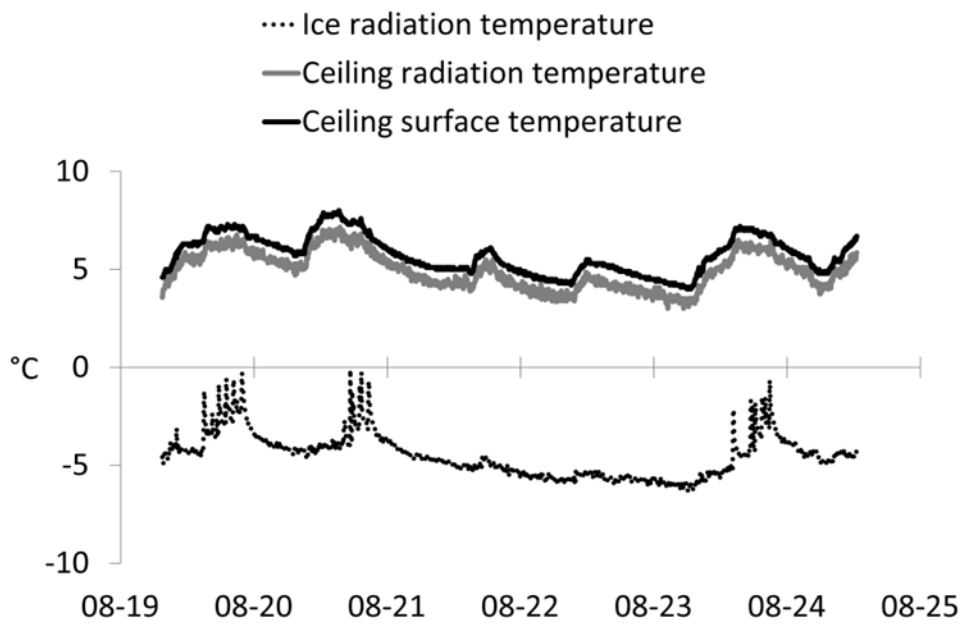

(a)

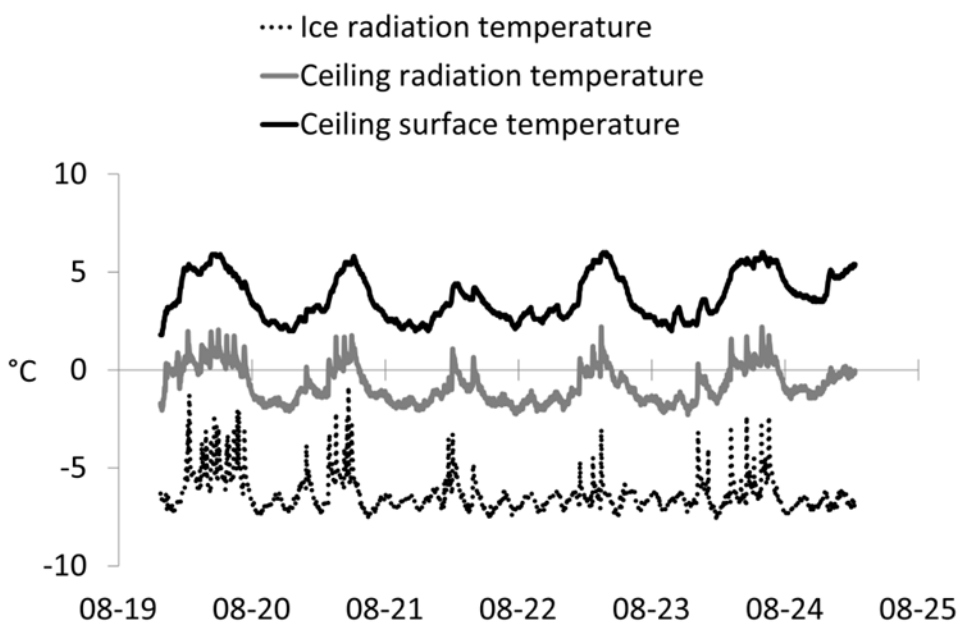

(b)

Figure 3-6 Surface and radiation temperatures in (a) Sunderbyn arena with high emissive ceiling and (b) Coop Arena C-Hall with low emissive ceiling 


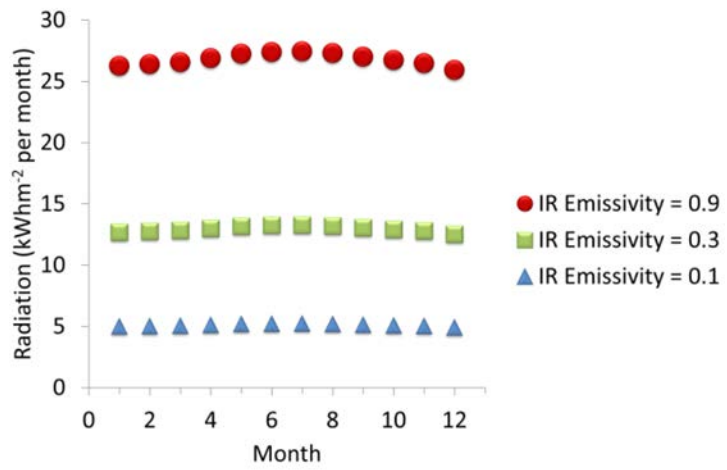

Figure 3-7 Thermal radiation to the ice surface

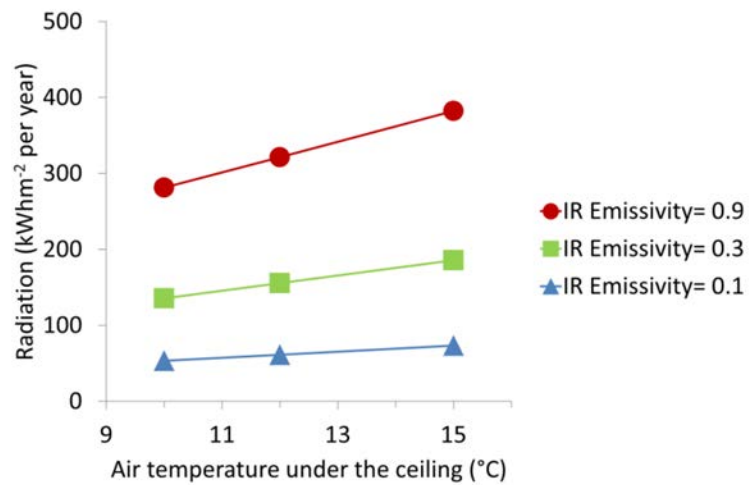

Figure 3-8 Thermal radiation to the ice surface, vs. adjacent air temperature under the ceiling, for three different values of interior roof emittance 


\subsection{Envelope heat flux and optical properties}

The time-resolved heat flux calculation through a horizontal roof with the properties give in table 2-3 is shown in figure 3-9 based on a schematic dynamic model where TSR is varied from 0.1 to 0.9 . Thermal emittance for the interior and exterior surfaces is 0.9. As shown in figure 3-9, heat fluxes varied transiently from negative values at night and when the ambient temperature falls below $10^{\circ} \mathrm{C}$, to positive values when the heat flux is from the exterior sun-heated surfaces to the interior sides.

When the heat flux is positive as seen in figure 3-9, the increase in the TSR both reduces the total heat flux and contributes to a peak shaving trend with the maximum saving at the maximum peak load. The peak load is important for example in dimensioning the HVAC equipment based on the maximum needed capacity.

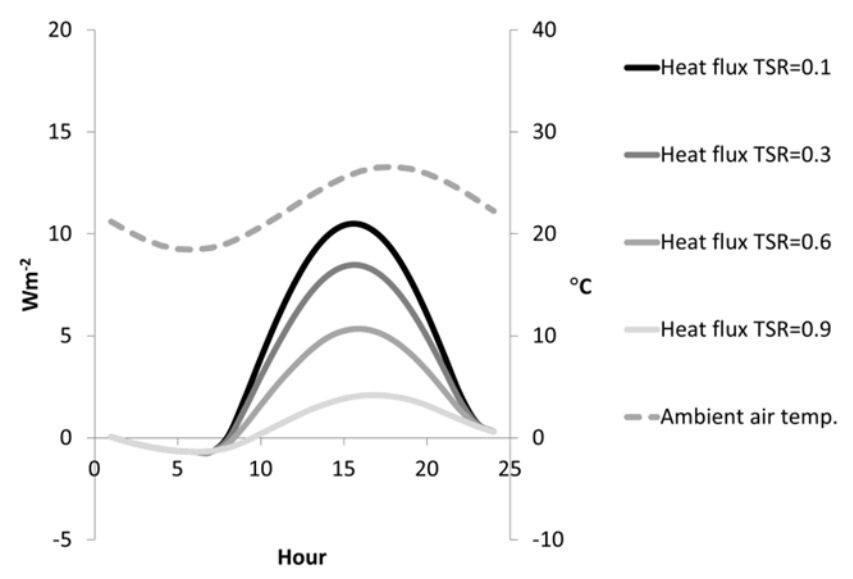

Figure 3-9 Heat flux - Stockholm summer design day

The maximum exterior surface temperatures during one year is calculated by the use of hourly dynamic model for three locations in north, middle and southern Europe as shown in figure 3-10. The maximum surface temperature is an important parameter for the mechanical strain and thermal stresses for the outer steel sheet 
construction. For the given condition, each $20 \%$ increase in the TSR reduces the maximum surface temperature by about $10^{\circ} \mathrm{C}$.

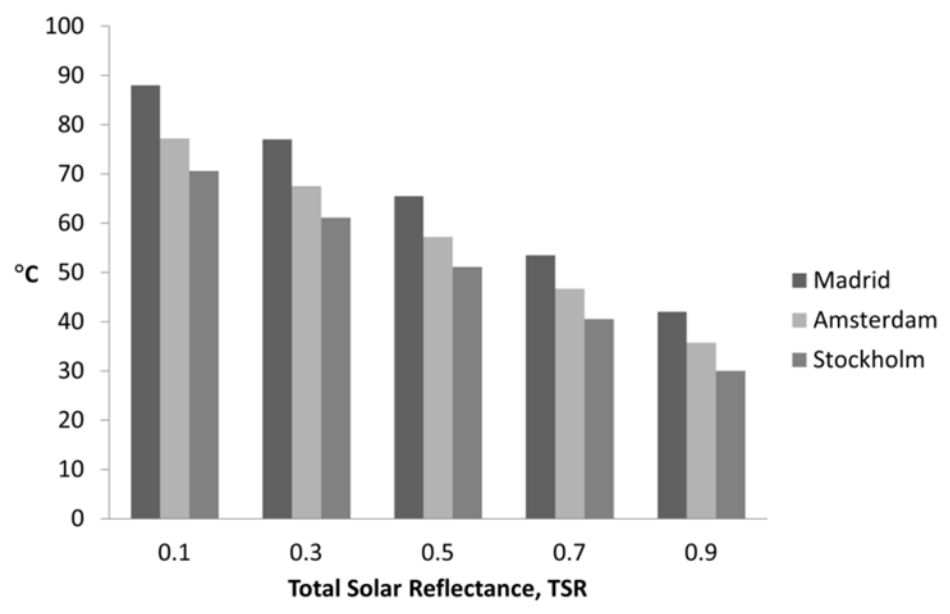

Figure 3-10 Maximum exterior surface temperature

The effect of the exterior thermal emittance on the total heat flux is given in figure 3-11. Depending on the boundary conditions, increasing the TSR can reduce the cooling load or increase the heating load. The increase in the exterior surface thermal emittance reduces the cooling load (heat surplus) and increases the heating load (heat deficiency). This is because the exterior surface can be more efficiently cooled by the colder environment with high thermal emittance. However, the compound effect of the exterior TSR and exterior thermal emittance on the total integrated heat flux is not always consistent. As seen in figure 3-11, increase in the exterior thermal emittance reduces the integrated heat flux for surfaces with 0.5 TSR. On the contrary, for the exterior surfaces with 0.9 TSR, increasing the exterior thermal emittance marginally increases the integrated heat flux or leaves it almost constant. This fact calls for extra attention when a compound coefficient such as solar reflectance index (SRI) is used to address the annual total energy calculation, as the thermal emittance and TSR have different interacting course with outdoor environment and may be treated separately. 


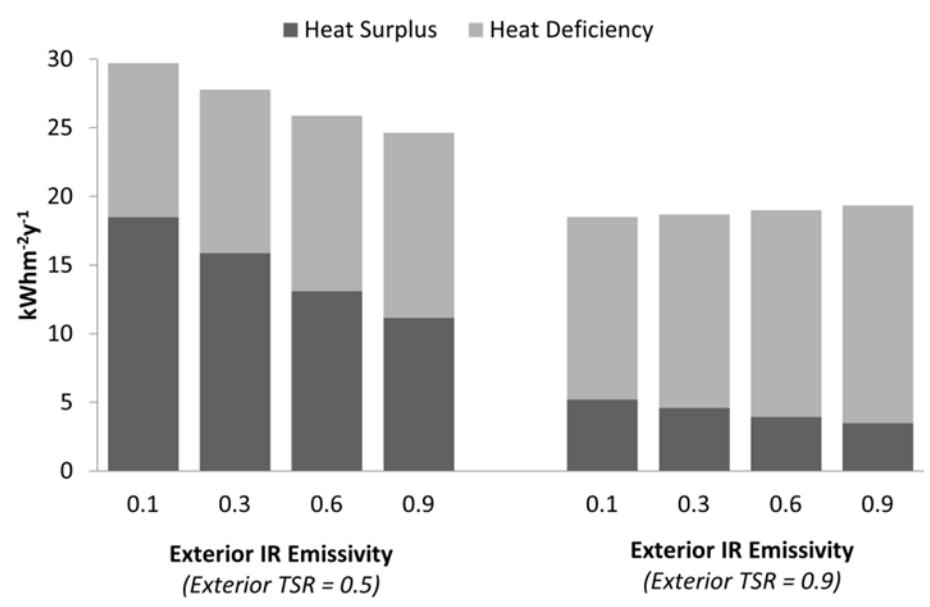

Figure 3-11 Integrated heat flux with different exterior thermal emittance and TSR, Madrid

For the interior surfaces, figure 3-12 shows the total integrated heat flux with different interior radiation temperatures, ranging from $20^{\circ} \mathrm{C}$ to $26^{\circ} \mathrm{C}$ e.g. in a floor heating case and Amsterdam climate. As seen in figure $3-12$, when the radiation temperature varies from the assumed $20^{\circ} \mathrm{C}$ indoor air temperature, the emittance from the interior surfaces (radiation part of the heat flux) becomes important. In the cases where the radiation temperature is very close to the air temperature, i.e. $20^{\circ} \mathrm{C}$ indoor air and radiation temperature, the emittance has very small effect on the integrated heat flux from the panel. As the interior radiation temperature increases, the importance of the interior surface emittance grows larger. The other fact, as seen in figure 3-12 is the sharp heat flux changes with the lower thermal emittance. The reduction of heat flux when changing from thermal emittance of 0.4 to 0.2 is larger than when changing the emittance of the coatings from 0.9 (usual material) to 0.7 . This fact can be important for setting goals for the coating optimization and paint development. 


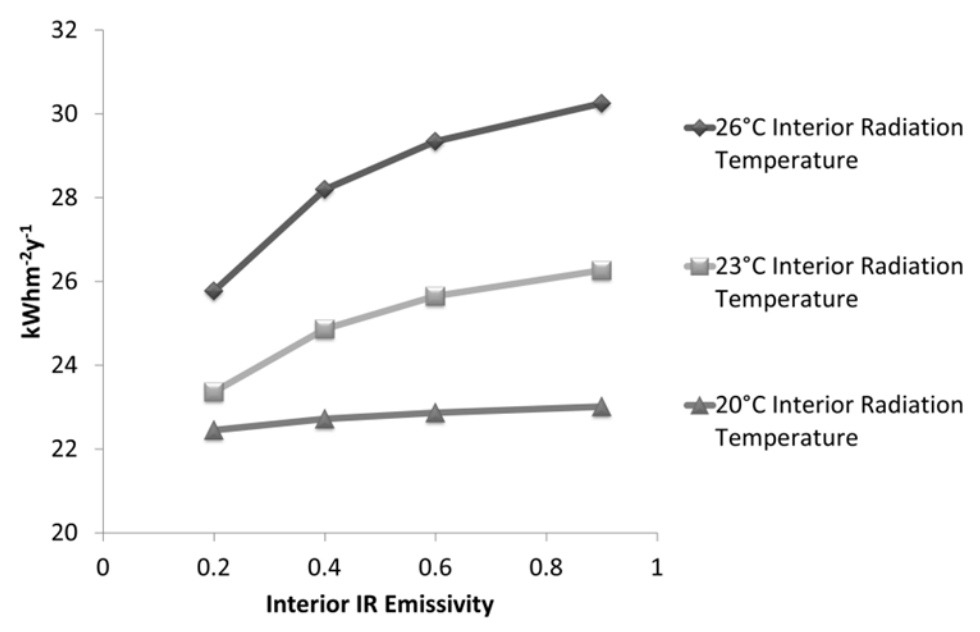

Figure 3-12 Integrated absolute heat flux vs. interior surface emittance

The effect of the insulation thickness is presented in figure 3-13. The exterior and interior surface nodes of a panel are coupled with the building envelope conductance. The better the insulation, the lower the heat flux and the weaker the interconnection of the surfaced nodes. The optical properties affect the temperature at interior and exterior surface. As seen in figure 3-13, the influence of the optical properties on the total heat flux is considerably higher with thinner insulation thickness for Amsterdam climate.

However, as seen in the figure 3-13, the reduction in the integrated absolute heat flux and increase of the insulation thickness does not have a linear relationship. There is an optimal insulation thickness with regards to the material use. Reducing the total heat fluxes by improving the optical properties can lead to efficient material building insulation material saving. 


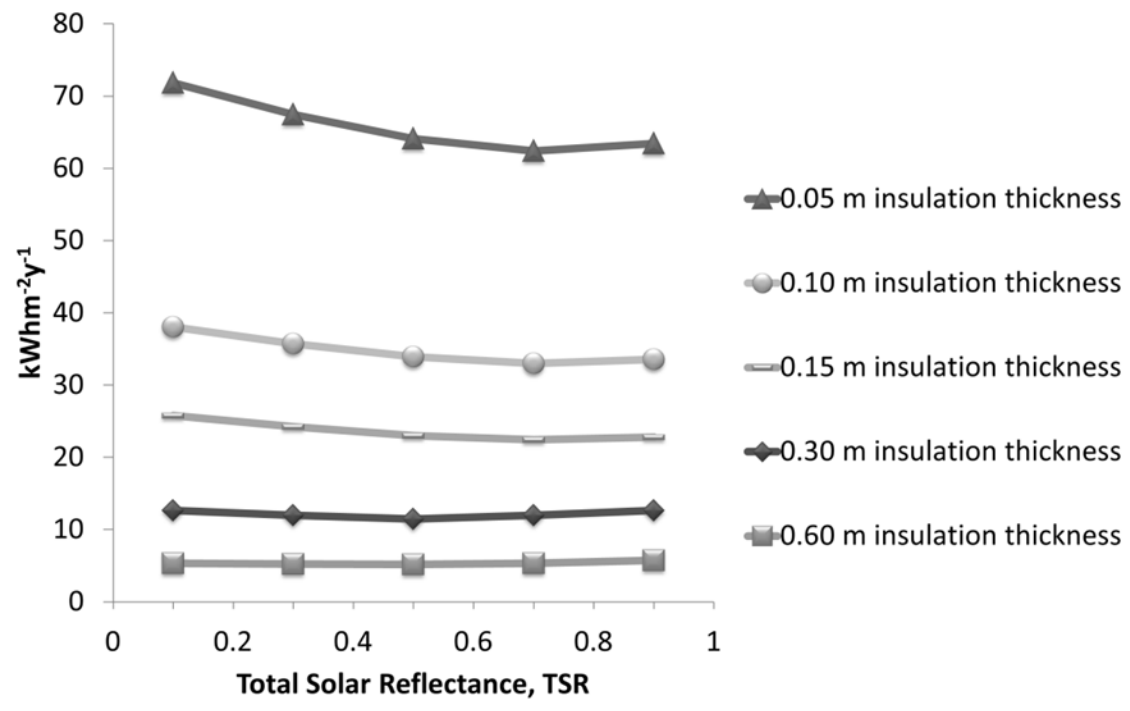

Figure 3-13 Integrated absolute heat flux vs. TSR for different insulation thicknesses 


\subsection{Internal load, climate factors and optical properties}

The interaction of the building surface optical properties, internal load and climate factors is addressed by the use of building energy simulation (Joudi et al. 2013). Figure 3-14 indicates the interaction of reflective interior cabin with different amount of internal load where $40 \%$ of the internal load is assumed to be via radiation. The operative temperature inside the cabin is set to $21 \pm 1^{\circ} \mathrm{C}$. The savings given are in comparison with the normal cabin. As the internal load increases, the net heating load decreases until the internal load can fully compensate the need for heating. However, the cooling load increases as the cooling system should compensate for the radiative losses of internal load which are reflected back in the interior reflective cabin.

Figure 3-15 indicates the compound effect of reflective interior and exterior surfaces. The cooling saving increases due to the use of high TSR exterior coating until the negative effects of the interior reflective coatings with high internal load start to decrease and finally overtake the net cooling saving with high internal load. The heating saving, however, stars from negative values due to high TSR exterior and lower solar gain in colder seasons in the case of both-side reflective cabin. The increase of the internal load compensates the heating load due to the role of interior reflective surfaces until there will be no need for auxiliary heating load. With the simulated optical properties, the building has the best energy performance around $20 \mathrm{Wm}^{-2}$ internal loads. Such an optimal point indicated the strong interaction of building surface optical properties and internal load of the building. 


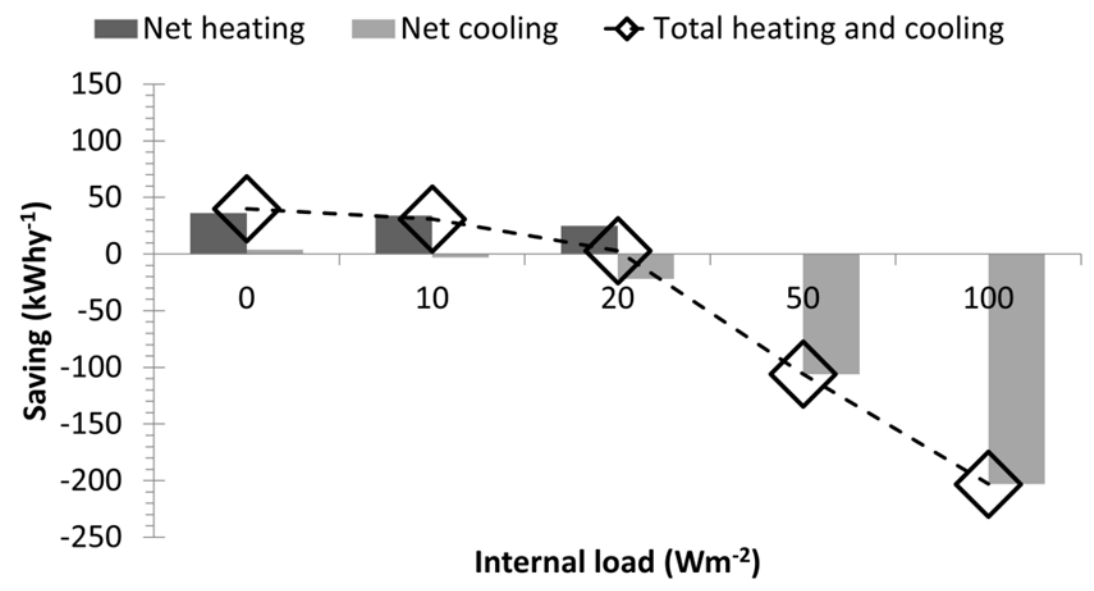

Figure 3-14 Saving vs. internal load; comparing interior reflective cabin with normal cabin.

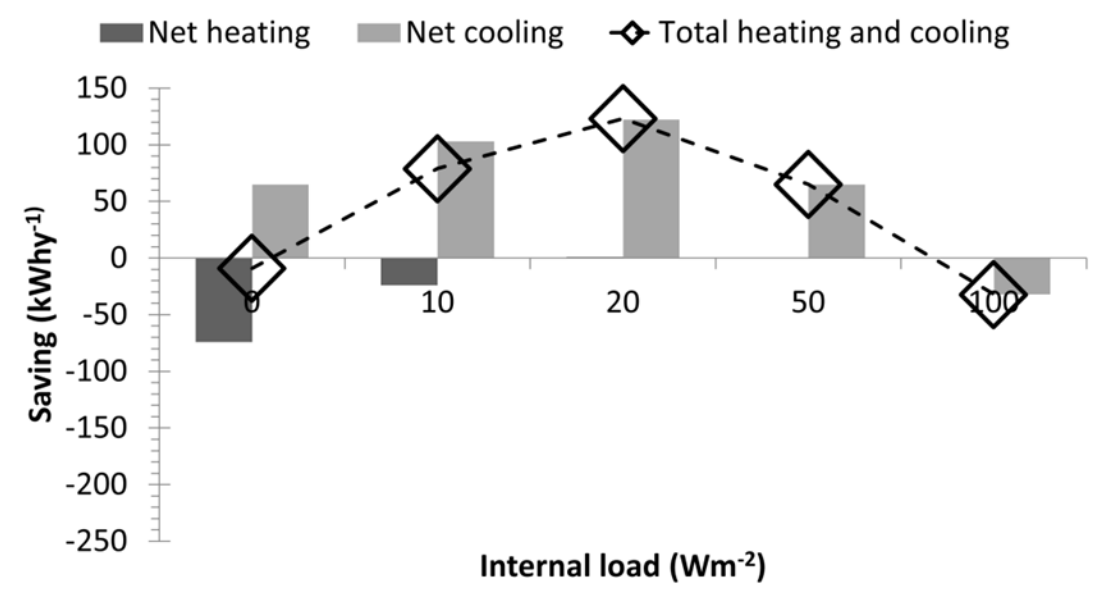

Figure 3-15 Saving vs. internal load; comparing both-side reflective cabin with normal cabin 
The simulated annual total heating and cooling savings due to the use of interior and exterior reflecting surfaces are given in table 3-1 for three different climates. High TSR exterior and high thermal reflective interior have the best annual energy performance for the warmest and coldest climate respectively. However, for the milder climate both-side reflective coatings are the best choice for the given condition. However, it shall be noted that the savings for both-side reflective coatings is not a simple accumulation of the interior and exterior coatings. This is due to the dynamic interaction between interior and exterior surface temperatures to the outdoor conditions.

Table 3-1 Net heating and cooling in a simulated retail house at three locations related to cold, mild and warm climates

\begin{tabular}{|c|c|c|}
\hline & & $\begin{array}{c}\text { Annual total heating and cooling } \\
\text { saving (kWh per year) }\end{array}$ \\
\hline \multirow{3}{*}{$\begin{array}{l}\text { Stockholm } \\
59^{\circ} \mathrm{N}\end{array}$} & Interior reflective coatings & 5384 \\
\hline & Exterior reflective coatings & -375 \\
\hline & Both-side reflective coatings & 5116 \\
\hline \multirow{3}{*}{$\begin{array}{l}\text { Paris } \\
49^{\circ} \mathrm{N}\end{array}$} & Interior reflective coatings & 2755 \\
\hline & Exterior reflective coatings & -4 \\
\hline & Both-side reflective coatings & 2817 \\
\hline \multirow{3}{*}{$\begin{array}{c}\text { Riyadh } \\
25^{\circ} \mathrm{N}\end{array}$} & Interior reflective coatings & -937 \\
\hline & Exterior reflective coatings & 923 \\
\hline & Both-side reflective coatings & -26 \\
\hline
\end{tabular}

* Positive value for savings and negative for total loss (compared with Normal coating) 


\subsection{Air and surface temperature gradients}

The CFD results for the test cabins at the time of maximum indoor air temperature gradient are presented for the indoor air temperature distribution at two cross-section views and the interior surface temperature are given in figures 3-16 and 3-17, respectively, as calculated by the CFD method in Paper V.

In figure 3-16, the normal cabin has more or less uniform temperature distribution while in the reflective cabin, temperature at the higher level remains higher and temperature at the lower levels close to floor are colder due to reduced radiation heat transfer. Use of reflective coatings for the interior surface can allow for lower air temperature at the occupied zone. This can help to generate desired air temperature at occupant height and warmer and contaminant air above the occupant zone and under the ceiling, reducing the total air volume that needs to be conditioned which is in line with the benefits of stratum ventilation (Lin et al. 2009) or under-floor air distribution systems for high-ceiling building compared to ceiling-based air distribution systems (Alajmi and El-Amer 2010). The vertical air temperature gradient is an important factor for thermal comfort and cooling load calculations in displacement ventilation design ( $\mathrm{Li}$, Sandberg, and Fuchs 1992;Park and Holland 2001).

In the air-conditioned buildings, the vertical air temperature gradient directly influences the indoor environment and may, depending on the type of ventilation, influence the building energy use. Ventilation with stratified air distribution and partially increased vertical temperature gradient can contribute to efficient heat removal and energy saving in comparison with mixing ventilation with uniform indoor air temperature (Cehlin and Moshfegh 2010; Chen 2014;Nielsen and Awbi 2008; Lin et al. 2009; Tian, Lin, and Wang 2011). In the stratified ventilations, cold air enters the occupant region at low height levels. Then, it rises to the upper parts via buoyancy driven airflow along warm surfaces and exhausts at higher levels. In the case of stable thermal stratification which is not disturbed by mixing ventilation or suppressed by e.g. cooled ceiling panels, increase in the vertical temperature gradient can contribute to energy efficiency by the ability to vent relatively warm air. In large halls, for example, the stratified flow with large vertical 
temperature gradient can prevent the warmer air at higher level from mixing with the colder occupied air below(Nielsen and Awbi 2008).

Interior surface temperature gradient pictured in multiple perspective views in figure 3-17 indicates higher temperature asymmetry in interior reflective cabin compared to the normal cabin. In response to the solar gain of the exterior surfaces, the interior surface temperature at the higher height levels such as south-facing roof is generally warmer than the lower height level surfaces including floor.

However, the temperature asymmetry is higher in the cabin with reflective interior surfaces. The higher south-facing ceiling surface temperature and lower floor temperature indicated an increased thermal resistivity to the flow of the heat flux from upper to lower height levels.

Comparing temperature distribution profiles in figure 3-16 and 3-17 indicates that there is a strong interconnection between the indoor air temperature and interior surfaces when it comes to the temperature profile and increase in the temperature gradient. The CFD simulation, allowing for the consistent discretization of indoor air and building envelope, could capture this interaction. 


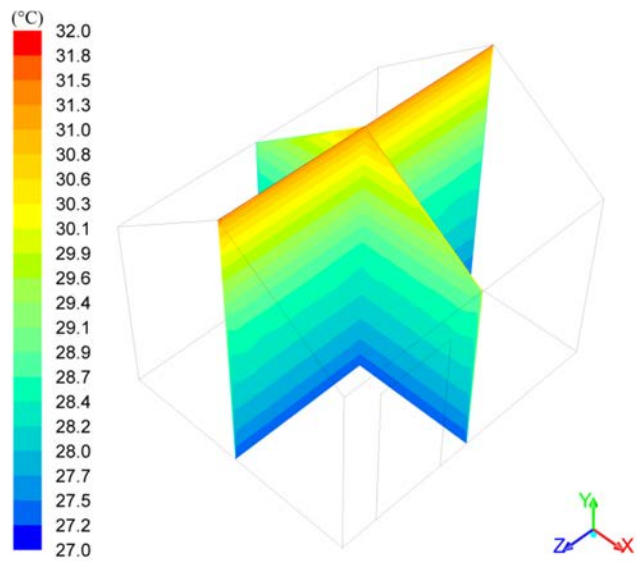

(a)

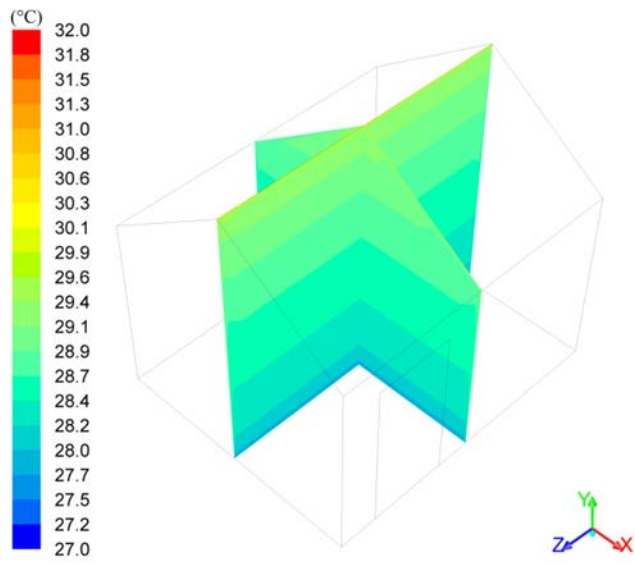

(b)

Figure 3-16 Indoor air temperature distribution for (a) interior reflective (b) normal cabins 

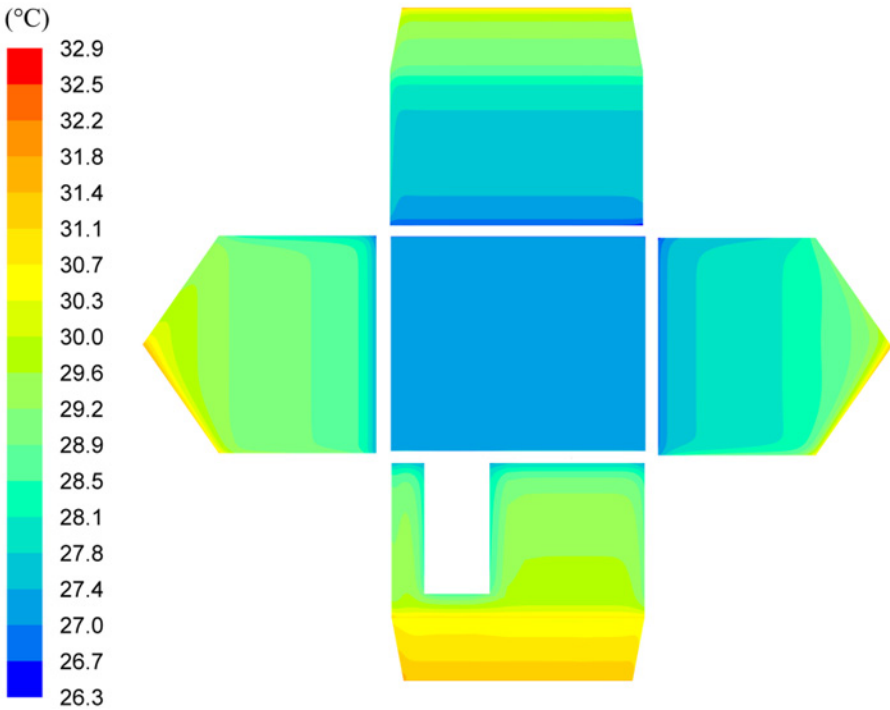

(a)
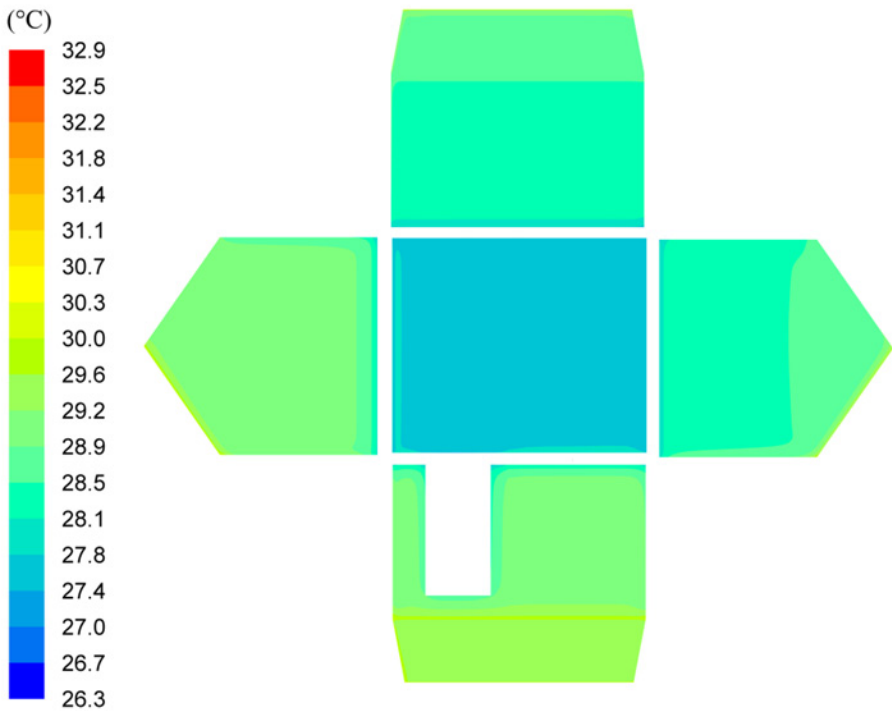

(b)

Figure 3-17 Interior surface temperature distribution for (a) interior reflective and (b) normal cabins 
Figure 3-18 shows different combinations of having interior reflective surfaces in comparison with the normal cabin. Having reflective surfaces only on the interior roofs has increased the temperature gradient under the ceiling above the occupant height which is similar to the interior reflective cabin. However, the lower part of the Reflective Interior Roof cabin (occupant zone) more resembles the normal cabin with small vertical temperature gradient. This will indicate that it is possible to partially increase the temperature gradient, in this case under the roofs, without causing any vertical temperature gradient at the occupant height (the ankle and neck) that is important for occupant thermal comfort.

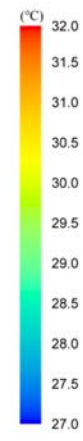

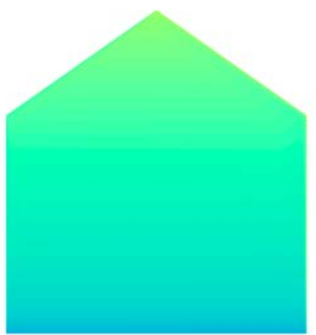

Normal cabin

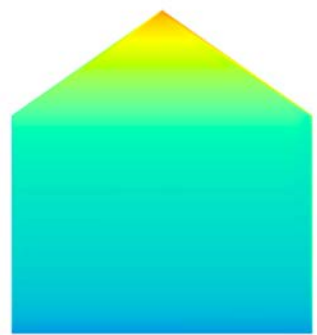

Normal cabin with reflective interior roofs

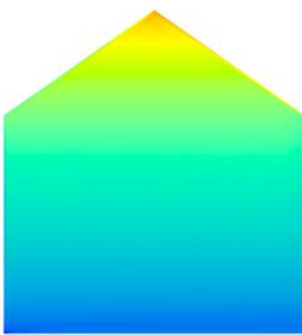

Reflective cabin

Figure 3-18 Indoor air temperature distribution for two different combinations of reflective surfaces for interior roofs and walls (right-hand) and only on interior roofs (middle) 


\subsection{Coupling BES and CFD}

The influence of interior reflective coatings on indoor thermal environment with high spatial resolution is investigated using coupling method and floor heating set to floor temperature $26^{\circ} \mathrm{C}$. The climate file is Stockholm winter design day (ASHRAE 2001). Figure 3-19 presents the mean radiation temperatures at the time of maximum floor heating energy use. The spatially resolved MRT distributions are calculated by discrete ordinates (DO) radiation model (ANSYS/Fluent 2009). As seen in figure 3-19, MRT in the reflective cabin is higher than the normal cabin as less of the direct radiation from the floor is absorbed and dissipated by the reflective interior surfaces. It can be noted that there is a distinct geometrical pattern in the MRT distribution, arguably enhanced by the uniform surface temperature assumption and the related lack of smoother surface temperature distribution in the simulations.

The uniform interior surface temperature as calculated by both BES and the coupling model is given in table 3-2 for both normal and interior reflective cabins, respectively. Both BES and coupling method (BES-CFD) give similar interior surface temperatures for the normal cabin. For the Interior reflective cabin, the interior roof and wall surfaces have significantly lower surface temperatures, compared to the normal cabin.

The spatial distributions of the indoor air and operative temperatures are in shown in figures 3-20 and 3-21, respectively. The lower indoor air temperature in the Interior reflective cabin is in line with lower enclosing surface temperature. However, the operative temperature, a combination of the indoor air and mean radiation temperatures with equal weight, remains comparatively equal in both cabins.

Table 3-2 Surface temperatures in ${ }^{\circ} \mathrm{C}$ for the normal and the interior reflective cabins

\begin{tabular}{|l|l|c|c|c|c|c|c|c|}
\cline { 3 - 9 } \multicolumn{2}{c|}{} & $\begin{array}{c}\text { Roof } \\
\text { North }\end{array}$ & $\begin{array}{c}\text { Roof } \\
\text { South }\end{array}$ & $\begin{array}{c}\text { Wall } \\
\text { North }\end{array}$ & $\begin{array}{c}\text { Wall } \\
\text { East }\end{array}$ & $\begin{array}{c}\text { Wall } \\
\text { South }\end{array}$ & $\begin{array}{c}\text { Wall } \\
\text { West }\end{array}$ & Floor \\
\hline $\begin{array}{l}\text { Normal } \\
\text { cabin }\end{array}$ & $B E S$ & 20.11 & 20.11 & 19.91 & 19.90 & 19.91 & 19.90 & 26.00 \\
\cline { 2 - 9 } & $B E S-C F D$ & 20.11 & 20.07 & 19.90 & 19.82 & 19.89 & 19.82 & 26.00 \\
\hline $\begin{array}{l}\text { Reflective } \\
\text { cabin }\end{array}$ & $B E S$ & 19.00 & 19.00 & 18.66 & 18.65 & 18.66 & 18.65 & 26.00 \\
\cline { 2 - 10 } & $B E S-C F D$ & 18.44 & 18.33 & 17.86 & 17.88 & 17.84 & 17.86 & 26.00 \\
\hline
\end{tabular}



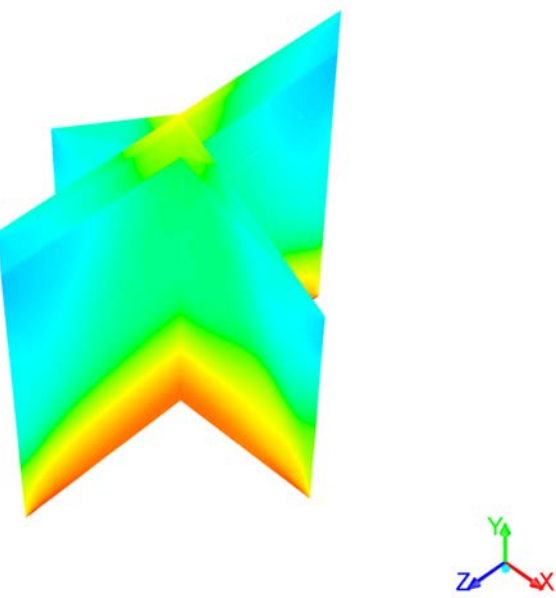

(a)
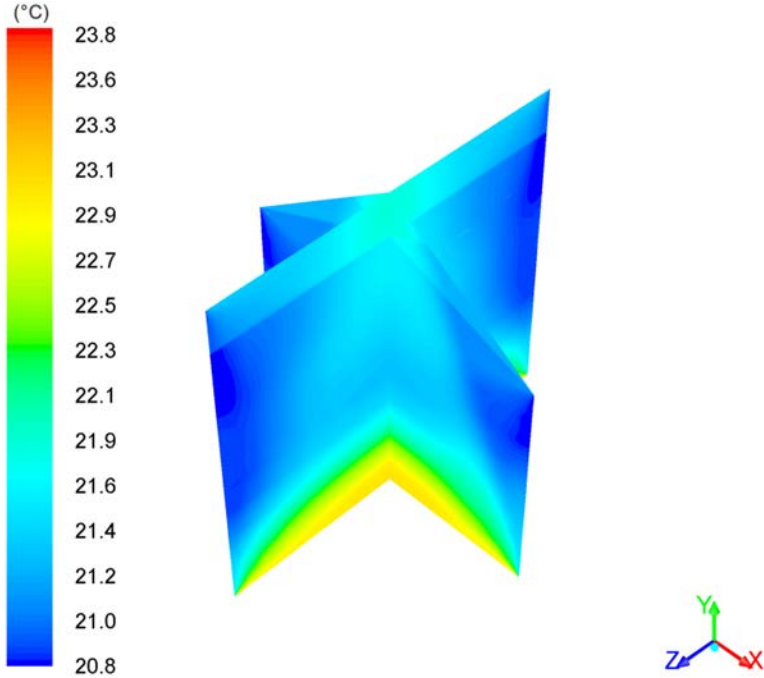

(b)

Figure 3-19 Mean radiation temperature for (a) interior reflective and (b) normal cabins 

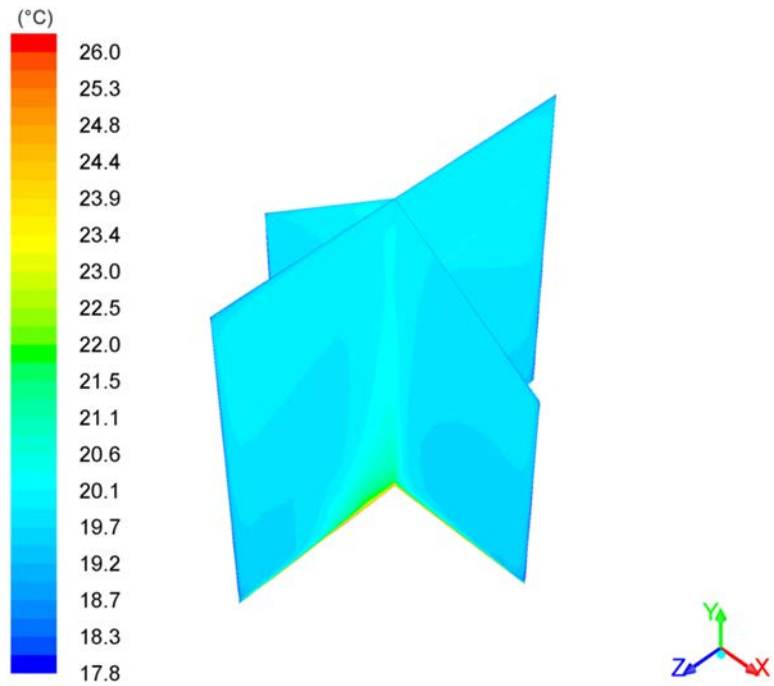

(a)
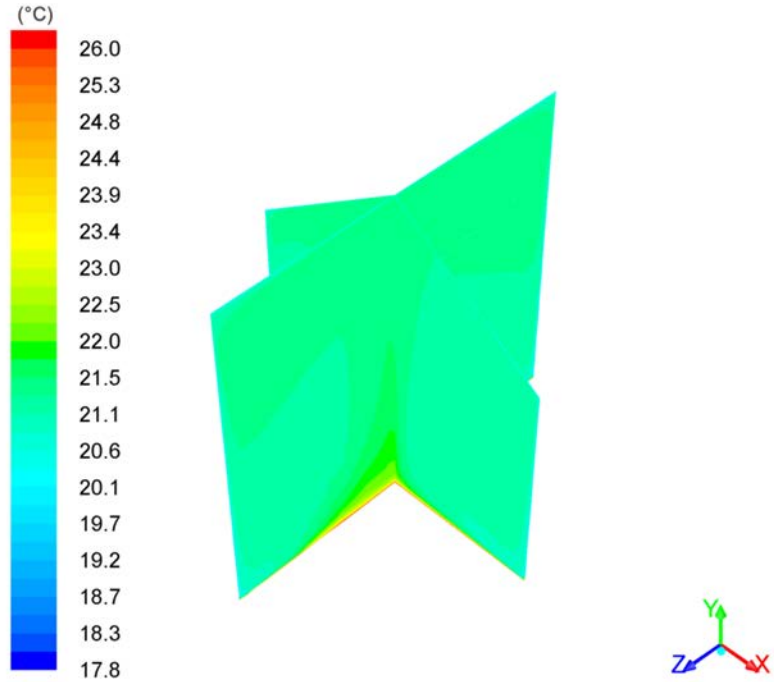

(b)

Figure 3-20 Indoor air temperature for (a) interior reflective and (b) normal cabins 

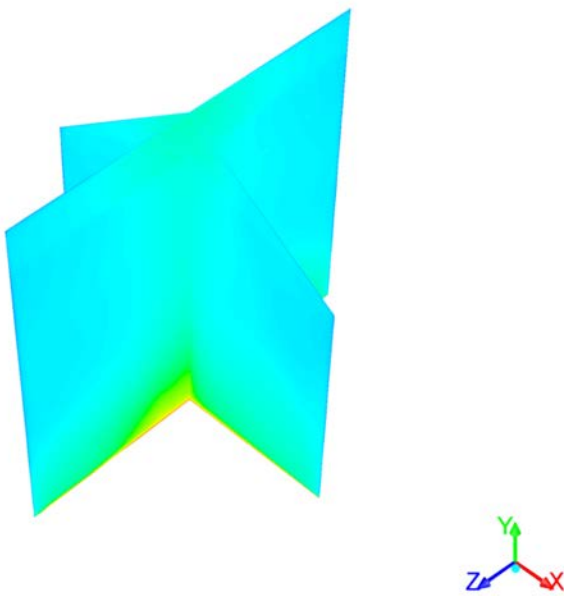

(a)
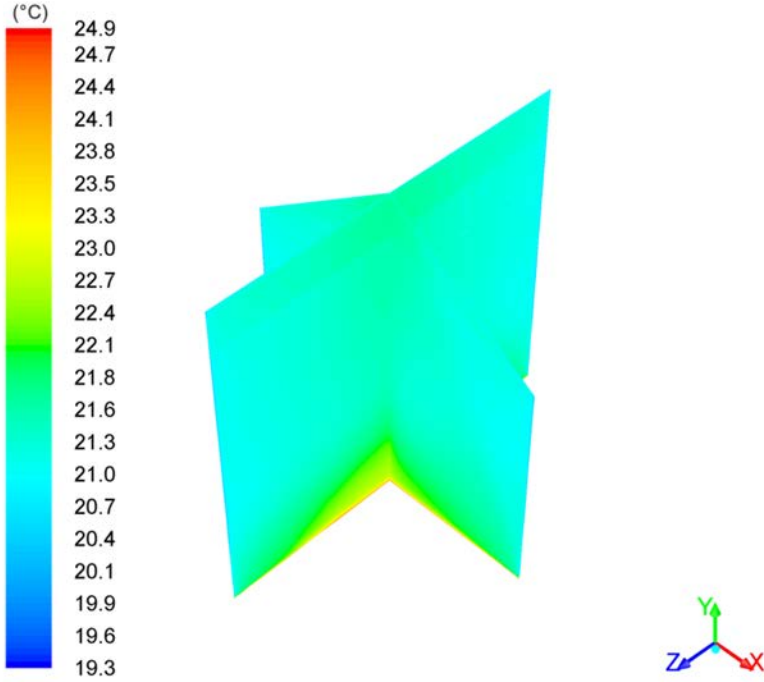

(b)

Figure 3-21 Operative temperature for (a) interior reflective and (b) normal cabins 
Using the coupling method makes it possible to address both the indoor thermal climate and energy use in the test cabins. Floor heating energy use for the test cabins are given in figure 3-22 with floor heating set to $26^{\circ} \mathrm{C}$.

In the normal cabin, there are marginal differences in energy use comparing BES and the coupling method. However, this difference is larger in the reflective cabin by the use of the coupling method (S2S radiation model and CFD). The predicted energy savings by the use of reflective surface is larger with the coupling method. Paper VI compares the radiation, convection and total heat flux at the time of maximum floor heating and addresses the contribution of different models.

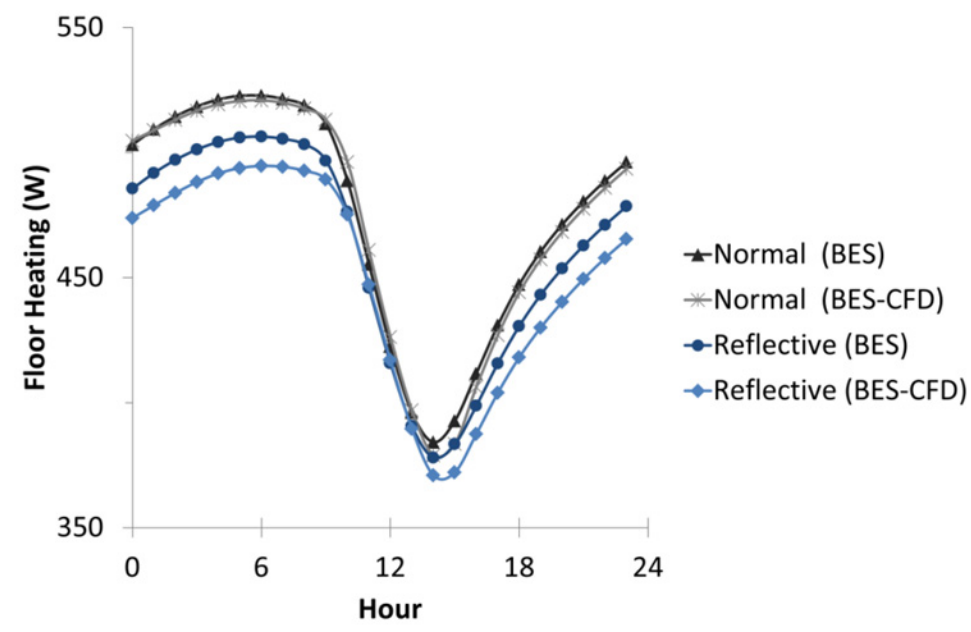

Figure 3-22 Floor heating energy use for the Normal and Interior reflective cabins, comparing BES and coupling method (BES-CFD) 


\section{Conclusions}

Different optical properties of building interior and exterior surfaces can influence the building thermal performance:

- In the case of thick insulation and low building envelope thermal conductivity, the influence for the surface optical properties falls considerably as the interior and exterior surface thermal nodes de-couple from each other. On the contrary, reflective interior surfaces can play an important role in the reduction of net transmission losses for the less insulated buildings.

- Increase in the vertical indoor air temperature gradient by the use of interior reflective coatings are compatible with ventilation with stratified air distribution; the systems that are designed to maintain the thermal comfort at the occupant height. This can reduce the volume of the conditioned air and create a buffer zone (above the occupant and under the ceiling). Having reflective surface on the ceiling can reduce the radiation from the upper part (the buffer zone) to the lower part and floor (the air conditioned zone) which can arguably save cooling.

- It was also found that the interior reflective surfaces can improve the mean radiation temperature. The consequence of reduced thermal reflectivity on the interior surfaces as calculated by the coupling method with the floor heating is seen as higher MRT, lower surface temperatures, lower indoor air temperature and reduced energy use while maintaining comparable operative temperature.

- The energy performance of the buildings with the given surface optical properties was found to be case dependent to the building thermal load. In the case of dominant heating load, the interior reflective surfaces contributed positively to the building energy performance while the exterior reflective surfaces contributed negatively. In the case of dominant cooling load, both the exterior and interior reflective surfaces could contribute to the reduction of the cooling load; the exterior reflective surface by 
reducing the solar gain and the interior reflective surface by acting as a radiant barrier towards the indoor heat fluxes. Nevertheless, in the case of dominant cooling mainly due to internal heat generation, only the exterior reflective surfaces were contributing to the cooling load reduction. Identifying the dominant cooling or heating loads (partially dependent on climate) can assist in the appropriate choice of surface properties at early stages.

- The combined performance of the interior and exterior surfaces was the result of dynamic interactions between the building envelope and the interfaces both indoors and outdoors and not a sum of individual performance of the interior or exterior reflective surfaces.

The numerical investigation of the building thermal behavior with reflective surfaces was performed at different detail levels: When the detailed information of indoor boundary condition is neither available nor motivated, the use of higher detail models is hardly encouraged. Nevertheless, care must be taken when it comes to simulation fidelity and compromising the spatial resolution as the reflective interior surface can affect the indoor temperature gradients.

- The more detailed building simulation levels using CFD could predict the indoor air temperature with high resolution in agreement with the measurement.

- The envelope heat flux model, differentiating between different wavelength regions, could calculate for the surface temperatures and the building envelope heat fluxes.

- An estimation of the overall annual thermal performance of the building was accomplished by the building energy simulation.

- The coupling BES and CFD could account for both indoor temperature distribution and energy use in a reconciliation of the detail level and computational requirement. 


\section{Outlook}

Parallel to this work a still unpublished investigation was made measuring surface, air and radiation temperatures in two comparable indoor ice rink facilities referred to in Paper III. Results indicate not only a significant reduction in the interior radiation temperature by the use of low thermal emittance on the interior ceiling surface but also significant indications of a vertical thermal air stratification being critically dependent on the ceiling emittance. It remains to be investigated how well these findings would be reproduced by use of the CFD model. The level of CFD accuracy and spatial resolution that is used in this study may be too computationally demanding for the evaluation of a realistic model of the ice arenas. The validity of necessary assumptions and simplifications or the effects of reductions in spatial or temporal resolution remains to be investigated. Characteristic for the ice rinks is the relatively large surface temperature difference between the interior roof and floor surfaces, the similarity in size of the floor surface to the total of the remaining interior surfaces and the considerably larger total size of the building, all compared to our test cabins. Additionally air humidity and the corresponding phase transfer phenomena are likely to play a significant role.

Extending the coupling method using BESTEST for standard office room including ventilation and expanding the program for automated coupling is an interesting task for the future after analysis of the initial results. 


\section{References}

Abadie, M. O., M. M. de Camargo, K. C. Mendonça, and P. Blondeau. 2012. "Improving the prediction of zonal modeling for forced convection airflows in rooms." Building and Environment 48 (1):173-182. doi: 10.1016/j.buildenv.2011.09.006.

Alajmi, A., and W. El-Amer. 2010. "Saving energy by using underfloor-air-distribution (UFAD) system in commercial buildings." Energy Conversion and Management 51 (8):1637-1642. doi: 10.1016/j.enconman.2009.12.040.

ANSYS/Fluent. 2009. 12.0 Theory Guide, 2009. In ANSYS FLUENT 12.0 Documentation, Theory Guide.

ASHRAE. 2001. ASHRAE Handbook of Fundamentals. SI ed. Atlanta, GA: American Society of Heating, Refrigeration and Air-Conditioning Engineers.

ASHRAE. 2005. ASHRAE Handbook of Fundamentals. SI ed. Atlanta, GA: American Society of Heating, Refrigeration and Air-Conditioning Engineers.

ASHRAE. 2006. ASHRAE Handbook of Refrigeration. SI ed. Atlanta, GA: American Society of Heating, Refrigeration and Air-Conditioning Engineers.

Attia, S., J. L. M. Hensen, L. Beltrán, and A. De Herde. 2012. "Selection criteria for building performance simulation tools: contrasting architects' and engineers' needs." Journal of Building Performance Simulation 5 (3):155-169. doi: 10.1080/19401493.2010.549573.

Awbi, H. B. 1998. "Calculation of convective heat transfer coefficients of room surfaces for natural convection." Energy and Buildings 28 (2):219-227. doi: 10.1016/s0378-7788(98)00022-x.

Awbi, H. B. 2013. Ventilation of Buildings. second ed. New York, NY: Spon Press.

Axley, J., and P. V. Nielsen. 2008. "Modeling of ventilation airflow." In Ventilation Systems Design and Performance, edited by H. B. Awbi. New York, NY: Spon Press.

Azemati, A. A., B. Shirkavand Hadavand, H. Hosseini, and A. Salemi Tajarrod. 2013. "Thermal modeling of mineral insulator in paints for energy saving." Energy and Buildings 56 (2013):109-114. doi: 10.1016/j.enbuild.2012.09.036.

Baldinelli, G. 2010. "A methodology for experimental evaluations of low-e barriers thermal properties: Field tests and comparison with 
theoretical models." Building and Environment 45 (4):1016-1024. doi: 10.1016/j.buildenv.2009.10.009.

Barbason, M., and S. Reiter. 2014. "Coupling building energy simulation and computational fluid dynamics: Application to a two-storey house in a temperate climate." Building and Environment 75 (0):30-39. doi: 10.1016/j.buildenv.2014.01.012.

Bartak, M., I. Beausoleil-Morrison, J. A. Clarke, J. Denev, F. Drkal, M. Lain, I. A. Macdonald, A. Melikov, Z. Popiolek, and P. Stankov. 2002. "Integrating CFD and building simulation." Building and Environment 37 (8-9):865-871. doi: 10.1016/s0360-1323(02)00045-8.

Beausoleil-Morrison, I. 2000. "The adaptive coupling of heat and air flow modeling within dynamic whole-building simulation." PhD diss., University of Strathclyde.

Beausoleil-Morrison, I., and P. Strachan. 1999. "On the significance of modelling internal surface convection in dynamic whole-building simulation programs." ASHRAE Transactions 105 (2):929-940.

Belusko, M., F. Bruno, and W. Saman. 2011. "Investigation of the thermal resistance of timber attic spaces with reflective foil and bulk insulation, heat flow up." Applied Energy 88 (1):127-137. doi: 10.1016/j.apenergy.2010.07.017.

Bonvini, M., A. Leva, and E. Zavaglio. 2012. "Object-oriented quasi-3D subzonal airflow models for energy-related system-level building simulation." Simulation Modelling Practice and Theory 22:1-12. doi: 10.1016/j.simpat.2011.11.001.

Borge-Diez, D., A. Colmenar-Santos, C. Pérez-Molina, and M. Castro-Gil. 2013. "Passive climatization using a cool roof and natural ventilation for internally displaced persons in hot climates: Case study for Haiti." Building and Environment 59 (0):116-126. doi: 10.1016/j.buildenv.2012.08.013.

Bring, A., P. Sahlin, and M. Vuolle. 1999a. Building Indoor Climate and Energy Simulation; A Report of IEA SHC Task 22: Building Energy Analysis Tools, Subtask B: Model Documentation. Stockholm.

Bring, A., P. Sahlin, and M. Vuolle. 1999c. IEA SHC Task 22 - Subtask B Models for Building Indoor Climate and Energy Simulation. In Dept. of Building Sciences. Stockholm: KTH.

Brown, G. 1963. "Metod för datamaskinberäkning av kyl- och värmebehov." Tidskrift för energi- och VVS-teknik Stockholm VVS 1930-1982.

Brown, G., and E. Isfält. 1974. Solinstrålning och solavskärmning : Solar irradiation and sun shading devices, Rapport / Byggforskningen, 0346-5616 ; 1974:19. Stockholm: Statens inst. för byggnadsforskning. 
Bulińska, A., Z. Popiołek, and Z. Buliński. 2014. "Experimentally validated CFD analysis on sampling region determination of average indoor carbon dioxide concentration in occupied space." Building and Environment 72 (0):319-331. doi: 10.1016/j.buildenv.2013.11.001.

Cehlin, M., and B. Moshfegh. 2010. "Numerical modeling of a complex diffuser in a room with displacement ventilation." Building and Environment 45 (10):2240-2252. doi: 10.1016/j.buildenv.2010.04.008.

Chen, H. 2014. "Experimental and numerical investigations of a ventilation strategy - impinging jet ventilation for an office environment." $\mathrm{PhD}$ diss., Linköping University.

Chen, Q. 1995. "Comparison of Different K-Epsilon Models for Indoor AirFlow Computations." Numerical Heat Transfer, Part B: Fundamentals 28 (3):353-369. doi: 10.1080/10407799508928838.

Chen, Q. 2009. "Ventilation performance prediction for buildings: A method overview and recent applications." Building and Environment 44 (4):848-858. doi: 10.1016/j.buildenv.2008.05.025.

Chen, Q., and J. Srebric. 2002. "A Procedure for Verification, Validation, and Reporting of Indoor Environment CFD Analyses." HVAC\&R Research 8 (2):201-216. doi: 10.1080/10789669.2002.10391437.

Clarke, J. A. 2001. Energy Simulation in Building Design. second ed. New York, NY: Routledge.

Crawley, D. B., J. W. Hand, M. Kummert, and B. T. Griffith. 2008. "Contrasting the capabilities of building energy performance simulation programs." Building and Environment 43 (4):661-673. doi: 10.1016/j.buildenv.2006.10.027.

Dabaieh, M., O. Wanas, M. A. Hegazy, and E. Johansson. 2015. "Reducing cooling demands in a hot dry climate: A simulation study for non-insulated passive cool roof thermal performance in residential buildings." Energy and Buildings 89 (0):142-152. doi: 10.1016/j.enbuild.2014.12.034.

Daoud, A., N. Galanis, and O. Bellache. 2008. "Calculation of refrigeration loads by convection, radiation and condensation in ice rinks using a transient 3D zonal model." Applied Thermal Engineering 28 (14-15):1782-1790. doi: 10.1016/j.applthermaleng.2007.11.011.

Djunaedy, E. 2005. "External coupling between building energy simulation and computational fluid dynamics." PhD diss., Eindhoven University of Technology.

Djunaedy, E., J. L. M. Hensen, and M. Loomans. 2003. "Toward external coupling of building energy and airflow modeling programs." ASHRAE Transactions 109 (2):771-787. 
Djunaedy, E., J. L. M. Hensen, and M. Loomans. 2004. "Comparing internal and external run-time coupling of CFD and building energy simulation software." Proc. 9th Int. Conf. on Air Distribution in Rooms ROOMVENT.

DOE. 2014. "Building Energy Software Tools Directory." U.S. Department of Energy, available at www.eere.energy.gov/buildings/tools directory, accessed date 2014.01.20.

Duffie, J. A., and W. A. Beckman. 2006. Solar Engineering of Thermal Processes. third ed. Hoboken, NJ: Wiley.

EQUA. 2009a. IDA ICE 4.0 Preview - IDA Indoor Climate and Energy. EQUA Simulation Technology Group.

EQUA. 2009b. IDA Indoor Climate and Energy 4.0 Manual. EQUA Simulation AB.

EQUA. 2010a. Validation of IDA Indoor Climate and Energy 4.0 build 4 with respect to ANSI/ASHRAE Standard 140-2004. Equa Simulation AB.

EQUA. 2010b. Validation of IDA Indoor Climate and Energy 4.0 with respect to CEN Standard EN 15265-2007. Equa Simulation AB.

Fan, Y., T. Hayashi, and K. Ito. 2012. "Coupled simulation of BES-CFD and performance assessment of energy recovery ventilation system for office model." Journal of Central South University 19 (3):633-638. doi: 10.1007/s11771-012-1049-7.

Ferziger, J. H., and M. Perić. 1996. Computational Methods for Fluid Dynamics. third ed. Vol. 3. Berlin: Springer.

Fohanno, S., and G. Polidori. 2006. "Modelling of natural convective heat transfer at an internal surface." Energy and Buildings 38 (5):548-553. doi: 10.1016/j.enbuild.2005.09.003.

Gebremedhin, K. G., and B. X. Wu. 2003. "Characterization of flow field in a ventilated space and simulation of heat exchange between cows and their environment." Journal of Thermal Biology 28 (4):301-319. doi: 10.1016/s0306-4565(03)00007-x.

Goldstein, K., and A. Novoselac. 2010. "Convective Heat Transfer in Rooms with Ceiling Slot Diffusers (RP-1416)." HVAC\&R Research 16 (5):629-655. doi: 10.1080/10789669.2010.10390925.

Gowreesunker, B. L., S. A. Tassou, and M. Kolokotroni. 2013. "Coupled TRNSYS-CFD simulations evaluating the performance of PCM plate heat exchangers in an airport terminal building displacement conditioning system." Building and Environment 65:132-145. doi: 10.1016/j.buildenv.2013.04.003. 
Hensen, J. L. M. 1999. "A comparison of coupled and de-coupled solution for temperature and air flow in a building." ASHRAE transactions $105(2)$.

Hensen, J. L. M., and R. Lamberts. 2011. "Introduction to building performance simulation " In Building Performance Simulation for Design and Operation, edited by J.L.M. Hensen and R. Lamberts. New York, NY: Spon Press.

Hernández-Pérez, I., G. Álvarez, J. Xamán, I. Zavala-Guillén, J. Arce, and E. Simá. 2014. "Thermal performance of reflective materials applied to exterior building components-A review." Energy and Buildings 80 (0):81-105. doi: 10.1016/j.enbuild.2014.05.008.

Hiyama, K., and S. Kato. 2011. "Integration of three-dimensional CFD results into energy simulations utilizing an Advection-Diffusion Response Factor." Energy and Buildings 43 (10):2752-2759. doi: 10.1016/j.enbuild.2011.06.027.

Icepak, ANSYS. 2009. "12.0 User's Guide." Fluent Inc.

Jo, J. H., J. D. Carlson, J. S. Golden, and H. Bryan. 2010. "An integrated empirical and modeling methodology for analyzing solar reflective roof technologies on commercial buildings." Building and Environment 45 (2):453-460. doi: 10.1016/j.buildenv.2009.07.001.

Joudi, A., M. Cehlin, H. Svedung, M. Rönnelid, and B. Moshfegh. 2015. "Numerical and experimental investigation of the influence of infrared reflective interior surfaces on building temperature distributions." Submitted to Indoor and Built Environment.

Joudi, A., M. Rönnelid, H. Svedung, and E. Wäckelgård. 2011. "Energy Efficient Buildings with Functional Steel Cladding." World Renewable Energy Congress, Linköping, Sweden, 2011.

Joudi, A., H. Svedung, C. Bales, and M. Rönnelid. 2011. "Highly reflective coatings for interior and exterior steel cladding and the energy efficiency of buildings." Applied Energy 88 (12):4655-4666. doi: 10.1016/j.apenergy.2011.06.002.

Joudi, A., H. Svedung, M. Cehlin, and M. Rönnelid. 2013. "Reflective coatings for interior and exterior of buildings and improving thermal performance." Applied Energy 103 (0):562-570. doi: 10.1016/j.apenergy.2012.10.019.

Joudi, A., H. Svedung, and M. Rönnelid. 2011. "Energy efficient surfaces on building sandwich panels-A dynamic simulation model." Energy and Buildings 43 (9):2462-2467.

Kim, J. Y., A. J. Ghajar, C. Tang, and G. L. Foutch. 2005. "Comparison of near-wall treatment methods for high Reynolds number 
backward-facing step flow." International Journal of Computational Fluid Dynamics 19 (7):493-500. doi: 10.1080/10618560500502519.

Konopacki, S. J., and H. Akbari. 2001. "Measured energy savings and demand reduction from a reflective roof membrane on a large retail store in Austin." Lawrence Berkeley National Laboratory.

Launder, B. E., and D.B. Spalding. 1974. "The numerical computation of turbulent flows." Computer Methods in Applied Mechanics and Engineering 3 (2):269-289.

Leenknegt, S., R. Wagemakers, W. Bosschaerts, and D. Saelens. 2012. "Numerical sensitivity study of transient surface convection during night cooling." Energy and Buildings 53:85-95. doi: 10.1016/j.enbuild.2012.06.020.

Levinson, R., H. Akbari, and J. C. Reilly. 2007. "Cooler tile-roofed buildings with near-infrared-reflective non-white coatings." Building and Environment 42 (7):2591-2605. doi: 10.1016/j.buildenv.2006.06.005.

Li, Y., M. Sandberg, and L. Fuchs. 1992. "Vertical Temperature Profiles in Rooms Ventilated by Displacement: Full-Scale Measurement and Nodal Modelling." Indoor Air 2 (4):225-243.

Lin, Z., T. T. Chow, and C. F. Tsang. 2006. "Validation of a CFD Model for Research into Stratum Ventilation." International Journal of Ventilation ISSN 1473-3315 Volume 5 No 3:345-363.

Lin, Z., T. T. Chow, C. F. Tsang, K. F. Fong, and L. S. Chan. 2009. "Stratum ventilation - A potential solution to elevated indoor temperatures." Building and Environment 44 (11):2256-2269.

Lin, Z., L. Tian, T. Yao, Q. Wang, and T. T. Chow. 2011. "Experimental and numerical study of room airflow under stratum ventilation." Building and Environment 46 (1):235-244. doi: 10.1016/j.buildenv.2010.07.018.

Miller, W. B., H. Akbari, R. Levinson, K. T. Loye, S. Kriner, R. G. Scichili, A. O. Desjarlais, S. Weil, and P. Berdahl. 2004. "Special infrared reflective pigments make a dark roof reflect almost like a white roof." in Thermal Performance of the Exterior Envelopes of Buildings, IX, proceedings of ASHRAE THERM VIII, Clearwater, FL., Dec.

Min, T. C. , L. F. Schutrum, G. V. Parmelee, and J. D. Vouris. 1956. "Natural convection and radiation in a panel heated room." ASHRAE Transactions 62:337-358.

Miranville, F., A. H. Fakra, S. Guichard, H. Boyer, J. P. Praene, and D. Bigot. 2012. "Evaluation of the thermal resistance of a roof-mounted multireflective radiant barrier for tropical and humid conditions: 
Experimental study from field measurements." Energy and Buildings 48:79-90. doi: 10.1016/j.enbuild.2012.01.013.

Moosberger, S. 2007. IDA ICE CIBSE-Validation Test of IDA Indoor Climate and Energy version 4.0 according to CIBSE TM33, Issue 3. HTA LUZRN /ZIG.

Mora, L., A. J. Gadgil, and E. Wurtz. 2003. "Comparing zonal and CFD model predictions of isothermal indoor airflows to experimental data." Indoor Air 13 (2):77-85.

Morrison, G. L. 2001. "Solar energy-the state of the art: ISES position papers." In, edited by J. M. Gordon. London: James \& James.

Nakahashi, K. 2008. "Building-Cube Method; A CFD Approach for NearFuture PetaFlops Computers." Proceedings of the 8th World Congress on Computational Mechanics (WCCM8), Venice, Italy.

Negrao, C. O. R. 1995. "Conflation of computational fluid dynamics and building thermal simulation " $\mathrm{PhD}$ diss., University of Strathclyde.

Negrão, C. O. R. 1998. "Integration of computational fluid dynamics with building thermal and mass flow simulation." Energy and Buildings 27 (2):155-165. doi: 10.1016/s0378-7788(97)00036-4.

Nielsen, P. V., and H. B. Awbi. 2008. "Air distribution: system design." In Ventilation systems design and performance, edited by H. B. Awbi. New York, NY: Spon Press.

Novoselac, A. 2005. "Combined airflow and energy simulation program for building mechanical system design." $\mathrm{PhD}$ diss., Pennsylvania State University.

Park, H. J., and D. Holland. 2001. "The effect of location of a convective heat source on displacement ventilation: CFD study." Building and Environment 36 (7):883-889. doi: 10.1016/s0360-1323(01)00014-2.

Peeters, L., I. Beausoleil-Morrison, and A. Novoselac. 2011. "Internal convective heat transfer modeling: Critical review and discussion of experimentally derived correlations." Energy and Buildings 43 (9):2227-2239. doi: 10.1016/j.enbuild.2011.05.002.

Posner, J. D., C. R. Buchanan, and D. Dunn-Rankin. 2003. "Measurement and prediction of indoor air flow in a model room." Energy and Buildings 35 (5):515-526. doi: 10.1016/s0378-7788(02)00163-9.

Revel, G. M., M. Martarelli, M. Emiliani, L. Celotti, R. Nadalini, A. Ferrari, S. Hermanns, and E. Beckers. 2014. "Cool products for building envelope - Part II: Experimental and numerical evaluation of thermal performances." Solar Energy 105 (0):780-791. doi: 10.1016/j.solener.2014.02.035. 
Rossi, F., B. Castellani, A. Presciutti, E. Morini, M. Filipponi, A. Nicolini, and M. Santamouris. 2015. "Retroreflective façades for urban heat island mitigation: Experimental investigation and energy evaluations." Applied Energy 145 (0):8-20. doi: 10.1016/j.apenergy.2015.01.129.

Rouaud, O., and M. Havet. 2002. "Computation of the airflow in a pilot scale clean room using K- $\varepsilon$ turbulence models." International Journal of Refrigeration 25 (3):351-361. doi: 10.1016/s0140-7007(01)00014-7.

Ruukki. 2015. "Sandwich panels." Ruukki Construction, available at http://www.ruukki.com/Construction/Sandwich-panels, accessed date 2015.04.12.

Saber, H. H. 2012. "Investigation of thermal performance of reflective insulations for different applications." Building and Environment 52:32-44. doi: 10.1016/j.buildenv.2011.12.010.

Sagaut, P. 2006. Large eddy simulation for incompressible flows. Berlin: Springer.

Sahlin, P. 2000. "The Methods of 2020 for Building Envelope and HVAC Systems Simulation - Will the Present Tools Survive?".

Sahlin, P. 2003. "On the effects of decoupling airflow and heat balance in building simulation models." Transactions - American Society of Heating, Refrigerating and Air Conditioning Engineers 109 (2):788800.

Sahlin, P., L. Eriksson, P. Grozman, H. Johnsson, A. Shapovalov, and M. Vuolle. 2004. "Whole-building simulation with symbolic DAE equations and general purpose solvers." Building and Environment 39 (8):949-958. doi: 10.1016/j.buildenv.2004.01.019.

Santamouris, M. 2014. "Cooling the cities-a review of reflective and green roof mitigation technologies to fight heat island and improve comfort in urban environments." Solar Energy 103:682-703.

Santamouris, M., N. Gaitani, A. Spanou, M. Saliari, K. Giannopoulou, K. Vasilakopoulou, and T. Kardomateas. 2012. "Using cool paving materials to improve microclimate of urban areas - Design realization and results of the flisvos project." Building and Environment 53:128136. doi: 10.1016/j.buildenv.2012.01.022.

Sekar, M., M. Sakthivel, S. Satheesh Kumar, and C. Ramesh. 2012. "Attaining the room comfort by solar reflective paint." American Journal of Environmental Sciences 8 (5).

Shati, A. 2013. "The interaction between radiation and turbulent natural convection in square and rectangular enclosures." $\mathrm{PhD}$ diss, Department of Mechanical Engineering, University of Sheffield. 
Song, J., J. Qin, J. Qu, Z. Song, W. Zhang, X. Xue, Y. Shi, T. Zhang, W. Ji, R. Zhang, H. Zhang, Z. Zhang, and X. Wu. 2014. "The effects of particle size distribution on the optical properties of titanium dioxide rutile pigments and their applications in cool non-white coatings." Solar Energy Materials and Solar Cells 130 (0):42-50. doi: 10.1016/j.solmat.2014.06.035.

Srebric, J. 2011. "Ventilation performance prediction " In Building Performance Simulation for Design and Operation, edited by J. L. M. Hensen and R. Lamberts. New York, NY: Spon Press.

Synnefa, A., T. Karlessi, N. Gaitani, M. Santamouris, D. N. Assimakopoulos, and C. Papakatsikas. 2011. "Experimental testing of cool colored thin layer asphalt and estimation of its potential to improve the urban microclimate." Building and Environment 46 (1):38-44. doi: 10.1016/j.buildenv.2010.06.014.

Tian, L., Z. Lin, and Q. Wang. 2011. "Experimental investigation of thermal and ventilation performances of stratum ventilation." Building and Environment 46 (6):1309-1320. doi: 10.1016/j.buildenv.2011.01.002.

Van Treeck, C. 2011. "Indoor thermal quality peformance." In Building Performance Simulation for Design and Operation, edited by J.L.M. Hensen and R. Lamberts. New York, NY: Spon Press.

Versteeg, H. K., and W. Malalasekera. 2007. An Introduction to Computational Fluid Dynamics: The Finite Volume Method. Harlow: Pearson.

Wallenten, P. 1999. "Heat transfer coefficients in a full scale room with and without furniture." Building Simulation.

Wang, L., and Q. Chen. 2007. "Theoretical and numerical studies of coupling multizone and CFD models for building air distribution simulations." Indoor Air 17 (5):348-61. doi: 10.1111/j.1600-0668.2007.00481.x.

Wang, L., and Q. Chen. 2008. "Evaluation of some assumptions used in multizone airflow network models." Building and Environment 43 (10):1671-1677. doi: 10.1016/j.buildenv.2007.10.010.

Wang, L., and N. H. Wong. 2008. "Coupled simulations for naturally ventilated residential buildings." Automation in Construction 17 (4):386-398. doi: 10.1016/j.autcon.2007.06.004.

Wang, L., and N. H. Wong. 2009. "Coupled simulations for naturally ventilated rooms between building simulation (BS) and computational fluid dynamics (CFD) for better prediction of indoor thermal environment." Building and Environment 44 (1):95-112. doi: 10.1016/j.buildenv.2008.01.015. 
Wang, X., C. Kendrick, R. Ogden, and J. Maxted. 2008. "Dynamic thermal simulation of a retail shed with solar reflective coatings." Applied Thermal Engineering 28 (8-9):1066-1073. doi: 10.1016/j.applthermaleng.2007.06.011.

Wang, Y., X. J. Meng, X. Yang, and J. Liu. 2014. "Influence of convection and radiation on the thermal environment in an industrial building with buoyancy-driven natural ventilation." Energy and Buildings 75:394-401. doi: 10.1016/j.enbuild.2014.02.031.

Wilcox, D. C. 1998. Turbulence Modeling for CFD. Vol. 2. La Cãnada, Calif.: DCW industries.

Woloszyn, M., C. Rode, A. Sasic Kalagasidis, A. Janssens, and M. De Paepe. 2009. "From EMPD to CFD-overview of different approaches for Heat Air and Moisture modeling in IEA Annex 41." ASHRAE Transactions.

Wray, C., and H. Akbari. 2008. "The effects of roof reflectance on air temperatures surrounding a rooftop condensing unit." Energy and Buildings 40 (1):11-28. doi: 10.1016/j.enbuild.2007.01.005.

Xamán, J., G. Mejía, G. Álvarez, and Y. Chávez. 2010. "Analysis on the heat transfer in a square cavity with a semitransparent wall: Effect of the roof materials." International Journal of Thermal Sciences 49 (10):1920-1932. doi: 10.1016/j.ijthermalsci.2010.05.023.

Yakhot, V., and S. Orszag. 1986. "Renormalization group analysis of turbulence. I. Basic theory." Journal of Scientific Computing 1 (1):351.

Yakhot, V., S. A. Orszag, S. Thangam, T. B. Gatski, and C. G. Speziale. 1992. "Development of turbulence models for shear flows by a double expansion technique." Physics of Fluids A: Fluid Dynamics 4 (7):1510. doi: 10.1063/1.858424.

Zhai, Z. 2003. "Developing an integrated building design tool by coupling building energy simulation and computational fluid dynamics programs." PhD diss., Massachusetts Institute of Technology.

Zhai, Z., and Q. Chen. 2003. "Solution characters of iterative coupling between energy simulation and CFD programs." Energy and Buildings 35 (5):493-505. doi: 10.1016/s0378-7788(02)00156-1.

Zhai, Z., and Q. Chen. 2004. "Numerical determination and treatment of convective heat transfer coefficient in the coupled building energy and CFD simulation." Building and Environment 39 (8):1001-1009. doi: 10.1016/j.buildenv.2004.01.023.

Zhai, Z., Q. Chen, P. Haves, and J. H. Klems. 2002. "On approaches to couple energy simulation and computational fluid dynamics programs." 
Building and Environment 37 (8-9):857-864. doi: 10.1016/s03601323(02)00054-9.

Zhai, Z. J., and Q. Y. Chen. 2005. "Performance of coupled building energy and CFD simulations." Energy and Buildings 37 (4):333-344. doi: 10.1016/j.enbuild.2004.07.001.

Zhai, Z. J., and Q. Y. Chen. 2006. "Sensitivity analysis and application guides for integrated building energy and CFD simulation." Energy and Buildings 38 (9):1060-1068. doi: 10.1016/j.enbuild.2005.12.003.

Zhang, R., K. P. Lam, S. Yao, and Y. Zhang. 2013. "Coupled EnergyPlus and computational fluid dynamics simulation for natural ventilation." Building and Environment 68:100-113. doi: 10.1016/j.buildenv.2013.04.002.

Zhang, T., H. Zhou, and S. Wang. 2013. "An adjustment to the standard temperature wall function for CFD modeling of indoor convective heat transfer." Building and Environment 68:159169. doi: 10.1016/j.buildenv.2013.06.009.

Zhang, W., K. Hiyama, S. Kato, and Y. Ishida. 2013. "Building energy simulation considering spatial temperature distribution for nonuniform indoor environment." Building and Environment 63:89-96. doi: 10.1016/j.buildenv.2013.02.007.

Zhang, Z., W. Zhang, Z. J. Zhai, and Q. Y. Chen. 2007. "Evaluation of Various Turbulence Models in Predicting Airflow and Turbulence in Enclosed Environments by CFD: Part 2 - Comparison with Experimental Data from Literature." $H V A C \& R$ Research 13 (6):871886. doi: 10.1080/10789669.2007.10391460.

Zheng, S., Y. Xu, Q. Shen, and H. Yang. 2015. "Preparation of thermochromic coatings and their energy saving analysis." Solar Energy 112 (0):263271. doi: 10.1016/j.solener.2014.09.049.

Zuo, W., and Q. Chen. 2009. "Real-time or faster-than-real-time simulation of airflow in buildings." Indoor Air 19 (1):33-44. doi: 10.1111/j.16000668.2008.00559.x. 


\section{Papers}

The articles associated with this thesis have been removed for copyright reasons. For more details about these see:

http://urn.kb.se/resolve?urn=urn:nbn:se:liu:diva-118291 